International Journal of Astrobiology

\section{cambridge.org/ija}

\section{Review Article}

*The online version of this article has been updated since original publication. A notice detailing the change has also been published.

Cite this article: Changela HG et al (2021). Mars: new insights and unresolved questions. International Journal of Astrobiology 20, 394-426. https://doi.org/10.1017/

S1473550421000276

Received: 29 April 2021

Revised: 14 September 2021

Accepted: 23 September 2021

First published online: 1 December 2021

\section{Keywords:}

Ethics and religion; human habitation; in situ resource utilization; Mars habitability; microbial extremophiles; planetary protection

\section{Author for correspondence:}

Hitesh G Changela,

E-mail: changela@mail.iggcas.ac.cn

\title{
Mars: new insights and unresolved questions
}

Hitesh G. Changela ${ }^{1,2}\left(\mathbb{D}\right.$, Elias Chatzitheodoridis ${ }^{3,4}(\mathbb{D})$ Andre Antunes $^{5}(\mathbb{D}$, David Beaty ${ }^{6}$, Kristian Bouw ${ }^{7}$, John C. Bridges ${ }^{8}$, Klara Anna Capova ${ }^{9}$, Charles S. Cockell ${ }^{10}$, Catharine A. Conley ${ }^{11}$, Ekaterina Dadachova ${ }^{12}$, Tiffany D. Dallas ${ }^{13}$ (D), Stefaan de Mey ${ }^{9}$, Chuanfei Dong ${ }^{14}$ (D), Alex Ellery ${ }^{15}$,

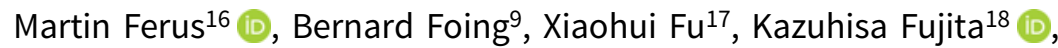
Yangting Lin ${ }^{1 \star}$, Sohan Jheeta ${ }^{4}$, Leon J. Hicks ${ }^{8}$ (D), Sen $\mathrm{Hu}^{1}$, Akos Kereszturi ${ }^{19}$, Alexandros Krassakis ${ }^{20}$, Yang Liu' ${ }^{21}$, Juergen Oberst ${ }^{22}$, Joe Michalski²3, P. M. Ranjith ${ }^{1}$, Teresa Rinaldi24, David Rothery ${ }^{25}$ (D) Hector A. Stavrakakis ${ }^{3}$ (D), Laura Selbmann ${ }^{26}$, Rishitosh K. Sinha ${ }^{27}$ (D), Alian Wang ${ }^{28}$, Ken Williford ${ }^{6}$, Zoltan Vaci ${ }^{2}$ (D), Jorge L. Vago ${ }^{9}$, Michael Waltemathe ${ }^{29}$ (D) and John E. Hallsworth ${ }^{13}$ (D)

${ }^{1}$ Key Laboratory of Earth \& Planetary Physics, Institute of Geology \& Geophysics, Chinese Academy of Sciences, Beijing, China; ${ }^{2}$ Department of Earth \& Planetary Science, University of New Mexico, New Mexico, USA;

${ }^{3}$ Department of Geological Sciences, National Technical University of Athens, School of Mining and Metallurgical Engineering, Athens, Greece; ${ }^{4}$ Network of Researchers on the Chemical Evolution of Life, Leeds, UK; ${ }^{5}$ State Key Laboratory of Lunar and Planetary Sciences, Macau University of Science and Technology (MUST), Macau SAR, China; ${ }^{6}$ Mars Program Office, Jet Propulsion Laboratory/California Institute of Technology, Pasadena, California, USA; ${ }^{7}$ Creative Division, Notion Theory, Miami, Florida 33131, USA; ${ }^{8}$ Space Research Centre, School of Physics and Astronomy, University of Leicester, Leicester LE17RH, UK; ${ }^{9}$ Human and Robotic Exploration, European Space Agency (HRE/ESA), European Space Research and Technology Centre (ESTEC), Noordwijk, The Netherlands; ${ }^{10}$ School of Physics and Astronomy University of Edinburgh James Clerk Maxwell Building, Peter Guthrie Tait Road, Edinburgh EH9 3FD, UK; ${ }^{11}$ NASA Ames Research Center, Mountain View, California 94035, USA; ${ }^{12}$ College of Pharmacy and Nutrition, University of Saskatchewan, Canada; ${ }^{13}$ Institute for Global Food Security, School of Biological Sciences, Queen's University Belfast, 19 Chlorine Gardens, Belfast BT9 5DL, UK; ${ }^{14}$ Department of Astrophysical Sciences and Princeton Plasma Physics Laboratory, Princeton University, USA; ${ }^{15}$ Department of Mechanical and Aerospace Engineering, Carleton University, Ottawa, Ontario Canada; ${ }^{16} \mathrm{~J}$. Heyrovsky Institute of Physical Chemistry, Czech Academy of Sciences, Prague, Czech Republic; ${ }^{17}$ Institute of Space Sciences, Shandong University (Weihai), Shandong Province, China; ${ }^{18}$ Japanese Aerospace Exploration Agency (JAXA), Tokyo, Japan; ${ }^{19}$ Research Centre for Astronomy and Earth Sciences, Budapest, Hungry; ${ }^{20}$ Worldwide Business Applied Limited, GRC (Governance, Risk \& Compliance), Athens, Greece; ${ }^{21}$ National Space Science Centre NSSC, Chinese Academy of Sciences, Beijing, China; ${ }^{22}$ DLR Institute of Planetary Research, Berlin, Germany; ${ }^{23}$ Hong Kong University, Hong Kong, Beijing, China; ${ }^{24}$ Department of Biology and Biotechnology, Sapienza University of Rome, Rome, Italy;

${ }^{25}$ School of Physical Sciences, The Open University, Milton Keynes, UK; ${ }^{26}$ Department of Ecological and Biological Sciences, University of Tuscia, Viterbo, Italy; ${ }^{27}$ Physical Research Laboratory, ISRO, Ahmedabad, India;

${ }^{28}$ Department of Earth \& Planetary Sciences and McDonnell Center for Space Sciences, Washington University, St Louis, USA and ${ }^{29}$ Evangelisch-Theologische Fakultät, Ruhr-Universität Bochum, Bochum, Germany

\section{Abstract}

Mars exploration motivates the search for extraterrestrial life, the development of space technologies, and the design of human missions and habitations. Here, we seek new insights and pose unresolved questions relating to the natural history of Mars, habitability, robotic and human exploration, planetary protection, and the impacts on human society. Key observations and findings include:

- high escape rates of early Mars' atmosphere, including loss of water, impact present-day habitability;

- putative fossils on Mars will likely be ambiguous biomarkers for life;

- microbial contamination resulting from human habitation is unavoidable; and

- based on Mars' current planetary protection category, robotic payload(s) should characterize the local martian environment for any life-forms prior to human habitation.

Some of the outstanding questions are:

- which interpretation of the hemispheric dichotomy of the planet is correct;

- to what degree did deep-penetrating faults transport subsurface liquids to Mars' surface;

- in what abundance are carbonates formed by atmospheric processes;

- what properties of martian meteorites could be used to constrain their source locations; 
- the origin(s) of organic macromolecules;

- was/is Mars inhabited;

- how can missions designed to uncover microbial activity in the subsurface eliminate potential false positives caused by microbial contaminants from Earth;

- how can we ensure that humans and microbes form a stable and benign biosphere; and

- should humans relate to putative extraterrestrial life from a biocentric viewpoint (preservation of all biology), or anthropocentric viewpoint of expanding habitation of space?

Studies of Mars' evolution can shed light on the habitability of extrasolar planets. In addition, Mars exploration can drive future policy developments and confirm (or put into question) the feasibility and/or extent of human habitability of space.

\section{Introduction}

Mars, our closest planetary analogue, once had a more substantial hydrological cycle (Wordsworth, 2016), possibly with oceans (Carr and Head, 2003; Redd 2020; Scheller et al., 2021) and lakes shaping its surface and hosting microbial life (Cabrol and Grin, 1999). Over the Red Planet's history, this water cycle (Jakosky, 2021), dynamo (Mittelholz et al., 2020), and igneous activity either diminished or virtually disappeared. Present-day Mars has active seasonal changes in ice caps (Becerra et al., 2020), permafrost (Wray, 2020) and atmospheric composition (Trainer et al., 2019). Undesired terrestrial microbes (Spry et al., 2017), or extant martian life might co-exist on Mars today (Cabrol, 2021).

We are now using orbiters, landers and rovers to explore these tantalizing possibilities (Smith et al., 2020a). The next frontier in space exploration is to return samples from and eventually land humans on Mars. The US National Aeronautics and Space Administration (NASA)'s Perseverance rover is paving the way for the first Mars-sample return (Farley et al., 2020); a future mission will also bring back those samples. Added to the existing fleet of rovers and orbiters is the Indian Space Research Organization (ISRO)'s Mangalyaan orbiter (Lele, 2014), the United Arab Emirates Mars Mission Hope (Sharaf et al., 2020) and the China National Space Administration's (CNSA)'s Tianwen-1 orbiter with the Zhurong rover (Wan et al., 2020). They are resolving the geology of the planet, mostly characterizing the surface and near-surface (to centimetre depths). The European Space Agency (ESA)'s and Roscosmos State Corporation (RSC)'s ExoMars Rosalind Franklin rover will explore the martian subsurface with a specialized payload designed for life detection down to depths of metres. The Japanese Aerospace Exploration Agency (JAXA) will return samples from the martian moon Phobos for launch in 2024 with the Martian Moons eXploration (MMX) sample-return mission (Usui et al., 2020). SpaceX has an ambitious programme for human settlement on Mars and the Moon (Bramson et al.) with the development of the Starship vehicle, bringing together a new era of humans in space.

Identifying habitable environments for both microbes (Cockell, 2021) and humans on Mars is a continuous process (Morgan et al., 2021). An important aspect of the current missions is the increasing internationalization of space research (Baitukayeva and Baitukayeva, 2020), providing an opportunity to unite nations in enabling humanity becoming an interplanetary species. Here, we pose questions on Mars relating to its natural history, the development of space technologies, the design of human missions and habitations, planetary protection policy, and impacts of Mars exploration on human society on Earth.

\section{Early Mars \\ Loss of atmosphere}

One of the most-striking differences between ancient and current Mars is that it once had a thicker atmosphere compared to the present day; the Noachian Mars atmosphere was more Earth-like in density. This raises the question of when most of the atmosphere was lost. There are compelling observation-based and theoretical calculations indicating that most of the martian atmosphere escaped into space early in the planet's history (Lammer, 2012; Jakosky et al., 2017), when the intensity of extreme ultraviolet (EUV) and the solar wind flux from the young Sun were much higher than today (Ribas et al., 2005). Moreover, the martian dynamo disappeared $\sim 4.1 \mathrm{Ga}$ ago (Lillis et al., 2013; Mittelholz et al., 2020), leaving present-day Mars with only weak crustal magnetic fields (Johnson et al., 2020). Our understanding of present-day escape of martian atmosphere, and thus our overview of atmosphere losses throughout Mars' history, has improved greatly with observations from NASA's Mars Atmosphere and Volatile EvolutioN (MAVEN) orbiter in conjunction with detailed theoretical models (Dong et al., 2018; Jakosky et al., 2018).

Atmospheric ion escape rates on Mars significantly varied over time, ranging from $\sim 10^{27} \mathrm{~s}^{-1}$ at $\sim 4 \mathrm{Ga}$ to $\sim 10^{24} \mathrm{~s}^{-1}$ at the present epoch (Fig. 1). Figure 1 also shows that the photochemical escape rate of hot atomic oxygen in the martian exosphere lies between $\sim 10^{26} \mathrm{~s}^{-1}$ at $\sim 4 \mathrm{Ga}$ and $\sim 10^{25} \mathrm{~s}^{-1}$ today. These simulations are also consistent with the idea that Mars transitioned from an early warmer and wetter world to a desiccated, planet with a frigid surface and tenuous atmosphere. It is noteworthy that space weather events at early epochs of solar evolution, such as Interplanetary Coronal Mass Ejections (ICMEs), could have catastrophically impacted Mars' atmospheric retention. Recently (8 March 2015), an ICME sideswiped Mars and led to a tenfold enhancement in the atmospheric ion escape rate (Dong et al., 2015), confirming that ICMEs - a highly frequent phenomenon of young stars and hence of the young Sun - could have had a direct effect on the removal of Mars' atmosphere.

The habitability of Mars was drastically affected by the loss of the planet's atmosphere. An atmosphere is necessary to maintain surface liquid water, and to protect putative biota from highenergy particles and radiation. The temporal changes of Mars' atmosphere may shed light on exoplanet habitability. Recent 


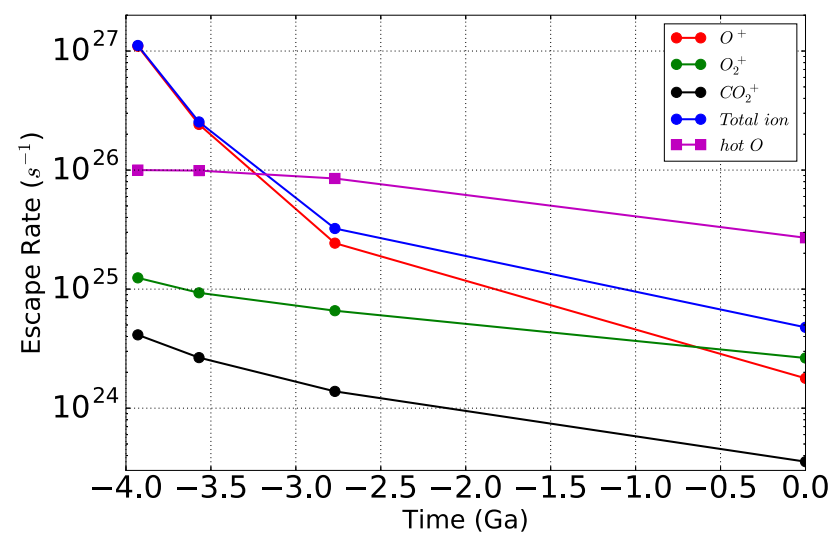

Fig. 1. Calculated atmospheric ion and photochemical (hot exospheric oxygen) escape rates over the martian history (under normal solar wind conditions) (Dong et al., 2018).

numerical and theoretical studies indicate that both magnetized and unmagnetized planets around $\mathrm{M}$ dwarfs (stars much smaller and dimmer than our Sun) might be particularly susceptible to the depletion of $\sim 1$ bar atmosphere over sub-Gyr timescales due to the high stellar radiation and particle fluxes within habitable zones (Dong et al., 2020). Such exoplanets orbiting M dwarfs, as well as those around young solar-type stars (Dong et al., 2019), could have been subjected to high atmospheric escape rates early in their history. It is important to take this time-dependence into account when modelling the habitability of Mars or exoplanets.

\section{Evidence for and against tectonics on Mars}

Early global tectonic-magmatic processes are part of Earth's geological record and have shaped Earth's crust (Stern, 2018). On Mars, radial grabens (Fig. 2) and concentric wrinkle ridges connected to the Tharsis rise (Andrews-Hanna, 2020), and Valles Marineris display properties of fault systems (Mège and Masson, 1996; Baker et al., 2007). A number of smaller tectoniclike features also occur in these regions of Mars. Tectonic processes could account for the alternating magnetized stripes in the southern highlands, possibly due to periodic changes in the magnetic polarity of the martian core, and the gradual spreading at mid-oceanic ridges during crustal formation.

The short length of strike slip faults on Mars may not be related to plate tectonics (Schultz, 1989). Evidence of crustal consumption in the form of subduction zones is also lacking. However, certain faults - abrupt contacts of different rock units and related topographic features - suggest plate boundary-like structural lines (Kidman et al., 2014). Such features would have formed early on in Mars' history. Mars is a planet of modest size planet with limited heat within, leading to relatively rapid rates of cooling and a thick crust. Therefore, a considerable amount of energy must have been required to cause large-scale fracturing of the martian crust. In addition, temperatures in the mantle may not have been high enough to maintain global plate recycling. This could also relate to the depletion of Mars' magnetic dynamo, convention currents, and possible magmatic plumes in its early mantle.

NASA's InSight Mars lander mission measured faint seismic activity to shed some light onto the question of Mars' internal structure (Knapmeyer-Endrun and Kawamura, 2020). Recent results suggest a larger, less dense and still-molten core (Stähler et al., 2021). Combined with the relatively thick crust, we should

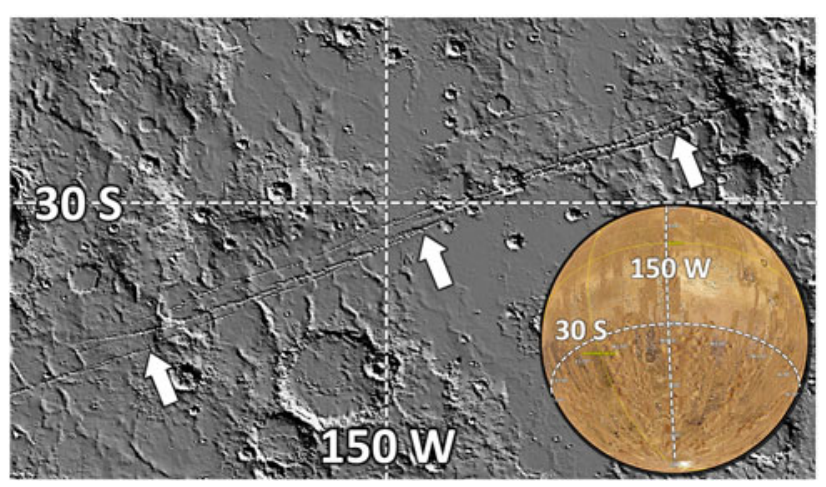

Fig. 2. Radial grabens and fractures in the Sirenum Fossae region of southern Tharsis.

not expect active tectonism. Any large temperature gradients, therefore, must have been created by impacts.

Impact events occurred frequently in Mars' early history. After the cessation of early global impact bombardment, compressive stresses may have occurred for extended periods of time (Watters, 1993), producing wrinkle ridges in several volcanic regions (Schultz, 2000). Moderately small, up to $100 \mathrm{~m}$-long extension-and-compressional features (Plescia and Golombek, 1986) may have shaped these volcanic plains. However, displacements up to $100 \mathrm{~km}$ in size have also been observed (Yin, 2012).

Weak plate recirculation does not remobilize as much material from the Mars interior to the surface as occurs on Earth. This produces a low redox gradient; it is the greater redox gradient on Earth that has supported life. However, UV-driven chemistry on the surface of present-day Mars has led to strong redox gradients occurring at depths of centimetres to decametres below the surface. Subsurface measurements, such as those from the ExoMars Rosalind Franklin rover (see Robotic exploration section), are expected to confirm this.

\section{What explanation(s) are there for the hemispheric dichotomy?}

The lower density of impact craters in Mars' northern hemisphere is coupled with a difference in topographic height between the two hemispheres. The northern hemisphere is lower-lying, and the most-ancient craters there have been buried beneath regolith (and/or rock) material whereas the ancient craters of the southern hemisphere can still be seen (Bouley et al., 2020).

The northern lowlands cover about a third of the planet, and in some places, the southern highlands reach more than 30 degrees north of the equator. The boundary between the northern lowlands and the southern highlands is marked by steep erosional slopes, with apparent traces of ancient shorelines (Sholes et al., 2020), suggesting that the northern lowlands were occupied by an ocean about 3.8-4.1 billion years ago. However, if an ocean existed with a water-depth of several kilometres, the northern lowlands would not have been shielded from impact craters. Why the two hemispheres exhibit dichotomy in their topographic heights is not known (Fig. 3). It has been inferred from studies of the planet's gravitational field that the crust in the north is only about 32 $\mathrm{km}$ thick whereas the southern crust is about $58 \mathrm{~km}$ thick. The difference in crust thickness should be explained to elucidate the origin of this dichotomy.

It would be tempting to compare Mars' northern lowlands to Earth's thin ocean crust. However, Earth's oceanic crust is 


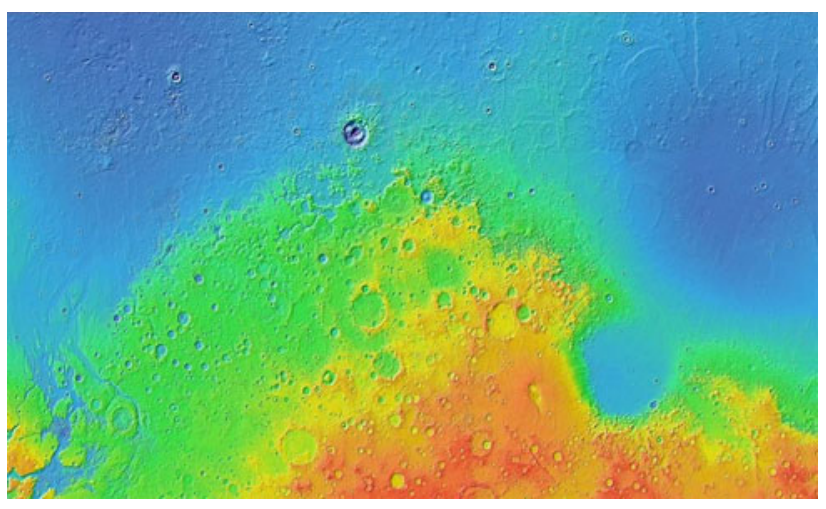

Fig. 3. Colour-coded digital elevation map of a latitudinal belt of Mars centred at 24 degrees north. The east-west extent is about $8000 \mathrm{~km}$. Blue-coded elevations are low, whereas green, yellow and red are progressively higher. The total range in this image is about $9 \mathrm{~km}$. The blue, low lying area is north of the dichotomy boundary. It has relatively few superimposed craters, because the surface has relatively young lavas and sediments. The green-yellow-red terrain is south of the dichotomy boundary. This is more ancient and has more craters, despite many of them having been partially erased by erosion. (NASA/JPLK/GSFC/Arizona State University).

produced by seafloor spreading which requires tectonic plates to be moving apart. This type of tectonic process is balanced by convergence elsewhere on the globe (accommodated by subduction, where the edge of one plate descends below the edge of its neighbour). Mars shows no evidence of multiple tectonic plates. In fact, it has been described as a 'one-plate planet'. This difference should be explained to elucidate the origin of this dichotomy.

There are three distinct theories:

- the low northern hemisphere was excavated by an extremely large impact soon after Mars' formation about 4.5 billion years ago (Andrews-Hanna et al., 2008; Leone et al., 2014);

- a persistent upwelling in the southern hemisphere mantle (Harder and Christensen, 1996) caused partial melting that produced magma which intruded into and erupted onto the planet's earliest crust, resulting in locally enhanced thickness; and

- the southern mantle upwelling was a convection pattern created as a consequence of the northern basin-forming impact (Andrews-Hanna et al., 2008).

The impact event (first theory) would have created a sink for sediments and a site for lava eruptions, both capable of burying the earliest craters that formed on the floor of the giant basin. The second theory looks to processes in Mars' mantle for an explanation. Maybe in a Mars-sized planet (smaller than Earth), convection patterns are simpler, and the sharpness of the dichotomy boundary resulted from erosion rather than reflecting the edge of an impact basin. The third theory integrates the first two theories. Which theory is correct remains unresolved.

\section{The martian satellites}

Phobos and Deimos are the two small natural satellites of Mars with some characteristics similar to asteroids, suggesting that they are objects that were captured in the planet's early history. However, these satellites move in circular orbits that are closely aligned with Mars' equator, which is difficult to explain for captured objects. These orbits are different from that of Earth's
Moon, for example, which moves within a more or less ecliptic plane. The orbits of Phobos and Deimos suggest that these satellites formed from large impact ejecta from Mars that then accumulated/coalesced (Bagheri et al., 2021). Alternatively, these satellites may have formed at the same time as proto-Mars itself. The morphology of Phobos is consistent with the idea that the satellite consists of loosely consolidated materials (a so-called rubble pile). Phobos' shape is near ellipsoidal - this could possibly be a relic of the effects of gravitational, rotatonal and tidal forces during its formation. Such conditions are met at a distance of $\sim 3.3$ Mars radii (our Moon is $\sim 60$ Earth radii away), which is where Phobos probably accreted (Hu et al., 2020).

Phobos is orbiting at about $9000 \mathrm{~km}$ from the centre of Mars, and therefore is affected by strong tidal forces, resulting in orbital decay. Phobos will likely be disrupted into pieces within a rather short timescale, on the order of a few tens of millions of years. Deimos orbits Mars $\sim 23500 \mathrm{~km}$ from the centre ( 2.5 times greater than the orbit of Phobos) and is expected to escape from the martian system at some time in the distant future.

The Satellite-Ring Cycle model (Hesselbrock and Minton, 2017) suggests that the moons of Mars were repeatedly created, destroyed, and then recreated. Following a typical tidal disruption of Phobos, a debris ring will form and spread. Most of this material will eventually impact the surface of Mars, but a fraction will migrate into higher orbits. Once beyond the so-called 'Fluid Roche limit', located at about 3.1 Mars radii from the planet's surface, the remaining material will re-accrete to form an offspring moonlet, which will again enter orbital decay. Phobos may be a product of the fourth or fifth generation of the Satellite-Ring Cycle.

\section{Martian water, alteration minerals and methane}

\section{Lakes and seas on Mars}

Life on Earth potentially originated in the ocean (Martin et al., 2008; Osinski et al., 2020), and thrives not only in the modern sea but also in $>100$ million lakes. It may be in for this reason that there is a widespread interest in ancient lakes and seas on Mars, including the ancient lake of the Jezero Crater that is currently being explored by the Perseverance rover. Early reconnaissance of Mars revealed intriguing evidence for many crater lakes (i.e. channels apparently terminating in basins) (Cabrol and Grin, 1999; Horgan et al., 2020), and hinted that the northern hemisphere might have once contained a large ocean (Carr, 1987). Modern assessments, based mostly on laser altimetry, highresolution visible imaging, hyperspectral compositional remote sensing, and more sophisticated climate models strongly support the idea that many lakes have existed on Mars. However, they have created more questions than answers regarding a northern ocean.

It is widely accepted that several 100s of lakes existed on Mars, mostly during the Noachian (Cabrol and Grin, 2010; Boatwright and Head, 2021). Evidence of open-basin lakes is relatively easy to identify because of outflowing channels which also indicate the maximum height of a base level at some period in time (Fassett and Head, 2008b). Underfilled, closed-basin lakes are more difficult to characterize because the lake level, volume and lifespan are unclear. Aside from geomorphological evidence for lakes, compositional remote sensing reveals aqueous alteration minerals within specific lacustrine settings (Ehlmann et al., 2008a; Michalski et al., 2019). 
On Earth, lakes are geologically transient and on Mars this was also true. Based on estimates of erosion, sediment mobilization, and delta construction it appears that any individual lake might have only existed for $10^{4}-10^{6}$ years on Mars (Fassett and Head, 2008a; de Villiers et al., 2013). Aqueous mineral assemblages could have formed in similar timescales (Bishop et al., 2018). Placing this in the context of the Noachian period, which lasted $\sim 500 \mathrm{Myr}$, it is not clear that the existence of lakes implies warm climatic conditions or a substantially thicker atmosphere. It remains a question for debate whether most lakes on Mars formed in relatively short timescales in punctuated climate excursions on an otherwise relatively cold, frozen planet (Wordsworth et al., 2018).

One unusual lake that occurred in Mars' Eridania basin (Fig. 4) in the early Noachian could perhaps more accurately be referred to as a martian sea. This water body would have been kilometres deep, and contained as much water as most of the other lakes on Mars at that time combined. Extremely ancient, it contained thick, deep-water clays of likely hydrothermal origins and coastal evaporites, akin to deposits formed in Earth's oceans today (Michalski et al., 2017).

The case for a vast northern ocean is no stronger now than decades ago, but this hypothesis seems interesting and confusing in equal measure (Saberi, 2020). The vast channels that fed the putative ocean did not all occur at the same time (Warner et al., 2009). It is also not certain that these channels are formed exclusively by the action of water because lowviscosity lava is another possible erosive agent (Leverington, 2011). High-resolution remote-sensing data have been used to search for shorelines as evidence of a northern ocean, but this search has thus-far proved inconclusive. Currently, there is no definitive evidence to indicate that an ancient northern ocean once existed. One problematic issue is that, based on estimates, the amount of water present was insufficient to form a northern ocean, even taking into account the high rates of water loss to space (Carr and Head, 2015).

\section{Carbonates on Mars}

Mars' surface morphology was likely shaped by a warm and wet past (Carr, 1996), though how warm, how wet, and how intermittent these conditions were remains uncertain. Water on the Red Planet would remain in the liquid phase at temperatures maintained by greenhouse gases, mitigating the low intensity of solar radiation on Mars' surface (20-30\% lower than that on Earth's surface). It is uncertain whether Mars recycles crustal material (e.g. by plate tectonics) so surface materials ought to remain intact over time. Therefore, the relatively high $\mathrm{CO}_{2}$ pressure $\left(\mathrm{P}_{\mathrm{CO} 2}\right)$ in the atmosphere of ancient Mars should be evidenced by isotopic and mineralogical substances in the crust, such as carbonates. Geochemical modelling of evaporating mineral sequences in aqueous environments on early Mars, such as a closed basin lake, would likely indicate the precipitation of various carbonates. These might include siderite $\left(\mathrm{FeCO}_{3}\right)$, calcite $\left(\mathrm{CaCO}_{3}\right)$, hydromagnesite $\left(\mathrm{Mg}_{5}\left(\mathrm{CO}_{3}\right)_{4}(\mathrm{OH})_{2} \cdot 4 \mathrm{H}_{2} \mathrm{O}\right)$, and magnesite $\left(\mathrm{MgCO}_{3}\right)$ (Catling, 1999). Carbonates on present-day Mars could in this way provide insights into early Mars.

Carbonate-rich outcrops formed through aqueous chemistry have only been detected at a few sites on Mars; by orbital remote sensing and landed missions. These sites include the Nili Fossae grabens that are associated with phyllosilicate, olivine-rich deposits (Ehlmann et al., 2008b) and the Comanche outcrop that is located within the Gusev crater (16-34wt.\%) (Morris et al., 2010). The Jezero Crater also contains carbonate coexisting with olivine and/or Fe/Mg-smectite-bearing outcrops (Goudge et al., 2017; Horgan et al., 2020).

The scarcity of carbonate outcrops on Mars is currently an enigma. However, calculations may have shed some light on this issue. For example, calculations of aqueous equilibria (Fairén et al., 2004) are inconsistent with carbonate formation in an oceanic environment with $\mathrm{pH}$ values $<6.2, \mathrm{P}_{\mathrm{CO} 2}$ from 0.4 to 8 bar, and sulphate- and Fe concentrations of 13.5 and 0.8 $\mathrm{mM}$, respectively. Nevertheless, the possibility that many carbonate-rich outcrops occur that are undetected from orbit cannot be excluded. Some sulphates, not identified by orbital remote sensing, were subsequently discovered by landed missions. The Perseverance, Tianwen-1 and ExoMars Rosalind Franklin rovers may yet reveal martian carbonate outcrops not identified by orbiters.

\section{Carbonate formation by atmospheric processes}

Some carbonates of potential atmospheric origin were found by missions to Mars or by martian meteorite studies. For example, calcium carbonate in the soil around the Phoenix landing site (3-5 wt.\%) (Boynton et al., 2009) could form by the interaction of atmospheric $\mathrm{CO}_{2}$ with liquid water films on the surfaces of dust particles. Thermal Emission Spectrometer (TES) data analysis of dust from 21 regions of the martian surface measured 2-5 wt.\% carbonates dominated by magnesite (Bandfield et al., 2003), which is also consistent with MiniTES data at the landing site of the Opportunity rover where $\sim 5 \mathrm{wt} . \%$ carbonate was identified in the regolith (Christensen et al., 2004).

At Gale Crater, Curiosity rover's Sample Analysis at Mars (SAM) tool heated sediment and analysed emissions using gas chromatography mass spectrometry (GCMS). $\mathrm{CO}_{2}$ gas was detected at $450-800{ }^{\circ} \mathrm{C}$, a finding consistent with $<1 \mathrm{wt} \% \mathrm{Fe}-$, Mg-rich carbonates (Sutter et al., 2019).

Based on the oxygen-isotope study of carbonates in meteorite ALH84001, Farquhar et al. (1998) suggested two oxygen-isotope reservoirs; the atmosphere and the silicate planet. At the time of carbonate growth in this meteorite, the cause of an apparent atmospheric oxygen isotope disequilibrium $\left(\delta^{17} \mathrm{O}\right)$ might be the exchange between the atmospheric $\mathrm{CO}_{2}$ and $\mathrm{O}\left({ }^{1} \mathrm{D}\right)$ produced by the photodecomposition of ozone. In other words, some carbonate may be generated in the atmosphere by photochemistry.

If carbonate can form from atmospheric $\mathrm{CO}_{2}$ via UVCinduced photochemistry (Farquhar et al., 1998), the energetic electrons resulting from electrostatic discharge (ESD) during martian dust storms (common during the Amazonian) may cause a similar reaction, but through electrochemistry. In a laboratory simulation, $\mathrm{Na}_{2} \mathrm{CO}_{3}, \mathrm{NaClO}_{3}$ and $\mathrm{NaClO}_{4}$ were generated after only $1 \mathrm{~h}$ in an ESD-Normal Glow Discharge (NGD) process on $\mathrm{NaCl}$ under 3 mbar $\mathrm{CO}_{2}$ (Wu et al., 2018). Furthermore, Na-, $\mathrm{K}-$, $\mathrm{Al}$ - and $\mathrm{Ca}$ carbonates were identified in electrochemical reactions with chlorides under Mars atmospheric conditions (Wang et al., 2020a, 2020b).

\section{Fe-oxides}

Hematite - ferric oxide $\left(\mathrm{Fe}_{2} \mathrm{O}_{3}\right)$ - is widely distributed across the surface of Mars. Hematite spherules, known as blueberries, have been found in the Meridiani Planum by the Opportunity rover. On Earth, hematite can form in a variety of environments and 


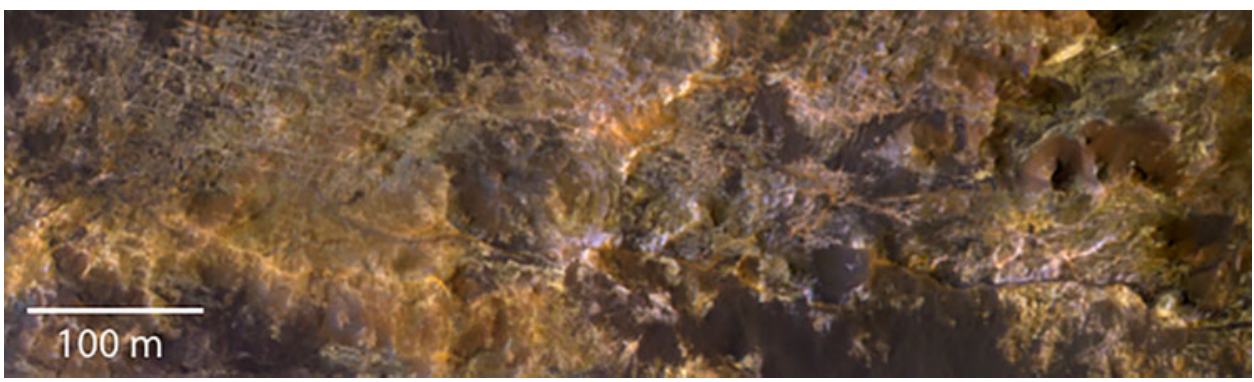

Fig. 4. A HiRISE false colour (IRB) image of putative hydrothermal seafloor clays in the deepest parts of Eridania basin. Yellow-brown-green clays are cut by a dense network of veins, and partially covered by younger, dark eolian material. from a variety of parent materials. It is widely accepted that the occurrence of hematite 'blueberries' on Mars indicates that liquid water was once present in Meridiani (Squyres et al., 2004; Golden et al., 2008). However, a clear understanding of the formation of these spherules is still a matter of debate. Various explanations have been investigated, such as the transformation of goethite $(\mathrm{FeOOH})$ and other iron hydroxides (Glotch and Kraft, 2008; Fu et al., 2020), that initially precipitated from aqueous solution and subsequently transformed into hematite. Other theories suggest the role of hydrothermal fluids and seabed water flows depositing the blueberries as observed on Earth (Di Bella et al., 2019), or that the formation of hematite spherules is associated with unique surface conditions on Mars, such as ablation of meteorites (Misra et al., 2014) or freezing aqueous suspensions of hematite nanoparticles (Sexton et al., 2017).

Hematite deposits at Meridiani Planum were first discovered by the TES on the NASA orbiter Mars Global Surveyor (Christensen et al., 2000). Strong absorptions at 315, 461 and $560 \mathrm{~cm}^{-1}$ observed by TES are characteristic of coarse, grey hematite (Christensen et al., 2001; Glotch et al., 2004). This finding prompted the selection of Meridiani Planum as the landing site for NASA's Mars Exploration Rovers mission (MER) that includes the Opportunity and Spirit rovers (Golombek et al., 2003). The images returned by Opportunity revealed the abundant accumulations of spherical balls $(<0.5 \mathrm{~cm}$ diameter). These spherules are ubiquitous on the surface of the martian landscape, shown as blue in the false-coloured images of the rover's panoramic camera (Fig. 5), and dubbed as 'blueberries' (their distribution was considered similar to that of the blueberries in a blueberry muffin) (Squyres et al., 2004). Multiple instruments on Opportunity (MiniTES, Pancam, Mossbauer spectrometer and APXS) confirmed that the mineralogy is hematite (Morris et al., 2006). Fragments of these spherules lack an internal structure (Klingelhöfer et al., 2004; Squyres et al., 2004).

The occurrences of these blueberries indicate hydrothermal activity in Meridiani Planum. By contrast, Spirit does not find any hematite in Gusev Crater. The Vera Rubin Ridge, also known as the Hematite Ridge, is an erosion-resistant feature within the Gale Crater, associated with a hematite spectral signature according to orbiter-derived data (Fraeman et al., 2013). The in-situ X-ray diffraction analysis shows that hematite is present in every Vera Rubin Ridge sample (Rampe et al., 2020) but no blueberries are found within these rocks either.

Fe-oxide concretions found in Utah and Mongolia have been investigated as analogues of martian hematite spherules (Chan et al., 2004; Yoshida et al., 2018). Terrestrial concretions have similar spherical shapes and compositions (Chan et al., 2004; Sefton-Nash and Catling, 2008; Yoshida et al., 2018) though differences between their sizes and mineralogy can occur. Terrestrial concretions (centimetres to metres) are larger than martian blueberries (diameter $<6.2 \mathrm{~mm}$ ) (McLennan et al., 2005; Sefton-Nash and Catling, 2008). Goethite and quartz are major minerals (each present at $\leq 10 \mathrm{wt} \%$ ) in terrestrial concretions (Yoshida et al., 2018), whereas martian blueberries are composed of pure hematite.

\section{Hydrous sulphates}

A range of hydrous sulphates occur on Mars (Mg-, $\mathrm{Fe}-$, $\mathrm{Al}-$ and $\mathrm{Ca}$ sulphates) with $\mathrm{Mg}$ sulphate the most abundant. Monohydrated $\mathrm{Mg}$ sulphate $\left(\mathrm{MgSO}_{4} \cdot \mathrm{H}_{2} \mathrm{O}\right)$ (identified as kieserite) and polyhydrated sulphates (interpreted as mostly $\mathrm{MgSO}_{4} \cdot 4 \mathrm{H}_{2} \mathrm{O}$ (Wang et al., 2016)) are the most-abundant hydrous sulphates on the martian surface according to remotesensing studies (Fig. 6). Several-km-thick layers of monohydrated and polyhydrated sulphates have been observed in the Hesperian-aged equatorial regions, such as the Valles Marineris interior layered deposits (Ehlmann and Edwards, 2014). Hydrated sulphates have also been found in the Noachian southern highlands (Wray et al., 2009; 2011, Wiseman et al., 2010; Ackiss and Wray, 2014).

Other types of hydrated sulphates, Fe sulphates (e.g. jarosite, hydroxylated ferric sulphates, and szomolnokite) and Al sulphate (alunite) have been identified in highly localized regions of Mars. Large quantities of gypsum occur in the North Polar regions of Mars (Fishbaugh and Head, 2005; Langevin et al., 2005; Fishbaugh et al., 2007; Horgan et al., 2009), while other Ca sulphates have a more localized distribution (Wray et al., 2010; Ackiss and Wray, 2014). The Fe- and Ca sulphates also seem to co-occur with monohydrated and polyhydrated $\mathrm{Mg}$ sulphates (Bishop et al., 2009; Lichtenberg et al., 2010; Wray et al., 2011; Weitz et al., 2012; Ackiss and Wray, 2014).

In-situ measurements made during surface-exploration missions-Vikings, Pathfinder, Mars Exploration Rovers (MER), Phoenix, and Mars Science Laboratory (MSL) - identified Mg-, $\mathrm{Ca}-$ and $\mathrm{Fe}^{3+}$ sulphates at all landing sites (Fig. 6). Additional sulphates were found at landing sites (e.g. in Gusev Crater, by the Spirit rover) whereas none was detected by orbital remote sensing. In particular, hydrous $\mathrm{Mg}$-, $\mathrm{Fe}$ - and $\mathrm{Ca}$ sulphates were identified in the trenches and tracks made by Spirit rover's wheels (Wang et al., 2006; 2008, Johnson et al., 2007; Arvidson et al., 2010). Furthermore, volatiles ( $\mathrm{S}$ and $\mathrm{Cl}$ ) were identified in X-ray amorphous phases in all samples analysed by CheMin (using XRD technology) and SAM (using GC-MS technology) at Gale Crater. Some of these phases might be the alteration products of sulphates.

Remote-sensing observations suggest that most martian hydrated sulphates formed when a relatively large quantity of 


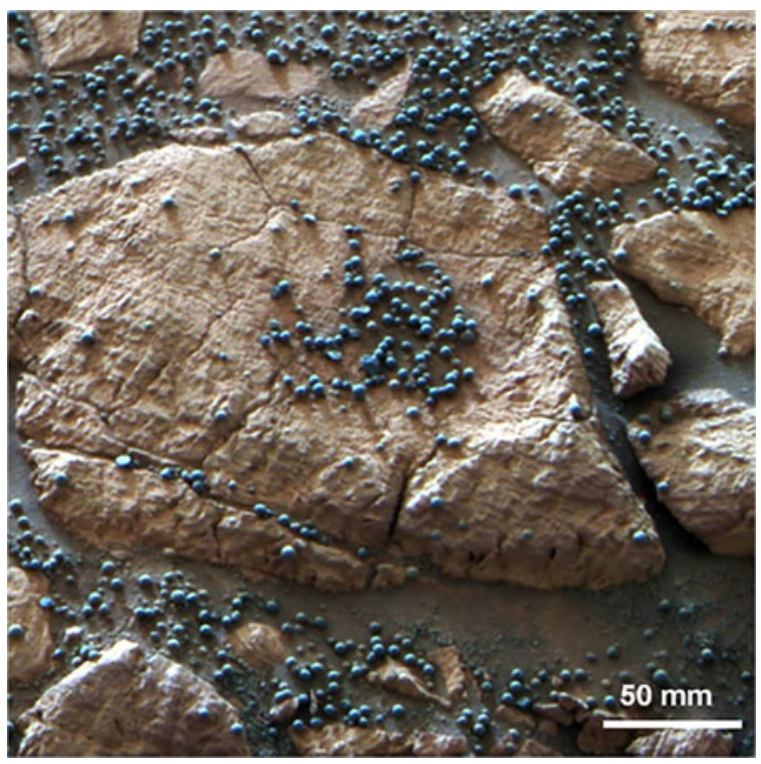

Fig. 5. Martian hematite spherules 'blueberries' discovered by the Opportunity rover. Image credit: NASA/JPL/USG.

water was available during the Hesperian period. The chemistry of the hydrous sulphates, being $\mathrm{Mg}$-rich and $\mathrm{Fe}-$, $\mathrm{Al}-$, and $\mathrm{Ca}-$ poor, with negligible $\mathrm{Na}$ and $\mathrm{K}$, reflects a chemical weathering sequence of basaltic rocks, with higher aqueous dissolution rates for olivine compared to pyroxene, plagioclase and K-feldspar (Hurowitz et al., 2006; McLennan et al., 2005). During hydrothermal episodes, the Ca sulphate veins found in the Endeavor Crater and Gale Crater may have formed (Squyres et al., 2012; Vaniman et al., 2018). Although most hydrated sulphates have been found in the Hesperian terrains, the largest gypsum deposits discovered to date have been found on the Amazonian-aged north polar dunes, which were formed in a unique local environment (Langevin et al., 2005). They have been interpreted to have either mineralized from local rock-water interactions or formed by the erosion of gypsum-bearing materials in the polar ice cap (Horgan et al., 2009).

During Mars' more recent past to the present, hydrated sulphates on the surface and in the shallow subsurface have continuously been affected by obliquity changes and the planet's seasonal and diurnal cycles (Laskar et al., 2004). For some sulphates, their degrees of hydration are dependent on the partial water vapour pressures $\left(\mathrm{P}_{\mathrm{H}_{2} \mathrm{O}}\right)$ (Kong et al., 2018). Environmental changes on Mars can induce phase transformations of hydrous sulphates, such as those among neutral, acidic and basic $\mathrm{Fe}^{3+}$ sulphates (Wang and Ling, 2011). Another potentially important process on present-day Mars is the plasma chemistry induced by martian dust activity. Laboratory simulations have demonstrated the dehydration, amorphization, and oxidation of hydrous sulphates (Wang et al., 2020a).

\section{Hydrated silicates}

The identification of and search for clays on the martian surface has been a key aspect of Mars exploration, in terms of their remote identification by the OMEGA (Observatoire pour la Mineralogie, l'Eau, le Glace e l'Activité) and CRISM (Compact Reconnaissance Imaging Spectrometer for Mars) near-infrared orbiting instruments (Murchie et al., 2009), the selection and characterization of landing sites (Carter et al., 2013), and science activities during landing missions. Phyllosilicates have been detected remotely in layered sediments but are also associated with impact cratering (Turner et al., 2016). Widespread phyllosilicates, particularly within the ancient highlands, include Fe-rich smectite $(\mathrm{NaCa})_{0.5}\left(\mathrm{Fe}^{2}\right.$ $\left.{ }^{+} \mathrm{Mg}\right)_{6}\left(\mathrm{SiFe}^{3+} \mathrm{Al}\right)_{8} \mathrm{O}_{20}(\mathrm{OH})_{4}$, chlorite $(\mathrm{FeMg})_{5} \mathrm{Al}\left(\mathrm{AlSi}_{3}\right) \mathrm{O}_{10}(\mathrm{OH})_{8}$ and serpentine $(\mathrm{Mg}, \mathrm{Fe})_{3} \mathrm{Si}_{2} \mathrm{O}_{5}(\mathrm{OH})_{4}$. Fe-rich smectite/saponite (with its characteristic $2.3 \mu \mathrm{m}$ absorption in CRISM data) was predicted for the Gale Crater central mound - Aeolis Mons (Thomson et al., 2011) before MSL's landing in 2012. Subsequently, CheMin $\mathrm{XRD}$ analyses have confirmed the presence of abundant smectite (e.g. Rampe et al., 2017).

\section{Clay mineralogy and the evolution of the martian crust}

A key result in understanding the formation of martian phyllosilicates is evidence that the abundance of clay in Gale Crater finegrained sediments formed through low-temperature, $<50{ }^{\circ} \mathrm{C}$ diagenesis - detrital grains such as olivine, plagioclase, etc., reacting with dilute groundwater in buried sediments (McLennan et al., 2014, Bridges et al., 2015). Strong evidence for diagenetic rather than detrital clay origins is given by the textures of sedimentary rocks, e.g. with nodules, veins and ridges (Léveillé et al., 2014). This is a likely origin for much of the clay detected in the ancient highlands. On the basis of the MSL results, we now know that the presence of smectite-dominated clays and an association with layered sediments is an indication of an ancient habitable environment and stable hydrological cycle (Grotzinger et al., 2015). The landing site of Mars2020, Jezero Crater, is partially filled with clay-bearing ancient deltaic deposits (Goudge et al., 2017). It will be important to ascertain if that clay is also predominantly of diagenetic origin, or, alternatively, if detrital clay input was important.

However, the most-closely studied martian clays to date (prior to the MSR mission) are within the nakhlite martian meteorites (Chatzitheodoridis et al., 2014). These have siderite, ferric saponite and ferric serpentine-rich veins (Lee and Chatzitheodoridis, 2016) in their olivine grains and mesostases (Changela and Bridges, 2010; Hicks et al., 2014). The saponite and serpentine formation postdates carbonate mineralization and occurred under near-neutral conditions, and at lower temperatures $\sim 50{ }^{\circ} \mathrm{C}$ (Bridges and Schwenzer, 2012). These meteorites may offer a clue about the origin of phyllosilicates associated with impact craters on Mars. Clays like those preserved in the nakhlites may result from impact-induced hydrothermal activity.

\section{Methane on Mars}

An understanding of methane in the martian atmosphere has been a challenge for the scientific community since the '70s, when the Mariner 9 spectrometer IRIS provided the first hints of methane on Mars. The upper concentration limit was estimated at $20 \mathrm{ppb}$ (Mège and Masson, 1996). In 2003, methane detection changed dramatically. Observations made at the Keck Observatory (Keck II Telescope) and the Gemini South Observatory, and the NASA Infrared Telescope Facility (NASA IRTF) in Mauna Kea, Hawaii detected $\mathrm{CH}_{4}$ vibrational bands. In 2004, Krasnopolsky et al. (2004), then Formisano et al. (2004) reported the ground-based detection of methane in a 
90

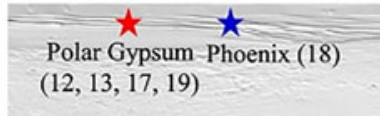

$0^{\circ} \mathrm{N} \quad \mathrm{T}$

$(12,13,17,19)$

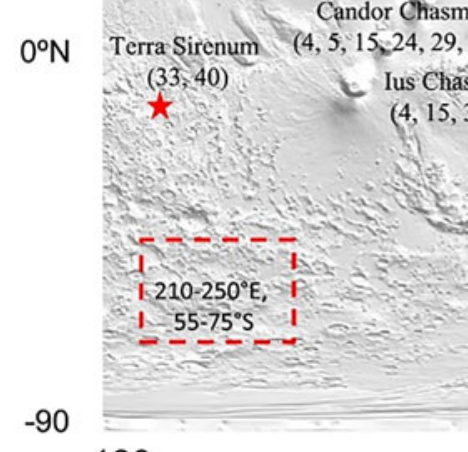

$-180$
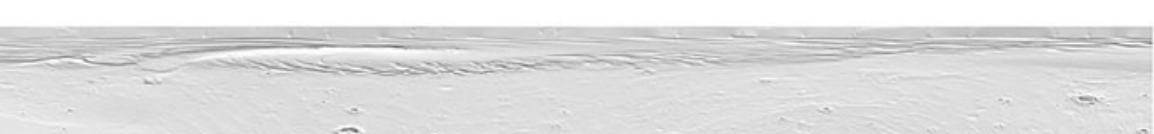

$$
\text { t) }
$$

$0^{\circ} \mathrm{E}$ mixing ratio of $10 \pm 3$ ppbv during the martian northern summer of 1999 using Fourier Transform Spectroscopy at the CanadaFrance-Hawaii Telescope.

Subsequently, Formisano et al. (2004) measured methane in the martian atmosphere using the Planetary Fourier Spectrometer (PFS) on board the Mars Express spacecraft. The average data from 16 orbits measuring the northern winter hemisphere in 2004 found local variations between 0 and 30 ppbv across the planet. The Mars Express data also showed the methane mixing ratio to slowly decrease from the northern spring to the southern summer with an average value of $14 \pm 5 \mathrm{ppbv}$, and to coincide with the water vapour diurnal cycle on Mars (Geminale et al., 2008). The northern mid-summer plume was calculated to contain $\sim 19000$ metric tons $\mathrm{CH}_{4}$ and interpreted to be from different regions of Mars (Mumma et al., 2009). The TES on-board of Mars Global Surveyor over $\sim 3$ martian years (Clancy et al., 2000; Fonti and Marzo, 2010) suggested a seasonal cycle of the methane, as well as inter-annual variations - increases over $32 \mathrm{ppbv}$ with peak values over $60 \mathrm{ppm}$ during the northern summer and autumn, and a decrease during the winter. A subsequent study using the Mars Express PFS (Geminale et al., 2011) also documented an increase of methane to a mixing ratio of $34 \mathrm{ppbv}$ over the north polar ice cap during the summer, which cannot be explained by global circulation. Geminale et al. (2011) suggested that there could be a methane reservoir associated with the polar ice cap, producing in one year 16000-24000 tons $\mathrm{CH}_{4}$, and the methane lifetime could be of the order of 4-6 martian years. Further ground-based observations using the CSHELL (Cryogenic Echelle Spectrograph) and NIRSpec (Near InfraRed Spectrograph) confirmed a far lower maximum limit of methane at 8 ppbv (Zahnle et al., 2011; Krasnopolsky, 2012; Villanueva et al., 2013).

More recently, surface-based measurements of the atmosphere by Curiosity, performed for 605 martian sols in the period 20122014, measured methane with a background concentration of $0.69 \pm 0.25 \mathrm{ppbv}$ (Webster et al., 2015). Occasional spikes were also measured up to $7.2 \pm 2$. 1 ppbv in Gale Crater by the Tunable Laser Spectrometer of SAM. This led to the interpretation that the seasonal variation of methane was $0.24-0.65 \mathrm{ppbv}$ from 2014 to 2017 (Webster et al., 2018). This seasonal variation is also consistent with other atmospheric gas variations in $\mathrm{CO}_{2}$, $\mathrm{H}_{2} \mathrm{O}, \mathrm{O}_{2}$ and $\mathrm{CO}$ (Trainer et al., 2019). However, the magnitude of the seasonal variation in the $\mathrm{CH}_{4}$ background is greater than the other long-lived atmospheric volatiles. This variation may be related to geological and/or meteorological effects, such as losses from photochemistry, sputtering, escape or condensation under any of the conditions reached during the current seasonal cycle (Trainer et al., 2019). It should be noted that the Curiosity does not have any instrument that can distinguish between biological and geological sources of methane.

\section{The origin of methane}

On Earth, 95\% methane is produced biogenically, by microbial methanogens (Atreya et al., 2007). The process begins with the oxidation of dihydrogen by hydrogenase (equation (1)), followed by the reduction of $\mathrm{CO}_{2}$ (equation (2)) (Thauer, 1998). Methanogens generate energy via the reductive acetyl CoA (Wood-Ljungdahl) pathway, and it is during this process that methane is produced as a by-product (Parkes et al., 2011). Such microorganisms are classified as chemolithoautotrophs because they make their own source of energy by breaking bonds within inorganic molecules (equation (1) and (2)) and can fix $\mathrm{CO}_{2}$.

$$
\begin{gathered}
\mathrm{H}_{2} \leftrightarrow 2 \mathrm{e}^{-}+2 \mathrm{H}^{+} \mathrm{E}_{0}^{\prime}=414 \mathrm{mV} \\
\mathrm{CO}_{2} \leftrightarrow 8 \mathrm{e}^{-}+8 \mathrm{H}^{+} \rightarrow 2 \mathrm{H}_{2} \mathrm{O}+\mathrm{CH}_{4} \Delta \mathrm{G}^{0^{\prime}}=-131 \mathrm{kJM}^{-1}
\end{gathered}
$$


Dihydrogen gas in Equation (1) can also form abiotically as in Equation (3), or degas from erupting volcanoes on Earth.

$$
3 \mathrm{Fe}_{2} \mathrm{SiO}_{4}+2 \mathrm{H}_{2} \mathrm{O} \rightarrow 2 \mathrm{Fe}_{3} \mathrm{O}_{4}+3 \mathrm{SiO}_{2}+\mathrm{SH}_{2}
$$

The only way to ascertain the existence of life elsewhere in our Milky Way Galaxy is via spectral signals (Jheeta, 2013). Methane can be generated both abiotically and biotically. It can be made abiotically by serpentinization (Equation (4)). It should be noted that to produce one molecule of methane abiotically requires 26 molecules of water (Equation (4)). Present-day Mars is extensively depleted of water. This may be the reason why the methane plumes that are produced on Mars are only occasional spikes.

$$
\begin{array}{r}
18 \mathrm{Mg}_{2} \mathrm{SiO}_{4}+6 \mathrm{Fe}_{2} \mathrm{SiO}_{4}+26 \mathrm{H}_{2} \mathrm{O}+\mathrm{CO}_{2} \\
\rightarrow 12 \mathrm{Mg}_{3} \mathrm{Si}_{2} \mathrm{O}_{5}(\mathrm{OH})_{4}+4 \mathrm{Fe}_{3} \mathrm{O}_{4}+\mathrm{CH}_{4}
\end{array}
$$

Methanogens have two very important attributes, namely they are thought to be the most-primitive organisms on present-day Earth; and they are anaerobic hardy microorganisms able to withstand extreme temperatures and acidities. Such conditions were probably more common on the early Earth. Martian life may be present below the surface, especially if similarly robust microorganisms are harboured within an anaerobic subsurface lake (Westall et al., 2015). This however requires that these microorganisms can utilize dihydrogen in order to produce methane by the reduction of $\mathrm{CO}_{2}$. In anaerobic lakes, there may not be enough dihydrogen for this process which would seep into the atmosphere and then escape to space. For the detection of life on an exoplanet there needs to be a continuous supply of a biogenic gas such as methane maintained at certain levels rather than sporadic tenuous degassing from a planet's surface, as is the case with Mars. Thus, intermittent plumes of methane are more consistent with an abiotic origin.

Recent investigation on the photochemical synthesis of $\mathrm{CH}_{4}$ by the reduction of $\mathrm{CO}_{2}$ over acidic minerals (Shkrob et al., 2012), including a wide range of clays found on both the surface of Mars and in martian meteorites such as Nakhla (Civiš et al., 2017, 2018), can explain not only the formation of methane, but also of perchlorates and chlorinated organic compounds. It can also account for the seasonal variations of methane and carbon monoxide concentrations in the atmosphere (Civiš et al., 2017, 2018). Additional abiotic surface sources involve the decomposition of organics delivered to the martian surface by fragments of comets and asteroids (Fries et al., 2016), volcanic outgassing (Craddock and Greeley, 2009), and slow photocatalytic decomposition of carboxylated molecules in kerogen by photo-Kolbe reactions with $\mathrm{Fe}(\mathrm{II})$ oxides in the martian regolith (Shkrob et al., 2010). Finally, the formation of subsurface methane in high pressure-temperature hydrothermal fluids (Welhan, 1988), deep subsurface aquifers ( $\mathrm{Hu}$ et al., 2016), and the serpentinization of olivine (Oze and Sharma, 2005) cannot be ruled out.

\section{The habitability of Mars}

\section{Was Mars ever inhabited?}

On the question of whether Mars was inhabited, there are two points that we should consider and factor into the experimental search for martian life. We tend to focus closely on the question whether Mars is or was inhabited. However, although it will be difficult to show a definitive lack of life anywhere on Mars, if we eventually explore many potentially habitable environments and find no evidence of life then this would suggest that the planet has been lifeless (Cockell and McMahon, 2019). This finding would be profound. If a planet that was similar to early Earth 4 billion years ago was sterile, yet Earth went on to host about $10^{29}$ microbes (Kallmeyer et al., 2012), this would be more difficult to explain than finding life on another planet that began in a very similar state to Earth. We should remember not to get too focused on a quest to find life on Mars, but rather maintain our interest in testing the hypothesis of life on Mars, either outcome of which would be important.

However, was there life around to take advantage of these habitable conditions? We do not know enough about the origin of life to be able to provide a definitive answer to this (Michalski et al., 2018), nor do we know, despite promising impact-shock experiments, whether panspermia could have successfully occurred between Earth and Mars if Mars was not suitable for an origin of life (Horneck et al., 2008). Further advances in origins of life research on Earth may well elucidate whether Mars had environments suitable for an origin of life, but even if these insights return affirmative answers, that does not demonstrate that this process did occur on Mars. Advances in our understanding of the origin of life and experimental tests of panspermia in shock experiments can never answer definitively the question posed, only provide information that will help us explain what we ultimately observe on the planet itself. We need to go to Mars to unambiguously detect biosignatures.

\section{What if Mars was never habited?}

A habitable, but lifeless Mars would raise important questions. Some people regard such a state as logically impossible - that we cannot define a place as being habitable without the presence of life, but this is incorrect. Microbiologists all the time make agar plates that are habitable to known organisms but are uninhabited (uninhabited habitats). We might find environments on Mars that have all the requirements for known forms of life (such as methanogens), but those environments were never inhabited, either because Mars was always uninhabited, or if it was inhabited, transient habitable environments came and went without being colonized by existing life. Such environments can be demonstrated even on the fecund Earth (Cockell, 2020). These facts do not necessarily bear on the search for biosignatures, but they are important to bear in mind since the paradigm that where there are habitable conditions there is life, which is generally true in most habitable environments on the Earth, may not hold on other planets and clearly would not be true on a planet where there had never been life. Investigating habitable, but uninhabited environments is difficult because one is looking for definitive evidence of the lack of life, which could either be the lack of a biosignature or the presence of some condition that requires a lack of life (such as the presence of some trace element or nutrient that is always depleted by life, and whose presence would truly be an anti-biosignature; however, examples of such signatures are difficult to identify). The search for uninhabited habitats raises these observations and experimental complexities.

At the current time, it is not possible to provide a definitive answer to the question, but we do know that the presence of 
habitable conditions on Mars makes this question a viable and important one to answer.

\section{Microfossils on Mars}

A 'biomarker' on Mars could be in the form of microfossils - fossilized individual or aggregates of microbial cells. A challenge for future exploratory missions would be the unambiguous identification of such features in martian bedrock. In the context of the search for life on Mars, or the earliest records of life on Earth, the term 'microfossil' is generally understood to mean the material remnants of a microbial cell, with recognizably cellular morphology, most commonly preserved as insoluble organic matter, or 'kerogen'. In this sense, there can be no 'microfossil' without fossil morphology.

Can mineralogy, organic chemistry and/or isotopes act as reliable biomarkers without morphology? The specific clarifying examples of isotopes, organic chemistry and mineralogy as potential exceptions might be addressed as follows. In the most-general sense, it could be argued that all three of these phenomena are rooted in form, that is, a spatial ordering of the physical world by life. From this point of view, the 'exceptions' are irrelevant. Certainly, this is true of organic chemistry - purely molecular evidence for biogenicity would occur either as a molecule or set of molecules of sufficient structural complexity that no abiotic mechanism can be established for their synthesis, or a set of molecules with a 'repeating' pattern of different, but related structures.

Minerals are defined in large part by their crystal structure. As such, any biological impact on mineralogy is an expression of form. From another point of view, the intriguing model of 'mineral evolution' advanced by Hazen et al. (2008) maintains that much of the mineral diversity on the modern Earth emerged as at least an indirect result of biology (after biologically mediated accumulation of free oxygen in Earth surface environments). Through this lens, any mineral whose evolution required abundant free oxygen is a biosignature. Would the presence of such a mineral, on its own, be sufficient as definitive proof of an inhabited extraterrestrial planet? This is likely not so. It is certainly possible, though, that a very strong case for the past influence of biology could be made on the basis of a terrestrial planet's mineralogy, but mineralogy alone would likely be insufficient. Biomineralization on Earth produces diverse and diagnostic forms (e.g. in carbonates or iron oxides) that are unknown in abiotic systems, but in these cases, chemical formulae and structure of unit cells are the same as minerals formed abiotically.

Considering isotopic fractionation as an expression of form, there are thresholds of isotopic fractionation in certain Earth systems that are generally accepted as strongly - even conclusively indicative of biology. Sedimentary organic matter with apparent carbon isotope fractionations (i.e. relative to co-occurring carbonate minerals reasonably expected to record the isotopic composition of inorganic carbon at the time of organic synthesis) $>40 \%$, and sulphide minerals with $\delta^{34} \mathrm{~S}$ well outside the range between -10 and $+10 \%$ are both strong indicators of biology on Earth. The comparative lack of knowledge about carbonand sulphur cycles on Mars would make any isotopic observation, on its own, more ambiguous. There is a good reason to believe, however, that a similar abiotic fractionation process acted on Earth and Mars, and large isotopic fractionations between co-occurring oxidized and reduced species containing biologically important elements, expressed in a geologic context consistent with habitability, should be considered as strong potential biosignatures.

\section{Organics on Mars}

Organics discovered from direct analysis of sediments of the martian surface include chlorine (Ming et al., 2014) and sulphur-bearing macromolecular organics (Eigenbrode et al., 2018). In martian meteorites (currently the only martian samples on Earth), nitrogen-bearing organics from the 4-Ga-old martian meteorite, Allan Hills 84001 , are found in carbonates (Koike et al., 2020). Macromolecular reduced carbon in other martian meteorites has also been identified (Steele et al., 2016).

The SAM instrument (Freissinet et al., 2015; Steele et al., 2016) onboard the MSL first measured indigenous organics on Mars above background levels. Analyses of the Sheepbed mudstone in Gale Crater - a sediment with 20 wt.\% smectite clay interpreted to represent a lacustrine environment - contains chlorine-bearing organic molecules, such as chlorobenzene $\left(\mathrm{C}_{6} \mathrm{H}_{5} \mathrm{Cl} ; 150-300 \mathrm{ppb}\right)$ and in much smaller amounts, dichloroalkanes (e.g. propane $\mathrm{C}_{3} \mathrm{H}_{6} \mathrm{Cl}_{2}$, ethane $\mathrm{C}_{2} \mathrm{H}_{4} \mathrm{Cl}_{2}$ and butane $\mathrm{C}_{4} \mathrm{H}_{8} \mathrm{Cl}_{2}$ ) in soil samples from the Cumberland drill hole, interpreted as either indigenous or pyrolyzed by reactions between martian aromatic or aliphatic molecules with oxychlorine phases. Sulphur-bearing organics were also identified by SAM in old mudstone fluviodeltaic sediments from the Murray formation at Pahrump Hills in Gale Crater including thiophenes (i.e. $\mathrm{C}_{4} \mathrm{H}_{4} \mathrm{~S}, \mathrm{C}_{5} \mathrm{H}_{6} \mathrm{~S}$ and $\mathrm{C}_{8} \mathrm{H}_{6} \mathrm{~S}$ ) and thiols $\left(\mathrm{CH}_{4} \mathrm{~S}\right.$ and $\left.\mathrm{C}_{2} \mathrm{H}_{6} \mathrm{~S}\right)$. Aliphatics (chains of one- to five carbons) and aromatic hydrocarbons (benzenes) were among the detected volatiles above the detection limit of the instruments.

Chlorination or sulphurization could be related to abiotic secondary processes on Mars and serve as a means to prevent organics breaking down under intense radiation on the martian surface. Nitrogen-bearing organics in ALH 84001 also have abiotic origins consistent with conditions on Hadean Mars (Koike et al., 2020). More conclusive evidence is expected when the deeper subsurface of Mars is analysed. The Rosalind Franklin rover in Oxia Planum will drill samples $2 \mathrm{~m}$ into the subsurface (Martian meteorites and sample return section). The Perseverance rover in Jezero Crater with the Raman and fluorescence SHERLOC spectrometer will search for organics within their mineralogical context. Perseverance is also the first mission caching samples for return back to Earth (Martian meteorites and sample return section). Careful sampling of a variety of geochemical environments and origins will be required. Hydrothermal alteration and vacant areas inside the volume of clays where water activity is higher can not only trap but can also catalyse the synthesis of organics from simpler precursors. Such clays are found in martian meteorites, such as in Nakhla (Chatzitheodoridis et al., 2014) which contain geochemical micro-environment niches where saponite clays form in similarity with, for example, saponite found in basalts near the Mid-Atlantic Ridge of the Atlantis Massif, in which aromatic amino-acids form abiotically (Ménez et al., 2018).

\section{Disambiguating biogenic and abiotic origins}

A biogenic interpretation of organic compounds discovered on Mars based on chemical composition alone is ambiguous; organic chemistry is not exclusive to biology. However, homochirality is a uniquely biological trait. For example, if amino acids were discovered on Mars, a left-handed homochirality would indicate a biological origin based on what we know of life's biochemistry on 
Earth. An organic biomarker could be preserved within a definitive biomorphic structure such as a microfossil (see above). Biogenic organic material also preferentially retains the lighter stable isotope of ${ }^{12} \mathrm{C}$. Organic material with any of these properties has yet to be discovered on Mars.

On Earth, organic material is mostly biogenic. An example of an exception is the abiotic organic material delivered to Earth by fragments of asteroids and comets as dust and meteorites. Interplanetary dust would have also delivered an order of magnitude more of organic carbon to Mars than to Earth (Flynn, 1996). The surface of Mars is also peppered by impact craters. Elevated organic distributions around impact craters on Mars could trace their meteoric origins (Frantseva et al., 2018). Higher fractions of stable isotopes heavier than those found in putative biomolecules (e.g. $\mathrm{D},{ }^{13} \mathrm{C}$ and ${ }^{15} \mathrm{~N}$ ) could also imply origins exogenous to Mars. This means that as well as endogenic processes, exogenous delivery should be considered when disentangling abiotic organic evolution on the surface of Mars.

\section{Putative martian life might have escaped extinction}

The endolithic niche is an important target of the search for life elsewhere in the Solar System. Specialized microbes able to exploit this habitat on Earth by developing in the airspaces of rocks are protected from intense solar radiation and desiccation, allowing their population to persist even in the most-extreme terrestrial climates (Walker et al., 2005). Endolithic microorganisms are often the predominant form of life in hot- and cold deserts (Coleine et al., 2021), including the McMurdo Dry Valleys of Antarctica characterized by extreme cold- and arid conditions, along with the intense UV irradiation reaching ground level (Onofri et al., 2004; Bernhard and Stierle, 2020). Therefore, they have value as Mars analogue sites (Friedmann, 1982; Selbmann et al., 2018).

Endolithic life-forms of the Antarctic desert are used as proxies for putative life on planets such as Mars. If putative martian life ever evolved, it may have found a last refuge within the rock pores during the cooling and drying over the early history of the Red Planet (Wierzchos et al., 2011).

\section{Implications for interplanetary life transfer}

Studies on these endolithic communities are pertinent to the concept of lithopanspermia (i.e. the interplanetary transport of microbial passengers inside rocks). Petrographic analyses of martian meteorites indicate that, if during ejection from Mars these rocks experienced shock in the range from 5 to $55 \mathrm{GPa}$ (Artemieva and Ivanov, 2004; Stöffler et al., 2007) and heating in the range from 40 to $350^{\circ} \mathrm{C}$, some of them have never been exposed to temperatures above $100{ }^{\circ} \mathrm{C}$ (Weiss et al., 2000; Shuster and Weiss, 2005). Therefore, some fragments of martian crust can be boosted into space whilst experiencing only relatively mild pressure/temperature shocks. Entering into the atmosphere of the recipient planet exposes the meteors to additional fragmentation because speeds, reaching $10-20 \mathrm{~km} \mathrm{~s}^{-1}$, lead to frictional heating melts of the surface. Yet, the short transit time of meteors through the atmosphere, of a few seconds, precludes penetration of heat more than a few millimetres below the surface, limiting the strong heating to $<1 \mathrm{~mm}$ of depth (meteorite fusion crust) (Fajardo-Cavazos et al., 2005).

Space conditions appear to be the main limit for microbial interplanetary transit; besides, endolithic microorganisms are highly extremotolerant life-forms, able to survive a wide range of injuries, including extremes of temperature, vacuum and high doses of UV and ionizing radiation partially simulating cosmic radiation (up to $60 \mathrm{kGy} 60 \mathrm{Co}$ ) (Selbmann et al., 2018) or $\mathrm{Fe}$ ions up to $1000 \mathrm{~Gy}$ (Aureli et al., 2020). They also are able to withstand periods as long as 1.5 years in Earth Low Orbit (Onofri et al., 2012; Selbmann et al., 2015; Billi et al., 2019). If shielded and protected by solar irradiation, spores from the (non-endonlithic) bacteria Bacillus subtilis and B. pumilus can survive under Mars-surface simulated conditions (Horneck et al., 2010, 2012; Cortesão et al., 2019). Furthermore, Mars' surface is not necessarily biocidal even for non-sporulating microorganisms (Hallsworth, 2021). Sporulation is a process which appeared early in the development of life on Earth (Tocheva et al., 2016). In addition to aerobic bacilli, present-day endospore formers include anaerobic bacteria, such as the Clostridium genus. Endospore-forming bacteria are candidates to survive extreme environments during interplanetary transit (Nicholson and Ricco, 2019). The evidences above show that the planets in our Solar System might not be biologically isolated, because potential micronauts (both prokaryotes and eukaryotes) may have undergone and survived interplanetary transfer.

\section{Microorganisms resilient to radiation exposure on the Mars surface}

Today, ultraviolet- and ionizing radiation through Mars' tenuous atmosphere would seemingly lead to an inhospitable environment for the survival of many kinds of microorganism on the martian surface. However, under some circumstances microbial cells may be able to survive at/near the martian surface (Hallsworth, 2021). Pigmented microorganisms will have better chances of survival because pigments such as melanin are known to be able to absorb/dissipate electromagnetic radiation such as UV and ionizing radiation. The presence of melanin correlates with increased survival and enhanced robustness, resulting in an advantage for melanized organisms over non-melanized ones under harsh conditions. In this regard, melanized fungi are a good example of the survival advantage conferred by melanin. There is a high incidence of melanized fungi in such extreme environments, such as the damaged nuclear reactor at Chernobyl (Zhdanova et al., 1991; Dighton et al., 2008) with $80 \%$ of the fungal species recovered from the reactor being melanized. Another example are the rocky deserts of Antarctica (Selbmann et al., 2015). It has also been demonstrated that melanized fungi can survive simulated Mars-like conditions (Onofri et al., 2008) and cosmic radiation while exposed on the Mir Spacecraft (Novikova, 2004). Besides exposure to high doses of ionizing and/or UV radiation, inhospitable environments can deliver additional forms of stress such as salinity, aridity, rapid and extreme temperature fluctuations, as well as little-to-no nutrients. The advantage that melanin presence confers on fungi is based, first of all, on its ability to act as a physical shield, reducing the relative biological effectiveness of ionizing radiation and reducing its potential for damaging living cells. Secondly, melanin protects the organism further by 'scavenging' reactive oxygen species generated by ionizing radiation (reviewed in Malo and Dadachova (2019)). Thirdly, melanin can convert solar radiation to heat. Thus, physical and chemical protective qualities of melanin can result in increased cell survival, and maybe even favour metabolic activity (and even growth) of melanized species under some conditions close to those that can occur on the martian surface. Analyses of the martian atmosphere show that the temperature : water-activity regimes would 
not allow metabolic activity of any known terrestrial microorganisms (Hallsworth et al., 2021).

\section{Robotic and remote exploration of Mars}

\section{Mars Science Laboratory}

The MSL Curiosity rover mission achieved a milestone in Mars exploration, landing a car-sized payload on Mars, manoeuvring through Gale Crater, climbing the flank of Aeolis Mons (informally known as Mount Sharp) and performing unprecedented science on the way. Curiosity's traverse path has been determined by both science and safety considerations.

Curiosity's traverse path is determined by science priorities across a variety of spatial and temporal scales. The primary goal for the MSL mission is to explore and quantitatively assess a local region on Mars' surface as a potential habitat for life, past or present. Gale Crater was selected as the landing site for the MSL mission in part because it contains a $5 \mathrm{~km}$ tall mound of stratified rocks (known as Aeolis Mons) with intriguing mineral signatures that may record changes in environmental history (c.f. (Milliken et al., 2010; Golombek et al., 2012; Grotzinger et al., 2012)). In order to meet this mission objective within Gale Crater, the traverse path is focused on the long-term goal of ascending the lower flanks of Aeolis Mons, with intermediate traverse decisions determined by focused science campaigns, and daily traverse decisions based on opportunistic science.

Curiosity landed on Bradbury Rise, initially mapped as hummocky terrain within the landing ellipse. This area is separated from Aeolis Mons by a large dune field known as the Bagnold Dunes. While the primary scientific goal is to investigate strata at the base of Aeolis Mons, due to traversability constraints the rover had to drive more than $12 \mathrm{~km}$ to the southwest to reach a gap in the dunes. The dunes were well-mapped prior to landing, so the general traverse path for the rover to ascend Aeolis Mons was also known since before landing.

While the long-term path has been predetermined, there are intermediate stops along the way based on focused science campaigns. An early example is the exploration of 'Yellowknife Bay', a region just to the east of the landing site that represents the intersection of three distinct geologic units as mapped from orbit. Although the long-term traverse path suggested that driving to the southwest was the way to ascend Aeolis Mons, the team decided to divert from the most efficient path to investigate this area first. This decision paid off. Yellowknife Bay lies at the distal extent of a large alluvial fan that extends from the northern crater rim; once the rover investigated the fine-grained fractured outcrops, we discovered that they represent ancient lake deposits. These lake deposits contain all of the chemical ingredients necessary for life and minerals that would have provided a source of energy for primitive organisms, so this campaign resulted in evidence for the first habitable environment explored by the rover (Grotzinger et al., 2015). Since then, Curiosity has explored about a dozen key waypoints for more detailed science campaigns. Some of these campaigns were motivated by orbital observations (e.g. Ehlmann et al., 2017; Rice et al., 2017; Bennett et al., 2019; Fraeman et al., 2020), while others were based on discoveries on the ground (e.g. Banham et al., 2018; Edgar et al., 2018; Stack et al., 2019).

Finally, on the short-term scale, daily traverse decisions are influenced by science through selection of the 'end-of-drive' location. On any given day, the science team works with the engineers to select drive locations that will provide adequate outcrops for future science analyses, or that provide a good perspective on the stratigraphy. The team is keeping an eye on the long-term path, but this is still a mission of exploration, and is ready to respond to findings as they arise.

\section{Mars 2020}

The Mars 2020 mission consisting of the Perseverance rover and Ingenuity drone landed successfully in Jezero Crater. The mission is dedicated towards geology and astrobiology. Ingenuity performed the first ever flight from the surface of another planet.

Jezero is an impact crater $\sim 45 \mathrm{~km}$ in diameter, located at $18.4^{\circ}$ $\mathrm{N}, 77.7^{\circ} \mathrm{E}$ in the Nili Fossae region, forming a fluvial sedimentary basin (Goudge et al., 2015). The landing site is close to the deltas of rivers that once flooded the crater. Aeolian sediments are also present, laying onto a volcanic floor. Multiple short flooding events composed of a variety of detrital sediments transported from very different provenances are suggested to have deposited the north and western watershed fans, increasing the probability of identifying materials of different origins accumulated around the landing site of Perseverance. This could have astrobiological implications, but is also important for understanding climatic processes on Mars such as the regularity of floods, its connection to periodic climatic epochs, and their possible connection to impact events. Apart from the transported and deposited sediments, authogenic clays might be also located and sampled; it is known that clays can record climatic conditions and also trap and preserve organics that are putative biosignatures, either chemical or textural. The close inspection of the samples in situ or in laboratories after sample return will enable the search for biosignatures or pseudo-biosignatures. Simulations run in the Mojave Desert have shown that PIXL (Planetary Instrument for X-ray Lithochemistry) can resolve trace element patterns that could be used to select samples for geochronology (Martin et al., 2020). The same applies to the identification of primary mineral phases and volcanic glasses. Resolving secondary mineral phases (i.e. carbonates, clays, sulphates) will be important to elucidate past environmental conditions. Combining all the above instruments will be paramount to identifing undisputed life on Mars.

On board the Perseverance rover, there are various optical cameras and microscopes for navigation, analysis and closer characterization. Navigation and remote identification of areas of interest is performed with the Navcam stereo camera, the Mastcam-Z hyperspectral imager and the SuperCam imaging and analytical system (remote Raman and Laser-Induced Breakdown Spectroscopy (LIBS) analysis). Chemical and mineralogical analyses can be performed by all spectroscopy instruments, with the advantage of organic compound detection and mapping with the Scanning Habitable Environments with Raman \& Luminescence for Organics \& Chemicals (SHERLOC) instrument (Martin et al., 2020). SHERLOC operates with a deep UV laser beam which can be scanned over a small area of a sample, providing mineralogical mapping over a $7 \times 7 \mathrm{~mm}$ area with a spot size of $100 \mu \mathrm{m}$, also captured with the WATSON colour imaging system (Williford et al., 2018). At the same time, SHERLOC acquires fluorescence images, enabling the identification and classification of the composition as well as the mapping of the spatial distribution of organic compounds. The detection sensitivity of organics can go down to $10^{-5}$ to $10^{-6} \mathrm{w} / \mathrm{w}$ over the entire scanned area. Both instruments are set up to investigate the habitability of the 


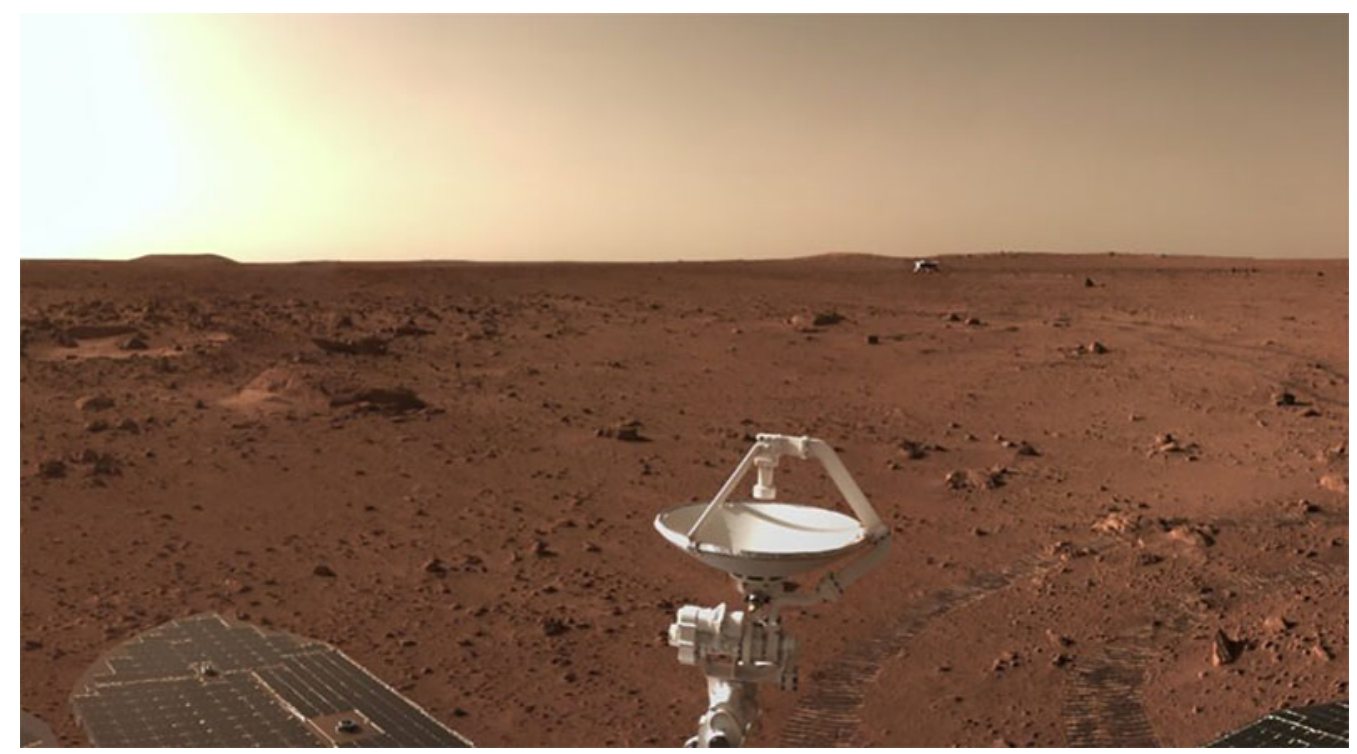

Fig. 7. The landscape of Mars at Utopia Planitia taken with the Zhurong rover's Navigation and Topography Cameras.

explored area based on the availability of CHNOPS chemistry. Mineral distribution patterns together with organic compounds will enable the identification of putative textural biosignatures.

\section{Tienwen-1}

The CNSA's Tienwen-1 spacecraft planetary mission is a threefold mission, involving an orbiter, a lander and the Zhurong rover. The Tienwen-1 lander and Zhurong rover landed on Mars on 14 May 2021. Zhurong deployed from the lander and touched the martian surface on 22 May 2021 in Utopia Planitia, a plain located within the Utopia impact basin (Fig. 7). The geological environment of Utopia Planitia is being studied, with a focus on volatiles and water in the region.

Utopia Planitia was formed during the Late Hesperian to Mid-Amazonian period, with mainly volcanic rocks and glacial clastic sediments. This region is known from NASA's Viking 2 landers to have permafrost that has shaped the surface by repeated freezing and thawing cycles. Estimating the amount of water in the martian subsurface is of importance for human missions to Mars.

The orbiter was used to select the landing area, relay data back to Earth, and remotely map Mars. The lander was used to carry the rover and commission it on the surface, but also employs a camera with which it took the first panoramic images to identify safe paths for driving the rover. Video footage was also obtained with a remote camera on the surface. It also has a multispectral imager for mineralogical identification and distribution of the surrounding area. Zhurong also employs a sub-surface penetrating radar to investigate the 3D stratigraphic history of the area (Wang et al., 2021), and estimate the consistency of the regolith and the depth of the permafrost. This will provide new insight into the ancient water present on Mars and climatic changes during the Red Planet's history. The magnetic field of the area will be measured with a magnetometer, while a LIBS instrument will analyse rocks, seeking very ancient martian rocks. The magnetic field of the planet will be studied remotely from the orbiter with a second magnetometer and a particle analyser. The rover employs instruments for meteorological studies, such as a microphone returning sounds of Mars.

\section{Mars Orbiter Mission}

The ISRO successfully launched the Mars Orbiter Mission (MOM), a probe also known as Mangalyaan, aboard the Polar Satellite Launch Vehicle (PSLV)-C25 on 5 November 2013 to Mars. MOM settled into martian orbit on 24 September 2014 and has been observing Mars ever since, far exceeding its 1-year design lifetime. The primary scientific goal of MOM is to explore the morphology, topography and mineralogy of surface features, and analyse the atmosphere using the indigenously developed instruments (Arunan and Satish, 2015). The MOM's payload includes a Mars Colour Camera (MCC) for optical imaging (Arya et al., 2015), a Thermal Infrared Imaging Spectrometer (TIS) for surface temperature estimation and mapping composition and mineralogy (Singh et al., 2015), a Mars Exospheric Neutral Composition Analyser (MENCA) to measure in-situ composition of the low-altitude neutral exosphere and its radial distribution (Singh et al., 2015), a Lyman Alpha Photometer (LAP) to determine the deuterium-to-hydrogen abundance ratio of the upper atmosphere (Sridhar et al., 2015), and a Methane Sensor for Mars (MSM) to measure total column of methane in the atmosphere (Mathew et al., 2015).

The large and highly elliptical orbit of the MOM $(261 \mathrm{~km}$ Perihelion to $78000 \mathrm{~km}$ Apoareion) has enabled the MCC to image the far-side of Mars' moon Deimos for the first time after more than three decades (Mathew et al., 2015). Subsequent analysis of the temporal and on-demand stereo images of the MCC led to the study of haze variability inside Valles Marineris and estimation of the optical depth of the martian atmosphere over the northern and southern walls of the valley (Mishra et al., 2016). Observations of the MCC have also enabled local-scale dust storm tracking over the Lunae Planum region and the Valles Marineris region (Guha et al., 2019).

MENCA observations have led to significant discoveries including in-situ compositional measurements for three major 
constituents of the martian exosphere, i.e. amu $44\left(\mathrm{CO}_{2}\right)$, amu 28 $\left(\mathrm{N}_{2}+\mathrm{CO}\right)$, and amu $16(\mathrm{O})$ corresponding to the local evening hours (Bhardwaj et al., 2015). These measurements are considered critical for setting up the important boundary conditions in the thermal escape models (Bhardwaj et al., 2017). Furthermore, the presence of suprathermal argon atoms (argon-40) has been reported in the martian exosphere using scale height and temperature measurements (Bhardwaj et al., 2015). To establish the boundary conditions for global circulation model calculations, the reflected solar radiance measured by the MSM in two Shortwave Infrared (SWIR) $(1.64-1.66 \mu \mathrm{m})$ channels has been used to prepare an albedo map of the martian surface (Singh et al., 2017).

After 5 years, MCC continues to capture intriguing views of Mars contributing significantly to the exploration of its surface. There is much more to be leveraged from the MOM datasets that can be fundamental in developing new insight for the surface and atmospheric evolution of Mars. The identification of scientific knowledge gaps and the optimization of suitable payloads are the key to success of the ISRO's continued planetary exploration programme.

\section{Exomars 2022}

The Rosalind Franklin rover of the ExoMars 2022 mission (Fig. 8) will land in Oxia Planum (Quantin-Nataf et al., 2021), an ancient location with strong potential for past habitability and preserving physical and chemical biosignatures (as well as abiotic/prebiotic organics). Oxia Planum is situated on the eastern margin of the Chryse basin, along the martian dichotomy border, and at the outlet of the Coogoon Valles system. At present, the coordinates for the nominal touchdown location are $18.159^{\circ} \mathrm{N}, 24.334^{\circ} \mathrm{W}$. The approximately $90 \times 4 \mathrm{~km}$ dispersion ellipse lies in the lower part of a wide basin, where extensive exposures of $\mathrm{Fe} /$ Mg-phyllosilicates ( $>80 \%$ of the ellipse surface area) have been detected with OMEGA and CRISM hyperspectral and multispectral data. The Fe/Mg-rich clay detections are associated with early/ middle- to late-Noachian layered rocks (with layering thickness ranging from a few metres to $<1 \mathrm{~m}$ for several tens of metres) (Mandon et al., 2021). They may represent the southwestern expansion (lowest member) of the Mawrth Vallis clay-rich deposits, pointing to a geographically extended aqueous alteration environment, and perhaps an ocean.

\section{Optimizing life detection with ExoMars}

The payload of the ExoMars rover has been put together based on the assumption that it is highly unlikely that lifeforms would exist on the surface of Mars today. Therefore, the focus was placed on the identification of traces of past life, from the time when the surface environment was able to host abundant liquid water, i.e. the Noachian (Vago et al., 2017). With this in mind, ESA decided to concentrate on the detection of physical (textural) and chemical biosignatures. Other possible, but less definitive classes of biosignatures, like isotopic analysis and the investigation of possible metabolites, will not be investigated with the current payload. To maximize the chance of having access to well-preserved biomolecules, the rover is equipped with a drill having a 2-m depth reach. This drill can be used to collect samples from top- and subsurface sedimentary rocks, which are then analysed for mineralogy and organic composition using instruments in the rover's analytical laboratory. The rover exploration strategy is based on a stepwise execution of nested-scale investigations, proceeding from the panoramic visual scale, to the microscopic, and concluding with molecular analyses. The rover's Pasteur payload includes panoramic instruments PanCam (Coates et al., 2017), wide-angle and high-resolution cameras; ISEM (Korablev et al., 2017), an infrared spectrometer; WISDOM (Ciarletti et al., 2017), a groundpenetrating radar; and ADRON (Litvak et al., 2008), a neutron detector; a subsurface drill to acquire samples; contact instruments for studying rocks and collected material (CLUPI (Josset et al., 2017), a close-up imager; and MaMISS (De Sanctis et al., 2017), an infrared spectrometer in the drill head); a Sample Preparation and Distribution System (SPDS); and the analytical laboratory, the latter including MicrOmega (Bibring et al., 2017), a visual and infrared imaging spectrometer; RLS (Rull et al., 2017), a Raman spectrometer; and MOMA (Goesmann et al., 2017), a Laser-Desorption, Thermal-Volatilization, Derivatization, Gas Chromatograph Mass Spectrometer (LD + Der-TV GCMS).

\section{Martian meteorites and sample return}

A few decades ago, it was realized that among meteorites on Earth, about a dozen had textures, young ages, oxygen isotopic ratios, and noble gas compositions consistent with a martian origin. Today there are $\sim 140$ martian meteorites. In particular, noble gas abundances trapped in shocked glass from martian meteorites are in a 1:1 ratio with Mars' atmospheric composition.

As well as being trapped from Mars, noble gases can also form in martian meteorites in situ. They can form from spallation, radioactive decay and fission reactions called cosmogenic, radiogenic and fissiogenic, respectively. Cosmogenic noble gas components, for instance, help us to trace the ejection time of rocks from the martian surface. Radiogenic noble gas nuclides, such as ${ }^{40} \mathrm{Ar}$ produced through the decay of ${ }^{40} \mathrm{~K}$, enable formation ages to be determined. ${ }^{129} \mathrm{Xe}$ from the decay of ${ }^{129} \mathrm{I}$, an extinct radionuclide with a half-life of $15.7 \mathrm{Myr}$, can unravel atmospheric evolution. Fissiogenic heavy Xe isotopes (e.g. ${ }^{134} \mathrm{Xe}$ and ${ }^{136} \mathrm{Xe}$ ) in martian meteorites record fission reactions of ${ }^{238} \mathrm{U}$ and ${ }^{244} \mathrm{Pu}$ from the martian atmosphere or interior (Smith et al., 2020b).

Cosmic ray exposure (CRE) age is the time a meteoroid spent in interplanetary space from ejection to arrival to Earth. Cosmogenic noble gases $\left({ }^{3} \mathrm{He},{ }^{21} \mathrm{Ne},{ }^{38} \mathrm{Ar},{ }^{83} \mathrm{Kr},{ }^{124} \mathrm{Xe}\right)$ produced in the meteoritic material by cosmic ray spallation reactions in specific target elements are measured to determine CRE ages. The ejection time is the sum of CRE age in space and the terrestrial residence time on earth. Terrestrial ages are determined by measuring radionuclides such as ${ }^{14} \mathrm{C},{ }^{10} \mathrm{Be},{ }^{36} \mathrm{Cl}$ and ${ }^{41} \mathrm{Ca}$. As the terrestrial residency times are negligible compared to the CRE ages, CRE ages directly indicate ejection times. Source-crater pairings of different martian meteorites are established on the basis of CRE age groupings and their petrologic affinities (Gladman, 1997). The martian meteorites group into 9-10 different CRE ages. Thus, there were around 9-10 different ejection events on Mars, which produced the current suite of martian meteorites that arrived on Earth.

\section{Source ejecta craters for the different SNC martian meteorites}

Martian meteorites are impact ejecta by the bombardment of fragments of asteroids or comets onto the surface of Mars, and the three main types of martian meteorites are shergottites, nakhlites, and chassignites (SNC). If one can identify the source impact 


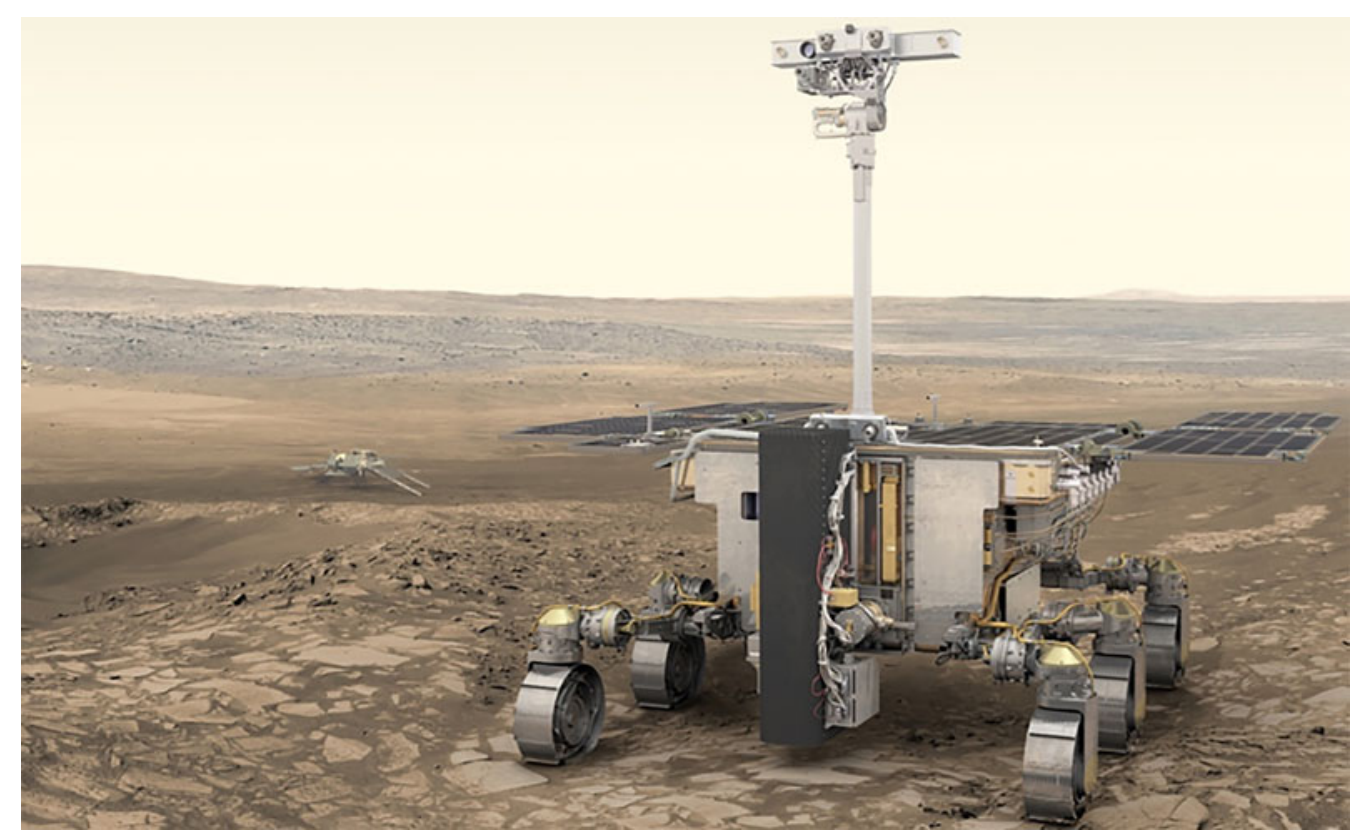

Fig. 8. Artist rendition of the Rosalyn Franklin ExoMars Rover.

crater of martian meteorites, we could more accurately describe its geological evolution, and more effectively plan for future missions.

Finding the source craters for our more than 140 martian meteorites is however very challenging. When we classify a martian meteorite on the basis of its mineral abundances and compositions, or trace element abundances, we are at a level of detail that is very hard to replicate from remote spectroscopy. It may happen for some meteorite samples, but we will learn about Mars from the meteorites as fragments of the crust, but not from known exact locations. Even if we are not sure exactly which craters they were derived from, they still give essential pieces of information about the planet's differentiation and the action of water in the crust.

\section{Noble gas composition of the martian atmosphere}

Signatures of the 'ancient martian atmosphere' (based on, e.g. the martian meteorite Alan Hills (ALH) 84001) and 'modern martian atmosphere' (from, e.g. Northwest Africa (NWA) 7034) can be traced by noble gases. Trapped noble gases ( $\mathrm{Ar}$ and $\mathrm{Xe}$ ) in martian meteorites such as shock-produced glasses are in good agreement with MSL measurements on Mars $\left({ }^{40} \mathrm{Ar} /{ }^{36} \mathrm{Ar}=1900 \pm 300\right.$, ${ }^{36} \mathrm{Ar} /{ }^{38} \mathrm{Ar}=4.2 \pm 0.1,{ }^{129} \mathrm{Xe} /{ }^{132} \mathrm{Xe}=2.5221 \pm 0.0063$ ) (Avice et al., 2018). Based on meteorite studies, ${ }^{40} \mathrm{Ar} /{ }^{36} \mathrm{Ar}$ on Mars is much higher and ${ }^{36} \mathrm{Ar} /{ }^{38} \mathrm{Ar}$ is lower than Earth's atmosphere, indicating enrichment in radiogenic ${ }^{40}$ Ar compared to ${ }^{36} \mathrm{Ar}$, possibly due to solar windinduced sputtering (Atreya et al., 2013). The ${ }^{129} \mathrm{Xe} /{ }^{132} \mathrm{Xe}$ ratio in martian meteorites and on Mars is elevated due to radiogenic ${ }^{129} \mathrm{Xe}$. This requires either very early loss from the atmosphere or storage in some reservoir until after atmospheric loss (Swindle, 2002).

\section{Noble gases from the martian surface and interior}

Mudstone on the floor of Gale Crater analysed by MSL determined K-Ar age of $4.21 \pm 0.35$ billion years, representing a mixture of detrital and authigenic components in ancient rocks making up the crater rim (Farley et al., 2014). Furthermore, the surface exposure age determined by the cosmogenic isotopes ${ }^{3} \mathrm{He},{ }^{21} \mathrm{Ne}$ and ${ }^{36} \mathrm{Ar}$ is $78 \pm 30$ million years, indicating surface exposure rather than primary erosion and transport. This absolute age data enables calibration of relative surface ages for crater chronology.

In addition to the atmospheric components, martian meteorites can also contain trapped martian interior components, which are more challenging to measure with the current Mars landers and rovers. Information we have on martian interior gases are primarily mostly from the meteorite Chassigny. Fluid inclusions in olivine in Chassigny have higher $\mathrm{Kr}$ and Xe content, and minimal radiogenic ${ }^{129} \mathrm{Xe}$, unlike the martian atmosphere (Swindle, 2002). Chassigny has also a much lower $\mathrm{Kr} / \mathrm{Xe}$ than Mars' current atmosphere and a Xe isotopic composition close to that of the solar wind, suggesting an undegassed interior martian reservoir (Swindle, 2002). In addition to solar Xe, another interior component has been suggested due to the addition of ${ }^{244} \mathrm{Pu}$ fission component from the martian interior (Mathew and Marti, 2001). In summary, noble gases can be highly diagnostic when unravelling planetary formation and evolution.

\section{The martian surface and interior revealed by martian meteorites}

The martian breccias, NWA 7034 and its many pairs, contain the most evolved martian igneous material and a high amount of volatiles including water. They are also the eldest martian samples yet identified. Water released by step-heating of the martian breccia showed concentrations of $\sim 3000 \mathrm{ppm}$, an order of magnitude above that of any other martian meteorite (Agee et al., 2013). Its composition is also enriched in alkalis and other volatiles relative to the SNC meteorites. The dating of zircons included within the breccia show ages around 4.4 and $1.7 \mathrm{Ga}$, suggesting an ancient initial crystallization age followed by a later major disturbance (Humayun et al., 2013; Bouvier et al., 2018). The most-precise analyses of zircons and geochemical modelling predict the 
existence of an evolved andesitic crust on Mars with a minimum age of $4547 \mathrm{Ma}$ (Bouvier et al., 2018). This would have had to predate the currently basaltic crust on Mars and was likely later destroyed by impacts and resurfacing.

\section{The shergottites}

The shergottites make up the highest fraction of martian meteorites. In the current collection of martian meteorites, $\sim 80 \%$ are shergottites, including basaltic, olivine-phyric and lherzolitic shergottites (martian Meteorite Compendium) (Wang and $\mathrm{Hu}$ 2020), as well as the recently identified augite-rich shergottites, NWA 7635 (Lapen et al., 2017) and NWA 8159 (Herd et al., 2017). Most of the shergottites have crystallization ages ranging from $\sim 600$ to $\sim 150 \mathrm{Ma}$ by the analyses of mineral isochrons of $\mathrm{Rb}-\mathrm{Sr}$ and Sm-Nd (Nyquist et al., 2001), and in-situ U-Pb dating of baddeleyite and phosphates (Niihara, 2011; Moser et al., 2013; Zhou et al., 2013). Two new augite-rich shergottites were however dated at $\sim 2.4 \mathrm{Ga}$ (Herd et al., 2017; Lapen et al., 2017). The relatively young ages of most shergottites (Váci and Agee, 2020) indicate that they were ejected from the Amazonian Epoch of Mars. On the other hand, the ejection ages of shergottites vary from $\sim 1$ to $\sim 5 \mathrm{Ma}$ except for the shergottite, Dhofar 019 at $\sim 20 \mathrm{Ma}$ (Fritz et al., 2005). These variations suggest that there may have been several impact events on Mars that eventually delivered material to Earth.

Some work has been carried out attempting to constrain the source craters of the shergottites (Mouginismark et al., 1992; Treiman, 1995; McFadden and Cline, 2005; Tornabene et al., 2006) and other martian meteorites (Kereszturi and Chatzitheodoridis, 2016). Some candidate craters have been proposed - examples being the Mojave Crater, forming $<5 \mathrm{Ma}$ ago, with a width of $\sim 55 \mathrm{~km}$, on the $4.3 \mathrm{Ga}$ old terrain of Mars. It was proposed as the ejection source for the shergottites due to its very similar reflectance spectra to the shergottite Queen Alexandria (QUE) 94201 and Shergotty in the wavelength range of 1-2.4 cm (Werner et al., 2014). However, the size of Mojave Crater (Fig. 9) is one order of magnitude higher than that simulated by the launch dynamics (Head et al., 2002). The very young age of Mojave Crater (Fig. 7) also requires better constraints because of the low accuracy of crater chronology for the young craters without ground-based calibration (Hartmann and Neukum, 2001). Moreover, the host terrain under the Mojave Crater is substantially older than most of the young shergottites. Future martian sample return missions will contribute greatly in clarifying this issue (Beaty et al., 2019).

\section{Alteration in the martian meteorites}

Alteration minerals and textures have been identified in martian meteorites, namely in the nakhlites. The nakhlites are clinopyroxenites (Treiman, 2005). Alteration mostly occurs along olivine fractures and in mesostases. A martian origin of alteration in the other types of martian meteorites are controversial, although carbonate globules in ALH 84001 are generally accepted as extraterrestrial (Treiman, 2021). Carbonate was first suggested to occur in a martian meteorite by (Carr et al., 1985) using C isotopic measurements during stepped combustion of Elephant Moraine (EETA) 79001 martian meteorite. Carbonate was later discovered in Nakhla as Mn-rich siderite (Chatzitheodoridis and Turner, 1990) in an assemblage with Ca-sulphate and halite. Additional evidence came from Gooding et al. (1991). Since then, the discoveries of alteration phases have been rapidly increasing in number. The list of secondary minerals includes siderite $\left(\mathrm{FeCO}_{3}\right)$, anhydrite $\left(\mathrm{CaSO}_{4}\right), \mathrm{NaCl}$, ferric saponite clay $\left(\mathrm{Ca}_{0.25}(\mathrm{Mg}, \mathrm{Fe})_{3}\left((\mathrm{Si}, \mathrm{Al})_{4} \mathrm{O}_{10}\right)(\mathrm{OH})_{2} \cdot \mathrm{nH}_{2} \mathrm{O}\right)$, hematite $\left(\mathrm{Fe}_{2} \mathrm{O}_{3}\right)$, oxyhydroxides (ferrihydrite $\mathrm{Fe}_{10}^{3+} \mathrm{O}_{14}(\mathrm{OH})_{2}$ ), serpentine ( $\mathrm{Mg}$, $\left.\mathrm{Fe})_{3} \mathrm{Si}_{2} \mathrm{O}_{5}(\mathrm{OH})_{4}\right)$, and opal $\left(\mathrm{SiO}_{2} \cdot \mathrm{nH}_{2} \mathrm{O}\right)$. Their discoveries are important for understanding martian weathering processes which have implications for interpreting the paleoenvironment of Mars. Moreover, they may hint at potential ecological niches in the subsurface of Mars, such as vesicles formed in mesostasis formed by bolide impact processes (Chatzitheodoridis et al., 2014) or for instance networks of microcavities of magmatic clays serving as microreactors for prebiotic chemistry (Viennet et al., 2021). Similar types of alteration on Mars provide direct comparisons between Earth-based samples and Mars prior to the eventual return of samples from the planet.

\section{Martian Moon eXploration sample return}

The Japanese Aerospace Exploration Agency has a Mars moon sample return mission planned for launch in 2024 to Phobos and Deimos; the Martian Moon eXploration Mission (MMX). The orbits of these satellites suggest that they formed either from large impact ejecta from Mars that then accumulated, or at the same time as proto-Mars itself (Bagheri et al., 2021), although they share morphological and spectral characteristics with asteroids (See Early Mars section). Subsequent to their formation, the martian moons accreted materials transported from Mars, probably delivered from cataclysmic impact events on the planet.

Phobos and Deimos may have therefore been contaminated by microorganisms if there was life in the martian subsurface. The mission will collect samples from Phobos, with successive flybys of Deimos. If putative martian life is transferred to Phobos or Deimos, what unique challenges will arise for a sample return mission? According to previous assessments of microbial contamination risk for samples collected on the martian moons (Fujita et al., 2019; Kurosawa et al., 2019), the probability that a single unsterilized particle occurring within samples can be maintained within the internationally agreed acceptable limit of $10^{-6}$, provided that the mass of samples is below 100 $\mathrm{g}$, and that they are taken within a depth of several tens of centimetres from the surface. The extant microbial density on the martian moons (if in fact Mars was inhabited) is subject to the rates at which microbes are inactivated by high-speed impacts of martian ejecta on the martian moons and by cosmic radiation after accretion onto the surface. The above assessment has been conducted based on laboratory simulation experiments. However, there still remains uncertainty with these results. For this reason, it is strongly recommended by the Committee on Space Research (COSPAR) that a re-evaluation is made before the return of martian moon samples to Earth. For this purpose, we have started new follow-up experiments to constrain these uncertainties.

\section{Sampling asteroids versus Phobos}

The Japanese Aerospace Exploration Agency also returned the samples from asteroid 162173 Ryugu in December 2020 with the Hayabusa-2 spacecraft, the first successful sample return mission to a carbonaceous asteroid. There are several challenges with a sample return mission from the martian moons that differ to the 


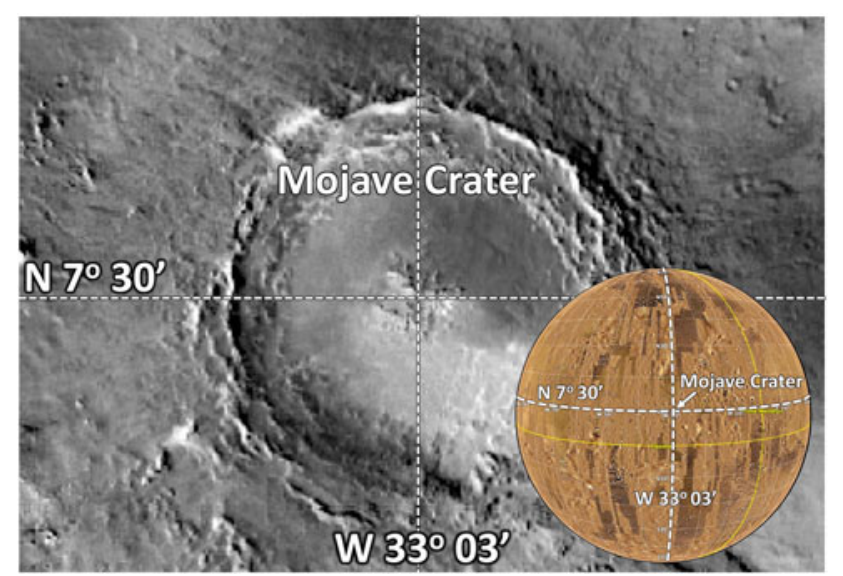

Fig. 9. Mojave crater (58 km across) on the Xanthe Terra plain of Mars. NASA/Caltech/ Arizona State University.

sample return from asteroids. From a technical viewpoint, it is a great challenge implementing a sampling method that complies with the above criteria in the absence of detailed information on the state of the regolith on the martian moons. Although gravity on the martian moons is much smaller than that of Mars or Earth's moon, it is several orders of magnitude larger than that of asteroids (Yang et al., 2019). This requires a more-tailored propulsion system directed towards the martian moons during touchdown and lift-off. The exhausts from the propulsion systems may disturb regolith on the martian moons, and potentially accrete regolith onto the spacecraft by electrostatic attraction. Regolith scattering can also occur by touchdown of the landing gears and sampling. Adhesion of regolith to the spacecraft will substantially affect the bulk amount of the martian moons samples brought back to Earth, potentially resulting in a higher probability of microbial contamination. In order to avoid such a risk, it is not only necessary to suppress the regolith scattering by optimizing the layout and operation of the propulsion system, by minimizing the touchdown velocity, and by devising the sampling mechanism so that it can quietly collect samples (without creating turbulence), but also to identify the area of regolith adhering to the spacecraft. The spacecraft system and its operation plan for the MMX mission are currently designed according to the above policies with the aid of the analysis on the regolith touchdown, sampling and lift-off dynamics.

\section{Mars 2020 sample caching}

Perseverance successfully collected and cached its first rock sample from the martian surface on 1 September 2021. This was the first sample collected for return from the surface of another planet. There are 43 sample containers in a carousel for sample caching in titanium hermetically sealed tubes. Five unsampled witness tubes are included to identify any possible crosscontamination from Earth by the sample caching process. Samples will be deposited locally on the martian surface of the planet to be picked up by a fetch rover or perhaps even delivered by Perseverance in a follow-up mission towards the end of the decade.

The first sample collected by Perseverance belongs to a rock named 'Rochette'. The sample caching system contains a drill used for abrasion of the surface of rocks to reveal their subsurface, followed by actual core drilling and sampling. The acquired sample is a drill tube of rock that weighs $15 \mathrm{~g}$ (core diameter of $1 \mathrm{~cm}$ and length of $5 \mathrm{~cm}$ ). Primary to the selection of samples, analytical information can be acquired with the instruments such as SHERLOC and PIXL. The selection of the samples will be based entirely on the remote detection of areas of interest; once an interesting sample is located, drilling and cashing operations will be performed.

\section{Mars human exploration}

\section{What are the essential requirements for humans to live and thrive on Mars?}

Eventually, sooner or later, human missions to Mars will occur. If they are to constitute footholds rather fleeting jaunts, martian resources must be utilized to support humans in a lifestyle that is both sustainable and, just as importantly, comfortable. It is clear that sustainable settlement in a martian environment must be systematic and as complete as possible to maximize the use of in-situ resources, and minimize reliance on Earth through a long, expensive, and slow-reacting supply chain. Resource technologies designed to enable the autonomy of humans on Mars (so that they do not rely on Earth), as well as to characterise the martian environment, are under development (atmospheric composition, hydrology, mineralogy, and geological history). A comprehensive review of martian in-situ resource utilization is given in Ellery and Muscatello (2017) and details on sustainable in-situ resource utilization in Ellery (2020). Agriculture, for the generation of food, and the recycling of nutrients to substitute for biogeochemical cycles on Earth is essential - of course, martian soil may be utilized or hydroponics and aeroponics provide the means to render agriculture independent of soil - but in all cases, nutrient recycling will be required.

Key technological challenges arising from human space travel to the exploration of Mars include (i) survival during our trip towards Mars in the frame of investigations on the stability and level of degradation of space-exposed biosignatures such as pigments, secondary metabolites and cell surfaces in contact with a terrestrial and Mars analogue mineral environment; (ii) space radiation, because it has been demonstrated that the particle radiation environment on Mars can vary according to the epoch concerned and the landing site selected; (iii) human-safe landing and return systems; (iv) life-support and learning to live sustainably on Mars (in synergy with technologies developed for extreme environments on the Earth and the Moon). However, we still have to address a number of important questions such as what are the limits to interplanetary human travel to Mars, which technologies have still to be developed, and what studies and human simulations should be performed? Substantial research and development is required to provide the basic information for appropriate integrated risk management, including efficient countermeasures and tailored life support. Methodological approaches could include research on the International Space Station (ISS), on robotic precursor missions to Mars, in ground-based simulation facilities, as well as in analogue natural environments on Earth (Foing et al., 2011a, 2011b).

\section{Resource utilization on Mars}

One key resource is the carbon dioxide atmosphere as it has long been proposed that carbon dioxide can be converted into methane using hydrogen feedstock via the Sabatier reaction (Zubrin et al., 
2013). Methane may be used as a propellant, which combined with an oxidizer, can provide the basis for refuelling Mars Ascent Vehicles and rover sorties during in-situ exploration activities. Water ice on Mars can provide another resource for life support, hydrogen feedstock, and oxygen for respiration. Acquiring water ice, however, will require extraction from the martian subsurface through drilling/mining techniques. Finally, raw regolith may be exploited by combining with binders (such as plastic or salts) for the construction of habitation shells using 3D printing (Cesaretti et al., 2014). There is much we can leverage from Mars in constructing the internal environment for a martian habitat (Ellery, 2020).

\section{Technologies for resource utilization}

To make Mars our home, an industrial capacity from martian materials should be built. Machines will provide the means of production to construct this industrial capacity. We need to build excavator rovers, comminution and beneficiation machines, unit chemical processors, milling machines, 3D printers, assembly manipulators, and other machines that convert raw material into useful products. These machines are all kinematic machines - the fundamental components of the kinematic machine are the electric motor, its control system and its power supply (Ellery, 2016). These technologies will require a basic set of materials including iron (from hematite), nickel, cobalt, tungsten and selenium (from nickel-iron meteorites), silica and silicon (from silicate minerals), plastics (from a mixture of $\mathrm{H}_{2}$ and $\mathrm{CO}$ ) and acid reagents (from salts). The core unit chemical processor is the Metalysis FFC (Fray-Farthing-Chen) process supported by a range of acid-based and carbonyl-based peripheral processes (Ellery, 2017). Combined with 3D printing technology (Ellery and Muscatello, 2017), this provides a powerful suite of techniques for universal construction capabilities including the construction of electric motors and computational electronics (Ellery, 2016), the latter based on neural network architectures (Prasad and Ellery, 2020). Human exploration can leverage these same components to support energy generation through solar concentrator-thermionic conversion and energy storage through motorized flywheels. We can thus construct an industrial infrastructure of machines as the fundamental requirement for self-sufficient habitability.

\section{Bio-materials for in-situ resource utilization}

Synthetic biology and applied microbiology can be used to produce resources in space (Rothschild, 2016). For example, carbonate biomineral-producing microbes are used on Earth in civil engineering, art restoration, soil improvement, bioremediation, and $\mathrm{CO}_{2}$ sequestration (Reddy, 2013; Anbu et al., 2016), as well as space. Calcite production is common among microorganisms and can be linked with different types of taxa and metabolisms (Boquet et al., 1973). Bacteria, such as Streptomyces species, promote the precipitation of calcium carbonate by activating specific metabolic pathways. For biotechnological applications, the genera Bacillus and Sporosarcina are the most studied (Han et al., 2019), but knowledge gaps remain about the microbes best-suited for each type of application, and how environmental conditions affect the characteristics and yields of biominerals. Terrestrial bacteria found in calcium-rich natural environments on Earth could be used on the Moon or Mars for the production of biobricks for constructing buildings (Santomartino et al., 2020). Some strains that precipitate calcium carbonate or gypsum (depending on the substrate provided; Cirigliano et al., 2018) are also able to produce melanin that protects against UV and ionizing radiation.

Biomineralization processes have been proposed as a means of cutting the construction costs on the Moon and Mars (Cockell, 2010; Dikshit et al., 2020; Kumar et al., 2020). More work is needed on the feasibility of the use of Mars dust and regolith for such a proposed in-situ resource utilization, e.g. testing this process under Mars-like conditions. One limitation may be the various salts that are known to inhibit or prevent microbial metabolism, including perchlorates and chaotropic salts, sulphate salts, and those that create multiple stresses and polyextreme conditions (Fox-Powell et al., 2016; Hallsworth, 2019; Benison et al., 2021). Work is therefore needed to identify strains tolerant to saltinduced stresses and optimize culture conditions to mitigate against the underlying cellular stress mechanisms.

\section{Human landing site on Mars}

At the current time, there is a major community-wide discussion taking place regarding the required/desired attributes of the future human landing site, and possible locations on Mars that have those attributes. At the present stage of the discussion, there are multiple sites actively under consideration. Some key factors include elevation (which has to be below a certain level), minimize landing site hazards such as slopes and large rocks, attributes related to the purpose of mission (such as science), access to water ice, and planetary protection. Some candidate regions for SpaceX's Starship are Phlegra Montes, Erbeus Montes and Arcadia Planitia (Golombek et al., 2021).

\section{Terrestrial simulations of human missions to Mars}

There is a number of ground-based simulation facilities in analogue natural environments on Earth. Building on the EuroGeoMars 2009 campaign (Foing et al., 2011a, 2011b), the ILEWG EuroMoonMars programme since 2009 has included research activities for data analysis, instrument tests and development, field tests in the MoonMars analogue, pilot projects, training and hands-on workshops, and outreach activities. Field tests have been conducted in ESTEC (European Space Research and Technology Centre) and EAC (the European Astronaut Centre) of ESA, as well as at the Utah's MDRS station (Mars Dessert Research Station), Eifel, Rio Tinto (Spain), Iceland, La Reunion (an island in the Indian Ocean that belongs to the French Republic), LunAres base at Pila Poland and the HISEAS base in Hawaii.

\section{Simulating human experience on Mars using virtual reality}

Humans can experience Mars using virtual reality. Current virtual reality engines can elevate the quality and immersion of Mars with the high-fidelity mechanics, interactions and continually evolving design principles.

By using Mars topological and in-situ data from current orbiters and rovers, respectively, extrapolation of a $3 \mathrm{D}$ virtual reality martian landscape can be made. All touch points within the experience (locations, mineral outcrops, weather, caves, tools, etc) can be scientifically accurate on a 1:1 scale, and provide transferable knowledge beyond the virtual reality experience (Fig. 10).

In virtual reality, humans can navigate the hazards of the martian surface, and use simulated rover playloads, spacesuits and 


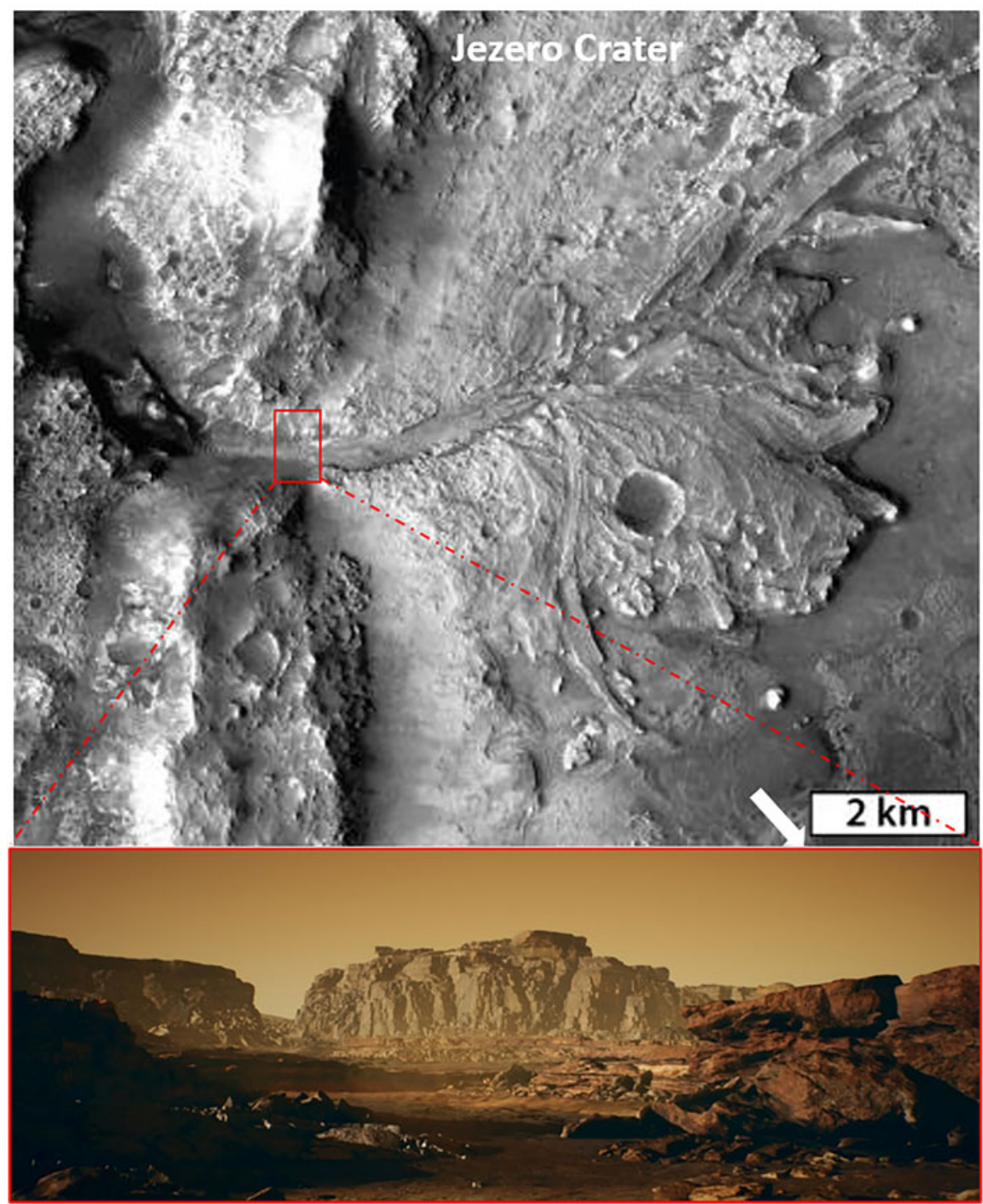

Fig. 10. In-engine virtual reality (VR) terrain of the Jezero Crater looking into the river delta (bottom) extrapolated from Mars Reconnaissance Orbiter imagery (top). Top image courtesy of NASA/JPL/JHUAPL/MSSS/ Brown University. With imagery from the Perseverance rover, the VR engine can be refined for more accuracy. Arrowed is the current approximate location of Perseverance.

handheld scientific instruments to conduct experiments on the surface of Mars and discover the viability of interplanetary human expansion.

\section{Mars human settlement is 'ante portas': are we ready for it?}

Human settlement on Mars is the next coming human milestone. However, societal risks emerge on a global scale (Shaghaghi and Antonakopoulos, 2012). Quantitatively estimating how to cope with those radical societal changes primarily invents a way of measuring and monitoring the societal readiness towards Mars human presence, from Earth's and Mars' points of view, and then identifying and remediating the risks that will arise for humanity. Such a tool could be quantitatively expressed with a risk index, such as the Mars Risk Index (MRI), a data-driven index estimated under the MRI Framework which monitors the societal readiness and identifies the risks that arise for humanity. It assists all stakeholders to orientate themselves as Mars human settlement takes shape. It is envisaged that two main sub-indices will allow the evaluation of the MRI: (a) The Mars Earth Risk Index ( $\mu$ RI:e) that measures Earth's societal readiness shifting towards the Mars human settlement.

(b) The Mars Ares Risk Index ( $\mu \mathrm{RI}: \mathrm{a})$ that measures Mars' future societies structures readiness to cope with Earth's existing societal structures.

To explain briefly the MRI's methodology (Fowler et al., 2004), the analysis of societal and political risks will take firstly place, based on the relationship between frequency and the number of people suffering from a specified level of harm in a given population from the realization of specified threats. The quantitative risk assessment approach is based on the estimations of the pair of frequency (f) and potential consequences, and the typical number of fatalities $(\mathrm{N})$, resulting in a cumulative frequency $(\mathrm{F})$ of events that has $\mathrm{N}$ or more fatalities, visually compared through sets of curves, commonly referred to as F-N curves. With the use of such curves, judgements will be made. To further establish this framework, possible threats, the available assets and the estimated impacts must be taken into account. 


\section{Minimizing human risks for settlements on Mars}

Human settlement of Mars will be a consorted international endeavour. Its stakeholders will span all societal pillars such as, nations, countries and their governments, international organizations, religious groups, and of course, people (i.e. individuals).

As a consequence of the societal risks that emerge on the global scale, unstable environments initiating domino effects might be created that will shake our societies' structures. It is our responsibility to adapt our societies to this endeavour, which is by far larger than, i.e. the discovery of the New World. MRI can help all stakeholders orientate themselves as Mars human settlement and colonization takes shape, alert them for changes that could mitigate those risks and confront the challenges.

\section{Planetary protection}

Mars has been categorized as a planetary protection restricted class Category V, relating to the return of space craft or space components. This means that where scientific opinion is unsure, destructive impact upon return to Earth is prohibited. Containment of all returned hardware which directly contacted the target body, and any unsterilized sample returned to Earth, is also required. The same is also required for the forward contamination of Mars itself.

\section{If either extinct or extant life is discovered on Mars, should the UN resolutions on planetary protection be amended?}

If any indications of Mars life are found in early assessments, one has to assume that life continues to exist on Mars until more data are collected.

Currently, the international policy on planetary protection as maintained by COSPAR states explicitly that any decisions about novel mission activities should be based on scientific advice from the COSPAR Member National Scientific Institutions and International Scientific Unions. This includes a reassessment on the status of Mars if evidence for indigenous life is discovered. The current COSPAR guidelines for analysis of samples returned from Mars focus on the potential for false-positive results, because a false positive might result in unnecessarily increased restrictions on Mars exploration.

However, any evidence for past Mars life would significantly increase concerns about the potential for false-negative detections of extant Mars life. If samples from Mars provide evidence of indigenous life in the distant past, it is not valid to assume all Mars life subsequently became extinct. Due to the potential for hazardous interactions between Mars life and Earth life, the detection of past life on Mars would appropriately lead to increased restrictions on the exploration of Mars and return of Mars' material to Earth. The 2020 pandemic of COVID-19 illustrates some potential consequences resulting from false-negative detections of hazardous organisms. Planetary protection was established and needs to continue in effective implementation, to prevent space exploration causing this sort of pandemic scenario. A thorough assessment of various modes of inactivation and containment of martian sampling is ongoing (Craven et al., 2021).
Regarding the contamination of Mars itself, should the planetary protection protocol between the Moon and Mars be any different?

The current COSPAR guidelines for missions to Mars are significantly different from those for the Moon, because Mars is considered to provide potentially habitable environments for indigenous Mars life. In addition, some environments on Mars, particularly in the subsurface, could be habitable for Earth organisms. Therefore, stringent limits are placed on the number of Earth organisms permitted on outbound missions to Mars, to reduce the potential for Earth organisms to be delivered to, and persist, on Mars.

There is no concern for contamination of the lunar surface, because the environment of the Moon is known to be uninhabitable by carbon-based life that functions in physical environments similar to the surface of Earth. In addition, for the purposes of planetary protection, Earth and the Moon are considered to be one system, which ensures no travel restrictions between these two bodies will be emplaced.

\section{Planetary protection is inextricably linked with human health}

The microbiomes of modern humans living in urban settings are less diverse than those of ancient indigenous peoples as shown by a range of recent seminal studies (De Filippo et al., 2010; Clemente et al., 2015; Eisenhofer et al., 2020; Sprockett et al., 2020; Weyrich, 2021). Diversity within the human microbiome is reduced when our lifestyle isolates us from contact with biodiverse soils (Blum et al., 2019) and the microbiomes of astronauts are known to become impoverished due to isolation and from Earth's biosphere (Sugita and Cho, 2015). Therefore, we can expect that humans living on Mars will not enjoy optimal microbial biodiversity. The additional use of ethanol-containing (or other) wipes to cleanse the skin further reduces the biodiversity of skin. These factors, along with the use of antibiotics or other drugs that perturb and diminish the microbiome, will reduce the usual competition within the microbiome. Biodiverse, healthy and climax microbial communities are most likely to suppress the proliferation of pathogens or pathogenic events (Cray et al., 2013).

Conversely, damage to microbial communities on and within the human body that are perturbed and diminished results in the creation open habitats (places that are resource-rich and promote proliferation of and competition between microbes) (Cray et al., 2013). These include excessively cleaned skin, wounds and surfaces of the gastrointestinal tract after use of antibiotics. Many of the potentially pathogenic microbes that occur with the human microbiome have a robust stress biology and are therefore selected for by the use of skin disinfectants (Suchomel et al., 2019). They are also more likely to be capable of survival if faecal waste is used as a fertilizer and so can re-enter the body via the oral-faecal route due to consumption of contaminated foods (see below). In the event that any human(s) become(s) infected with a highly contagious microbial pathogen, it has yet to be determined how to prevent an epidemic within the human population of Mars. In the unfortunate event of a human fatality on Mars, there is likely to be a contingency plan to recover the body to Earth. However, the time delay until this occurs raises real questions about planetary protection and safeguarding the health of the other people remaining in the habitation(s).

Indeed, there are ethical, technical and scientific dilemmas about humans and microbes living on Mars that have yet to be 
resolved. In relation to microbes on Mars, it will be difficult to live with them, yet we cannot live without them.

\section{Microbes for human medicine on Mars}

Human Exploration needs to address potential issues related to the health and illness of astronauts. Therefore, a broad range of basic medicines is needed within the payload, as well as the technology to produce them on demand whilst in transit or in the habitation(s) on Mars. This includes any unexpected medicines needed (different from those brought from Earth) and supplementing any exhausted medical supplies. The miniaturization of portable scientific instruments for use during space exploration has also benefited biotechnology on the Earth (especially the development of micro-bioreactors, mini-microscopes, mini-DNA/-RNA sequencer). Many active pharmaceutical compounds are of plant origin but it is expected that if plants grow on Mars, they will be intended for food. Synthetic biology, via the use of metabolically engineered bacteria and yeasts, can be used to produce (some of these are already produced commercially on Earth) complex molecules such as antibiotics and the antimalarial drug (Ro et al., 2006; Perez-Pinera et al., 2016; Liu et al., 2018; Malico et al., 2020). A culture collection of strains (kept freeze dried in small vials) to use for drug synthesis provides a choice for humans on Mars to be able to select the appropriate microorganism for growth in a micro-bioreactor and produce the required medicine. Currently, 3D printing technology can produce personalized medicine containing one or more active ingredients; this is already a reality on the Earth (Reddy et al., 2020).

Mars-related diseases, unknown on Earth, could arise and so plasticity of medical solutions and synthetic biology capability are required because there are considerable unknowns and astronauts need to have the capacity to respond and adapt to any eventuality. However, microorganisms in nature are metabolically versatile and are, for example, able to degrade chemically diverse hydrocarbons and other substrates (Timmis, 2002; Cray et al., 2013) and produce an indefinite number of secondary metabolites (Cray et al., 2015; Kai, 2020). This capacity has value in metabolically engineering strains to produce biofuels and plastics (Nielsen et al., 2013; Ko et al., 2020) as well as pharmaceuticals (see above). Another example is provided by Saccharomyces cerevisiae that can produce the precursors of analgesics such as morphine (Pyne et al., 2020) and cannabinoids (Luo et al., 2019). Unresolved issues of using microbes on Mars for this purpose are whether mutations might occur, and whether drugs can be produced in sufficient quantities and whether they can be readily purified. Apart from its use in drug production, yeasts might be useful to produce vanilla and raspberry flavours for use as food additives to help avert a sense of homesickness and to add to the joie de vivre.

\section{Mars and society}

\section{Society, ethics and theology on Mars exploration}

In regard to societal, ethical, and religious aspects of Mars exploration it is useful to distinguish between human exploration and scientific exploration. This is often described as a science versus exploration scenario in space exploration (Metzger, 2016). Human Mars exploration can be understood as an expansion of Earth society, while scientific exploration enables Earth society to learn about its place in the Universe. This perspective has been relevant for philosophers and theologians for centuries. One example of such debate is the question of life on other planets. Thomas Payne as well as John Calvin have discussed the theological aspects of life on other planets (Weidemann, 2014). For Immanuel Kant, life on other worlds was certain and this 'knowledge' informed his philosophical stance.

While scientific exploration of Mars via robotic probes and landers has been going on since the beginning of human space exploration, a human mission to Mars is still far-reaching. It is interesting to note, that the possible presence of life on Mars is one of the main drivers as well as one of the main obstacles in Mars exploration. The debate on planetary protection of Mars and its impact on mission profiles boils down to the ethical question of how we as humans should relate to possible extraterrestrial life. This ethics question has a wide range of answers: from very human-centred to biocentric perspectives that give all life the same value, and even, perspectives that ascribe non-inhabited areas of space the same value as inhabited areas. A religious perspective on this debate boils down to the question 'what role humans play within God's plan or creation'. If we are at the centre of it, we still might be obligated to care for the rest of the species and not just profit from them. For Mars exploration, this could mean an obligation to care for possible life on the Red Planet. Chris McKay and Robert Zubrin have discussed this in relation to the settlement of Mars (Waltemathe and Hemminger, 2019). While McKay argues from a biocentric stance to change the environment of Mars in such a way as to enable indigenous bacterial life to prosper and enable humans to learn about life itself, Zubrin basically argues to freeze indigenous life and keep it in the lab while making the planet liveable for humanity. $\mathrm{He}$ employs a strong anthropocentric view of planetary colonization. Brian Green of the University of Santa Clara, in an opinion piece for $\mathrm{CNN}$, questioned both positions from a philosophical as well as a theological point of view, and restructured their discussion to find a middle ground. All these discussions aim at giving the current planetary protection ruling an ethical framework. The current regulations are meant to protect scientific evidence from contamination through exploration. Their rationale is protection of science. One could argue, however, that this rationale needs an ethical and societal framework that includes more than science as a rationale (Sherwood et al., 2019).

The theological implications of life on Mars and the societal response to the discovery have received scholarly attention (e.g. Vakoch, 2013). The broader societal benefits of the planned robotic and potentially astronaut missions to Mars however relate to its immense inspirational and educational values and potentials. Such efforts can attract society and in particular young generations to expand the limits of our knowledge, to evoke interest in the study of sciences and related disciplines, draw attention to the values of international, peaceful cooperation in space, and even to the possibility of creating a sustainable human presence in the solar system beyond Earth. Using Mars as a teaching context, engaging students and general public with exploration efforts using the ever-popular Red Planet are all possible directions for science dissemination and popularization, engagement and even for correcting the misconceptions about science and space exploration (Capova et al., 2018).

\section{What is the motivation for space exploration?}

Human exploration of Mars often also has another motivational aspect: survival. Freeman Dyson frames it for interstellar 
exploration as assurance against even the worst imaginable of natural or man-made catastrophes that may overwhelm mankind within our Solar System (Dyson, 1968). Dyson also argues that a space colony would achieve 'total independence from any possible interference by the home government'.

William E. Burrows in 'The Survival Imperative' (Burrows, 2004) also argues for safeguarding humanity not only through space exploration but also in space. He draws on the ideas of O'Neil and Sagan and points out the pros and cons of their concepts. This can be directly applied to possible Mars settlements. With SpaceX planning such settlements for the near future, this perspective becomes immediate.

If one is to understand the motivation for Mars exploration for safeguarding humanity's future in nearby and distant solar systems to save us from a cataclysmic event that might destroy our habitat on Earth, the religious connotation of Noah's Ark immediately comes to mind. This story that is part of the Jewish, Christian and Muslim tradition (e.g. Gen 6-11 in the biblical text, but equally present in the Quran in different suras) is part of the religious and cultural foundation of European, Mid-Eastern and American societies. Flood mythology, however, can be found in all major religious traditions. As a consequence, Mars exploration scenarios would be well advised to take these religious and cultural connotations into account and relate to their specific challenges and opportunities. Another motivation is establishing new resource bases for humanity, thereby lightening the load on Earth's resources. Robert Zubrin in 'Entering Space' builds his argument in a similar way (Harris, 2000). Exploration as part of the human condition is something that is also argued in regard to space exploration and therefore to Mars exploration. The concept of 'Manifest Destiny', for example, is being invoked by the proponents of space exploration. William E. Burrows writes 'At the heart of it all, as usual, (were) the core of dreamers... who steadfastly believed it was their race's manifest destiny to leave Earth for both adventure and survival' (Burrows, 2010).

\section{What has shaped public opinion about Mars?}

Public attitudes about Mars are shaped by narrations created on Earth by science fiction authors, scientists, philosophers and politicians (Messeri, 2016). Historically, the Red Planet figures the public imagination about other worlds and its inhabitants. A prominent example is the 1897 novel 'The War of the Worlds' by H.G. Wells that has shaped the envisioning of an alien invasion and dominated a century-long narrative history. Today's explorers and science communicators are presented with a challenge of how to disseminate good science, its concepts and results in parallel to the many science fiction stories that are entertaining yet not always science-conformant. Here, for example, the robotic missions designed to find evidence of possible existence of life in habitable niche environments, e.g. Perseverance and Rosalin Franklin, have the capability to capture popular imagination as they seek answers to the questions: was there life on Mars, and what was it like?

\section{Societal benefits of Mars exploration}

Human and robotic space exploration responds to the deeply rooted quest of humankind for answering questions on the origins and nature of life in the Universe and extending human frontiers. More down-to-earth considerations are however important driving forces behind the actual decisions for investing in exploration programmes.

In the 1950s, geo-political considerations were the main driver for space exploration. What eventually evolved into a cold war space race to the Moon did and still continues to accumulate massive economic and societal benefits far beyond and above the outcomes initially envisaged. A study commissioned by the European Union in 2015 estimates that 6\% of Europe's entire economy (including non-space) is directly dependent on space infrastructure and accounting for around 14 million jobs. Satellites are able to address about $60 \%$ of the 57 essential climate variables (ECVs), with several exclusively derived from satellite measurements. ECVs are critically contributing to the characterization of Earth's climate, providing a picture of climate change at a global scale. The Climate Change Initiative of the ESA generates consistent, long-term and global data records for 21 key ECVs.

With the satellite applications fully integrated into society and becoming mainstream, exploration of outer space and Mars still entails significant short-term and long-term benefits for society. This is largely recognized by the International Space Exploration Coordination Group (ISECG), a coordination mechanism of space agencies from 25 countries. Largely building on ISECG's vision and roadmap with horizon goal human exploration of Mars, ESA's European Exploration Envelope Programme (E3P) is implementing a benefits-driven European Space Exploration Strategy, prioritising the scientific, economic, inspirational and international cooperation dimensions of exploration. Earth orbit, Moon, and Mars (ESA's three exploration destinations) should be seen as part of a single coherent programme expanding in a step-wise manner the places where humans will work and live in space.

\section{Earth sustainability}

In addition to the discoveries, advancement of science, technological development, and economic return can space technologies address other societal issues and assist in achieving sustainable development on Earth? The United Nations' Office for Outer Space Affairs (UNOOSA) has recognized space as a driver for the sustainable development and acknowledged the unique potential of space technologies in leveraging innovative solutions and technological developments. While the example of the Earth observations and geospatial data have already earned their recognition in contributing to the UN Sustainable Development Goals (SDG, a universal call to action to end poverty, protect the planet and ensure that all people enjoy peace and prosperity by 2030), the actual potential of space applications in supporting the SDGs is much wider. One example is the technology developed for analysing the atmosphere of Mars that now helps to cut greenhouse emissions on Earth (ESA SDG Catalogue 2018). Space activities, among those of ESA and other space agencies, are an important tool serving development (Duvaux-Béchon, 2019). The challenge remains in utilising those technologies and maximising their potential to make life on Earth more productive, clean and sustainable, securing safe future for our planet and human generations to come.

\section{Knowledge transfer from space exploration}

The ISS, continuously crewed since 2000, shows the benefits and potential of human activity in low Earth orbit, from basic science to innovation and knowledge fuelling emerging terrestrial 
applications in fields such as air filtration, protein crystal growth, robotic surgery, water recycling, materials, fluids and combustion (Thumm et al., 2012). The stringent challenges of space exploration to the next destinations are an accelerator for innovation. Exploration missions require the development of cutting-edge technology in areas such as advanced robotics, artificial intelligence and additive manufacturing (3D printing), and to enable next-generation life support, habitation and waste management systems for human exploration. This provides opportunities for other sectors to partner with the space sector on joint research and development. At the same time, scientific discoveries in weightlessness enabled by human exploration are applied widely. The results are touching every aspect of everyday life, from health and medicine, public safety, consumer goods, to energy and the environment, industrial productivity and transportation.

The process of developing a mission such as ESA's ExoMars 2022 mission sending the Rosalind Franklin Rover to search for life in the martian subsurface is already sparking spill-overs to the terrestrial economy. For example, welding techniques developed for the mission are also used to manufacture aluminium cans, with potential to save $12 \%$ on raw materials. A report commissioned by the UK Space Agency estimates that Rexam plc, a British-based multinational consumer packaging company and leading manufacturer of beverage cans, could have saved $£ 242$ million on raw materials in 2014 had the company implemented the technique. Mars Sample Return ground- and flight elements that ESA is contributing to an international end-to-end sample return capability will eventually allow scientists to analyse samples in terrestrial laboratories. Mars Sample Return will require the development of ground segments (such as the receiving and curation facilities) and a qualified workforce to handle the samples. This has the potential to push the boundaries of European technological achievement, directly creating thousands of high-tech jobs and spin-off industries to the benefit of the wider economy. Through the inspirational and motivational value of aiming high and beyond our current grasp, Mars exploration activities will result in increased participation of young people in STEM education and careers, thereby increasing their contribution to Europe's knowledge economy and capacity to address global challenges in the future. For example, Mars climate was once similar to the Earth's but has gone through massive changes. Importantly, Mars climate research may help better understand the past history and predict future changes in our Earth's climate (Read et al., 2015).

\section{Potential pitfalls of becoming an interplanetary species}

If the arguments on the motivation of exploration accurately describe human nature in regard to exploration and discovery, then perhaps space exploration is the ultimate form of human destiny, opening up the borders of our own planet. This can be made compatible with major religious traditions including views on humanity's role in creation. It certainly would serve as a motivation, but also bring with it all the cultural problems that historically, exploration has resulted in on planet Earth. The question arises of how to mitigate the negative effects of such concepts when trying to apply them to space exploration. Currently, a shift in language can be observed, addressing the difficult concepts of the past and the expressions they have shaped. Space colonies are different from space settlements in the potential negative historical connotation of words such as colonization, exploitation or even mining. Crewed vehicles describe the social reality of contemporary space explorations better than manned missions of the past. Grounding exploratory motivation in the space between scientific curiosity and human experience may serve to mitigate the problems. Religious and philosophical traditions can serve to motivate exploration on one hand but also as a careful reminder of the problems that we were, and still are, connected to it. Gaining knowledge about the Universe maybe the moredesirable first step, which also fuels human exploratory drive but with caution derived from more information.

\section{Epilogue}

Mars could have been more Earth-like before. The similarities between Noachian Mars ( 3.7-4.1 Ga ago) and early Earth have implications for the astrobiology of Mars, not least that traces of extinct martian life might remain at the planet's surface or subsurface. The tenuous atmosphere of present-day Mars evolved from the depletion of a thicker atmosphere. This drove a water cycle hosting numerous lakes and rivers that shaped the Noachian landscape. Whereas Earth evolved plate tectonics, Mars preserved two contrasting landscapes; the rough southern highlands and the smooth northern lowlands. How this 'Mars dichotomy' formed remains unanswered.

Evidence for Mars' aqueous past is recorded in surface minerals. Carbonates expand our understanding of carbon- and water cycles, as well as planetary habitability. They are commonplace on Earth but less abundant on the martian surface even though martian conditions could have been warm and wet; favourable for the formation of carbonates (in neutral $\mathrm{pH}$ water bodies). Although most carbonate on Mars formed under aqueous conditions (similar to Earth), some carbonates on Mars may have formed via other processes (that do not occur on Earth). Atmospheric $\mathrm{CO}_{2}$ photochemistry, or energetic electrons discharging martian dust particles are examples. Sulphates on Mars are mostly hydrated, supporting their formation under water-rich conditions, mostly during the Hesperian ( 3.0-3.7 Ga ago). Hematite, clays, and amorphous hydrated silicates are more widespread, providing further evidence of an aqueous past.

As for martian water, studies of martian methane are motivated by the question of life on Mars. Whereas the mechanisms of biogenic methane formation on Earth have been identified, mechanisms of methane formation on Mars have yet to be elucidated. Methane levels are known to vary on Mars, but its origin remains unclear. Seasonal variation in martian methane can be attributed to either a biological origin or inorganic formation, e.g. via serpentinization, photochemistry or the reduction of $\mathrm{CO}_{2}$ over acidic minerals and clays.

We are yet to ascertain the existence of past or present life on Mars. Habitable environments need to be studied, although a habitable environment does/did not necessarily harbour life. This said, the identificiation of biosignatures on Mars (whether textural, chemical, or isotopic) would confirm the existence of once-habitable environments. However, for many kinds of biosignature, there is no simple way to affirm that ancient life once existed in a specific extraterrestrial location. Microorganisms from Earth might not survive the harsh conditions on Mars surface, and no biomolecules would remain intact without the protection of minerals. However, Mars is not necessarily universally biocidal, and pigmented microorganisms are the most resistant to EUV exposure. The search for biomolecules should be focused in the subsurface of Mars. 
A better understanding of martian processes requires the characterization of Mars across diverse spatial and temporal scales. Martian meteorites have been the only martian samples available for study at the microscopic scale. After being recognized as martian only decades ago, we are now exploring where on Mars these meteorites could have been ejected from. Cosmic ray exposure ages, determined via analyses of noble gasses, can indicate ejection times, grouping the martian meteorite ejection events and constraining the number of impact craters associated with them. An impact event that led to the Mojave Crater has been hypothesized to have ejected some of the shergottite martian meteorites. However, determination of martian meteorite source locations remains a challenge even with accurate mineralogical data on both Mars and its meteorites.

Mars exploration will intensify during the coming decade. The increasing number of missions to Mars will improve our understanding of the Red Planet, increasing the likelihood of human habitability. In parallel, advancements made in human space exploration on the ISS and eventually the Moon will catalyse human exploration of Mars. First and foremost, will be to determine where humans could safely inhabit Mars. The elevation of selected sites is important due to the landing risks; atmospheric breaking technologies need to be established. The major technology drivers required to achieve this include resource utilization, i.e. converting $\mathrm{CO}_{2}$ into methane and oxygen for propellant fuel, life- and resource-support technologies, and water extraction from the polar ice and permafrost. Martian regolith and dust can be used with manufacturing technologies to produce human habitations. When sustainable agriculture is achieved, human habitability is finally supported. Further to that, additional risks associated with societal structures and human settlements require quantification and evaluation.

Humanity's encounter with a possibly inhabited world requires careful consideration of the United Nations resolutions on planetary protection. Contamination of Mars could occur from Earth as well as any potential bio-risk to Earth upon human or robotic return from Mars. This is particularly a concern towards the subsurface of Mars that could retain Earth-based organisms if contaminated. Precise countermeasures are required to prevent contamination from vehicles and instruments sent to Mars, and eventually from humans. An accurate characterization of the local martian environment for extant life is necessary prior to any human activities. If any forms of extant life were to be discovered, would it be ethical to tamper with their course of their evolution? Solving such ethical questions whilst sustaining human development on Mars is just as challenging as the technological feat itself.

Current and future Mars missions outline the technological achievements through which economic benefits arise and nations are brought together. Mars exploration will also support STEM education and careers addressing the global challenges we face together on Earth. Mars will ultimately act as a testing ground for humanity becoming an interplanetary species. This frontier is becoming more realistic, despite the technological challenges that need to be solved. These challenges, which involve the conservative and efficient use of resources, could also facilitate improved sustainability and economic prosperity on Earth.

Acknowledgements. HGC was supported by the NSFC 'Young International Scientist Award' Grant No. ED was supported by the Canadian Space Agency Grant No. 18FASASB13. 41750110488. MF acknowledges grants nos. 19-03314S of the Czech Science Foundation and ERDF/ESF 'Centre of Advanced Applied Sciences' (No. CZ.02.1.01/0.0/0.0/16_019/
0000778). FXH was funded by the B-type Strategic Priority Program of the Chinese Academy of Sciences (Grant No. XDB41000000). Lauren Edgar of the United States Geological Survey is thanked for her contribution in the 'Robotic and remote exploration of Mars' section of this article. The National Space Science Centre of the Chinese Academy of Sciences and the Space Studies Board of US National Academy of Sciences' National Research Council's $9^{\text {th }}$ and $10^{\text {th }}$ New Leaders in Space forum organizers Dr Quanlin Fan, Chinese Academy of Sciences, China and Dr David Smith, US National Academy of Sciences, USA are also thanked for bringing together some Mars scientists for this article.

\section{References}

Ackiss SE and Wray J (2014) Occurrences of possible hydrated sulfates in the southern high latitudes of Mars. Icarus 243, 311-324.

Agee CB, Wilson NV, McCubbin FM, Ziegler K, Polyak VJ, Sharp ZD, Asmerom Y, Nunn MH, Shaheen R and Thiemens MH (2013) Unique meteorite from early Amazonian Mars: water-rich basaltic breccia Northwest Africa 7034. Science 339, 780-785.

Anbu P, Kang C-H, Shin Y-J and So J-S (2016) Formations of calcium carbonate minerals by bacteria and its multiple applications. Springerplus 5, 1-26.

Andrews-Hanna JC (2020) The tectonic architecture of wrinkle ridges on Mars. Icarus 351, 113937.

Andrews-Hanna JC, Zuber MT and Banerdt WB (2008) The Borealis basin and the origin of the martian crustal dichotomy. Nature 453, 1212-1215.

Artemieva N and Ivanov B (2004) Launch of Martian meteorites in oblique impacts. Icarus 171, 84-101.

Arunan S and Satish R (2015) Mars Orbiter Mission spacecraft and its challenges. Current Science 109(6), 1061-1069.

Arvidson RE, Bell J, Bellutta P, Cabrol NA, Catalano J, Cohen J, Crumpler LS, Des Marais D, Estlin T and Farrand W (2010) Spirit Mars rover mission: overview and selected results from the northern Home Plate Winter Haven to the side of Scamander crater. Journal of Geophysical Research: Planets 115. E00F03, 19 pages, https://doi.org/10.1029/2010JE003633

Arya A, Moorthi SM, Rajasekhar R, Sarkar S, Sur K, Aravind B, Gambhir RK, Misra I, Patel V and Srinivas A (2015) Indian Mars-Colour-Camera captures far-side of the Deimos: a rarity among contemporary Mars orbiters. Planetary and Space Science 117, 470-474.

Atreya SK, Mahaffy PR and Wong A-S (2007) Methane and related trace species on Mars: origin, loss, implications for life, and habitability. Planetary and Space Science 55, 358-369.

Atreya SK, Trainer MG, Franz HB, Wong MH, Manning HL, Malespin CA, Mahaffy PR, Conrad PG, Brunner AE and Leshin LA (2013) Primordial argon isotope fractionation in the atmosphere of Mars measured by the SAM instrument on Curiosity and implications for atmospheric loss. Geophysical Research Letters 40, 5605-5609.

Aureli L, Pacelli C, Cassaro A, Fujimori A, Moeller R and Onofri S (2020) Iron ion particle radiation resistance of dried colonies of Cryomyces antarcticus embedded in martian regolith analogues. Life 10, 306.

Avice G, Bekaert D, Aoudjehane HC and Marty B (2018) Noble gases and nitrogen in Tissint reveal the composition of the Mars atmosphere. Geochemical Perspectives Letters 6, 11-16.

Bagheri A, Khan A, Efroimsky M, Kruglyakov M and Giardini D (2021) Dynamical evidence for Phobos and Deimos as remnants of a disrupted common progenitor. Nature Astronomy 5, 1-5.

Baitukayeva D and Baitukayeva A (2020) International cooperation of states in outer space exploration. International Relations and International Law Journal 90, 45-51.

Baker VR, Maruyama S and Dohm JM (2007) Tharsis superplume and the geological evolution of early Mars. In David AY, Shigenori M, Shun-ichiro K and Brian FW (eds). Superplumes: Beyond Plate Tectonics. Dordrecht: Springer, pp. 507-522.

Bandfield JL, Glotch TD and Christensen PR (2003) Spectroscopic identification of carbonate minerals in the Martian dust. Science 301, 1084-1087.

Banham SG, Gupta S, Rubin DM, Watkins JA, Sumner DY, Edgett KS, Grotzinger JP, Lewis KW, Edgar LA and Stack-Morgan KM (2018) Ancient Martian aeolian processes and palaeomorphology reconstructed 
from the Stimson formation on the lower slope of Aeolis Mons, Gale crater, Mars. Sedimentology 65, 993-1042.

Beaty DW, Grady MM, McSween HY, Sefton-Nash E, Carrier BL, Altieri F, Amelin Y, Ammannito E, Anand M, Benning LG, Bishop JL, Borg LE, Boucher D, Brucato JR, Busemann H, Campbell KA, Czaja AD, Debaille V, Des Marais DJ, Dixon M, Ehlmann BL, Farmer JD, Fernandez-Remolar DC, Filiberto J, Fogarty J, Glavin DP, Goreva YS, Hallis LJ, Harrington AD, Hausrath EM, Herd CDK, Horgan B, Humayun M, Kleine T, Kleinhenz J, Mackelprang R, Mangold N, Mayhew LE, McCoy JT, McCubbin FM, McLennan SM, Moser DE, Moynier F, Mustard JF, Niles PB, Ori GG, Raulin F, Rettberg P, Rucker MA, Schmitz N, Schwenzer SP, Sephton MA, Shaheen R, Sharp ZD, Shuster DL, Siljeström S, Smith CL, Spry JA, Steele A, Swindle TD, ten Kate IL, Tosca NJ, Usui T, Van Kranendonk MJ, Wadhwa M, Weiss BP, Werner SC, Westall F, Wheeler RM, Zipfel J and Zorzano MP (2019) The potential science and engineering value of samples delivered to Earth by Mars sample return. Meteoritics \& Planetary Science 54, 667-671.

Becerra P, Smith IB, Coronato A and Rabassa J (2020) Mars Polar Science at the End of the World. In (Nature Publishing Group, Nat Astron)4, 566-568.

Benison KC, O'Neill WK, Blain D and Hallsworth JE (2021) Water activities of acid brine lakes approach the limit for life. Astrobiology 21: 729-740.

Bennett KA, Fox VK, Bryk AB, Fedo C, Vasavada AR, Dehouck E, Thompson LM, O'Connell-Cooper C, Bristow T and Millan M (2019) Results from the Curiosity rover's traverse through the clay-bearing Glen Torridon region in Gale crater. AGUFM 2019, 33B-301.

Bernhard G and Stierle S (2020) Trends of UV radiation in Antarctica. Atmosphere 11, 795 .

Bhardwaj A, Mohankumar S, Das TP, Pradeepkumar P, Sreelatha P, Sundar B, Nandi A, Vajja DP, Dhanya M and Naik N (2015) MENCA experiment aboard India's Mars orbiter mission. Current Science 109, 1106-1113.

Bhardwaj A, Thampi SV, Das TP, Dhanya M, Naik N, Vajja DP, Pradeepkumar P, Sreelatha P, Thampi RS and Yadav VK (2017) Observation of suprathermal argon in the exosphere of Mars. Geophysical Research Letters 44, 2088-2095.

Bibring J-P, Hamm V, Pilorget C and Vago JL (2017) The micrOmega investigation onboard ExoMars. Astrobiology 17, 621-626.

Billi D, Staibano C, Verseux C, Fagliarone C, Mosca C, Baqué M, Rabbow E and Rettberg P (2019) Dried biofilms of desert strains of Chroococcidiopsis survived prolonged exposure to space and Mars-like conditions in low Earth orbit. Astrobiology 19, 1008-1017.

Bishop JL, Parente M, Weitz CM, Noe Dobrea EZ, Roach LH, Murchie SL, McGuire PC, McKeown NK, Rossi CM and Brown AJ (2009) Mineralogy of Juventae Chasma: sulfates in the light-toned mounds, mafic minerals in the bedrock, and hydrated silica and hydroxylated ferric sulfate on the plateau. Journal of Geophysical Research: Planets 114. E00D09, 23 pages, doi:10.1029/2009JE003352

Bishop JL, Fairén AG, Michalski JR, Gago-Duport L, Baker LL, Velbel MA, Gross C and Rampe EB (2018) Surface clay formation during short-term warmer and wetter conditions on a largely cold ancient Mars. Nature Astronomy 2, 206-213.

Blum WE, Zechmeister-Boltenstern S and Keiblinger KM (2019) Does soil contribute to the human gut microbiome? Microorganisms 7, 287.

Boatwright BD and Head JW (2021) A Noachian proglacial paleolake on Mars: fluvial activity and lake formation within a closed-source drainage basin crater and implications for early Mars climate. The Planetary Science Journal 2, 52.

Boquet E, Boronat A and Ramos-Cormenzana A (1973) Production of calcite (calcium carbonate) crystals by soil bacteria is a general phenomenon. Nature 246, 527-529.

Bouley S, Keane JT, Baratoux D, Langlais B, Matsuyama I, Costard F, Hewins R, Payré V, Sautter V and Séjourné A (2020) A thick crustal block revealed by reconstructions of early Mars highlands. Nature Geoscience 13, 105-109.

Bouvier LC, Costa MM, Connelly JN, Jensen NK, Wielandt D, Storey M, Nemchin AA, Whitehouse MJ, Snape JF and Bellucci JJ (2018) Evidence for extremely rapid magma ocean crystallization and crust formation on Mars. Nature 558, 586-589.
Boynton W, Ming D, Kounaves S, Young S, Arvidson R, Hecht M, Hoffman J, Niles P, Hamara D and Quinn R (2009) Evidence for calcium carbonate at the Mars Phoenix landing site. Science 325, 61-64.

Bramson AM, Byrne S, Beyer R, Cummings N, Golombek M, Head J, Hodges K, Levy J, Lim DS and Marinova M Accelerating Martian and Lunar Science through SpaceX Starship Missions. Unknown NASA technical document: https://surveygizmoresponseuploads.s3.amazonaws.com/ fileuploads/623127/5489366/111-381503be1c5764e533d2e1e923e21477_Held mannJenniferL.pdf

Bridges J and Schwenzer S (2012) The nakhlite hydrothermal brine on Mars. Earth and Planetary Science Letters 359, 117-123.

Bridges JC, Schwenzer SP, Leveille R, Westall F, Wiens RC, Mangold N, Bristow T., Edwards P and Berger G (2015) Diagenesis and clay mineral formation at Gale Crater. Mars. J. of Geophysical Research 10.1002/ 2014JE004757.

Burrows W (2004) The survival imperative: using space to protect Earth. 2004 Planetary Defense Conference: Protecting Earth from Asteroids.

Burrows WE (2010) This New Ocean: The Story of the First Space Age. Modern library. USA. https://www.amazon.com/This-New-Ocean-Library-Paperback/ dp/0375754857

Cabrol NA (2021) Tracing a modern biosphere on Mars. Nature Astronomy 5, 210-212.

Cabrol NA and Grin EA (1999) Distribution, classification, and ages of Martian impact crater lakes. Icarus 142, 160-172.

Cabrol NA and Grin EA (2010) Lakes on Mars. Elsevier, Amsterdam: The Netherlands

Capova K, Dartnell L, Dunér D, Melin A and Mitrikeski PT (2018) Society, worldview and outreach. In Klara AC, Erik PTM, David D (eds). Astrobiology and Society in Europe Today. Switzerland: Springer Nature, pp. 19-24.

Carr MH (1987) Water on Mars. Nature 326, 30-35.

Carr M (1996) Water on Mars. New York: Oxford University Press.

Carr MH and Head III JW (2003) Oceans on Mars: an assessment of the observational evidence and possible fate. Journal of Geophysical Research: Planets, 108. NO. E5, 5042, doi:10.1029/2002JE001963

Carr M and Head J (2015) Martian surface/near-surface water inventory: sources, sinks, and changes with time. Geophysical Research Letters 42, 726-732.

Carr R, Grady M, Wright I and Pillinger C (1985) Martian atmospheric carbon dioxide and weathering products in SNC meteorites. Nature 314, 248-250.

Carter J, Poulet F, Bibring JP, Mangold N and Murchie S (2013) Hydrous minerals on Mars as seen by the CRISM and OMEGA imaging spectrometers: updated global view. Journal of Geophysical Research: Planets 118, 831-858.

Catling DC (1999) A chemical model for evaporites on early Mars: possible sedimentary tracers of the early climate and implications for exploration. Journal of Geophysical Research: Planets 104, 16453-16469.

Cesaretti G, Dini E, De Kestelier X, Colla V and Pambaguian L (2014) Building components for an outpost on the Lunar soil by means of a novel 3D printing technology. Acta Astronautica 93, 430-450.

Chan MA, Beitler B, Parry WT, Ormö J and Komatsu G (2004) A possible terrestrial analogue for haematite concretions on Mars. Nature 429, 731-734.

Changela $\mathbf{H}$ and Bridges J (2010) Alteration assemblages in the nakhlites: variation with depth on Mars. Meteoritics \& Planetary Science 45, 18471867.

Chatzitheodoridis E and Turner G (1990) Secondary minerals in the Nakhla meteorite. Meteoritics 25, 354-354.

Chatzitheodoridis E, Haigh S and Lyon I (2014) A conspicuous clay ovoid in Nakhla: evidence for subsurface hydrothermal alteration on Mars with implications for astrobiology. Astrobiology 14, 651-693.

Christensen PR, Morris RV, Lane MD, Bandfield JL and Malin MC (2001) Global mapping of Martian hematite mineral deposits: remnants of waterdriven processes on early Mars. Journal of Geophysical Research: Planets 106, 23873-23885.

Christensen P, Wyatt M, Glotch T, Rogers A, Anwar S, Arvidson R, Bandfield J, Blaney D, Budney C and Calvin W (2004) Mineralogy at Meridiani Planum from the Mini-TES experiment on the Opportunity Rover. Science 306, 1733-1739. 
Christensen PR, Bandfield JL, Clark RN, Edgett KS, Hamilton VE, Hoefen T, Kieffer HH, Kuzmin RO, Lane MD, Malin MC, Morris RV, Pearl JC, Pearson R, Roush TL, Ruff SW and Smith MD (2000) Detection of crystalline hematite mineralization on Mars by the thermal emission spectrometer: evidence for near-surface water. Journal of Geophysical Research: Planets 105, 9623-9642.

Ciarletti V, Clifford S, Plettemeier D, Le Gall A, Hervé Y, Dorizon S, Quantin-Nataf C, Benedix W-S, Schwenzer S and Pettinelli E (2017) The WISDOM radar: unveiling the subsurface beneath the ExoMars Rover and identifying the best locations for drilling. Astrobiology 17, 565-584.

Cirigliano A, Tomassetti MC, Di Pietro M, Mura F, Maneschi ML, Gentili MD, Cardazzo B, Arrighi C, Mazzoni C and Negri R (2018) Calcite moonmilk of microbial origin in the Etruscan Tomba degli Scudi in Tarquinia, Italy. Scientific Reports 8, 1-10.

Civiš S, Knížek A, Ivanek O, Kubelík P, Zukalová M, Kavan L and Ferus $M$ (2017) The origin of methane and biomolecules from a CO 2 cycle on terrestrial planets. Nature Astronomy 1, 721-726.

Civiš S, Knížek A, Rimmer PB, Ferus M, Kubelík P, Zukalová MT, Kavan L and Chatzitheodoridis E (2018) Formation of methane and (per) chlorates on Mars. ACS Earth and Space Chemistry 3, 221-232.

Clancy R, Sandor B, Wolff M, Christensen P, Smith M, Pearl J, Conrath B and Wilson R (2000) An intercomparison of ground-based millimeter, MGS TES, and Viking atmospheric temperature measurements: seasonal and interannual variability of temperatures and dust loading in the global Mars atmosphere. Journal of Geophysical Research: Planets 105, 95539571.

Clemente JC, Pehrsson EC, Blaser MJ, Sandhu K, Gao Z, Wang B, Magris M, Hidalgo G, Contreras M and Noya-Alarcón Ó (2015) The microbiome of uncontacted Amerindians. Science Advances 1, e1500183.

Coates A, Jaumann R, Griffiths A, Leff C, Schmitz N, Josset J-L, Paar G, Gunn M, Hauber E and Cousins CR (2017) The PanCam instrument for the ExoMars rover. Astrobiology 17, 511-541.

Cockell CS (2010) Geomicrobiology beyond Earth: microbe-mineral interactions in space exploration and settlement. Trends in Microbiology 18, 308-314.

Cockell CS (2020) Persistence of habitable, but uninhabited, aqueous solutions and the application to extraterrestrial environments. Astrobiology. 20, 617-627.

Cockell CS (2021) The biological study of lifeless worlds and environments. Astrobiology 21, 490-504.

Cockell CS and McMahon S (2019) Lifeless Martian samples and their significance. Nature Astronomy 3, 468-470.

Coleine C, Stajich JE, de Los Ríos A and Selbmann L (2021) Beyond the extremes: rocks as ultimate refuge for fungi in drylands. Mycologia 113, 108-133.

Cortesão M, Fuchs FM, Commichau FM, Eichenberger P, Schuerger AC, Nicholson WL, Setlow P and Moeller R (2019) Bacillus subtilis Spore Resistance to Simulated Mars Surface Conditions. Front Microbiol 10, 333.

Craddock RA and Greeley R (2009) Minimum estimates of the amount and timing of gases released into the martian atmosphere from volcanic eruptions. Icarus 204, 512-526.

Craven E, Winters M, Smith AL, Lalime E, Mancinelli R, Shirey B, Schubert W, Schuerger A, Burgin M and Seto EP (2021) Biological safety in the context of backward planetary protection and Mars sample return: conclusions from the sterilization working group. International Journal of Astrobiology 20, 1-28.

Cray JA, Bell AN, Bhaganna P, Mswaka AY, Timson DJ and Hallsworth JE (2013) The biology of habitat dominance; can microbes behave as weeds? Microbial Biotechnology 6, 453-492.

Cray JA, Stevenson A, Ball P, Bankar SB, Eleutherio ECA and Ezeji TC (2015) Chaotropicity: a key factor in product tolerance of biofuel-producing microorganisms. Curr Opin Biotechnol 33, 228-259.

De Filippo C, Cavalieri D, Di Paola M, Ramazzotti M, Poullet JB, Massart S, Collini S, Pieraccini G and Lionetti P (2010) Impact of diet in shaping gut microbiota revealed by a comparative study in children from Europe and rural Africa. Proceedings of the National Academy of Sciences 107, 14691-14696.
De Sanctis MC, Altieri F, Ammannito E, Biondi D, De Angelis S, Meini M, Mondello G, Novi S, Paolinetti R and Soldani M (2017) Ma_MISS on ExoMars: mineralogical characterization of the martian subsurface. Astrobiology 17, 612-620.

de Villiers G, Kleinhans MG and Postma G (2013) Experimental delta formation in crater lakes and implications for interpretation of Martian deltas. Journal of Geophysical Research: Planets 118, 651-670.

Di Bella M, Sabatino G, Quartieri S, Ferretti A, Cavalazzi B, Barbieri R, Foucher F, Messori F and Italiano F (2019) Modern iron ooids of hydrothermal origin as a proxy for ancient deposits. Scientific Reports 9, 7107.

Dighton J, Tugay T and Zhdanova N (2008) Fungi and ionizing radiation from radionuclides. FEMS Microbiology Letters 281, 109-120.

Dikshit R, Dey A, Gupta N, Varma SC, Venugopal I, Viswanathan K and Kumar A (2020) Space bricks: from LSS to machinable structures via MICP. Ceramics International 47, 14892-14898

Dong C, Ma Y, Bougher SW, Toth G, Nagy AF, Halekas JS, Dong Y, Curry SM, Luhmann JG and Brain D (2015) Multifluid MHD study of the solar wind interaction with Mars' upper atmosphere during the 2015 March 8th ICME event. Geophysical Research Letters 42, 9103-9112.

Dong C, Bougher SW, Ma Y, Lee Y, Toth G, Nagy AF, Fang X, Luhmann J, Liemohn MW and Halekas JS (2018) Solar wind interaction with the Martian upper atmosphere: roles of the cold thermosphere and hot oxygen corona. Journal of Geophysical Research: Space Physics 123, 6639-6654.

Dong C, Lee Y, Ma Y, Lingam M, Bougher SW, Luhmann JG, Curry SM, Toth G, Nagy AF, Tenishev V, Fang X, Mitchell D, Brain D and Jakosky B (2018) Modeling Martian atmospheric losses over time: implications for exoplanetary climate evolution and habitability. Astrophysical Journal Letters 859, L14.

Dong C, Huang $\mathbf{Z}$ and Lingam $\mathbf{M}$ (2019) Role of planetary obliquity in regulating atmospheric escape: G-dwarf versus M-dwarf Earth-like exoplanets. The Astrophysical Journal Letters 882, L16.

Dong C, Jin M and Lingam M (2020) Atmospheric escape from TOI-700 d: Venus versus Earth analogs. The Astrophysical Journal Letters 896, L24.

Duvaux-Béchon I (2019) The European Space Agency (ESA) and the United Nations 2030 SDG Goals. In Annette F (eds). Embedding Space in African Society. Switzerland: Springer Nature, pp. 223-235.

Dyson FJ (1968) Interstellar transport. Physics Today 21, 41-45.

Edgar LA, Gupta S, Rubin DM, Lewis KW, Kocurek GA, Anderson RB, Bell III JF, Dromart G, Edgett KS and Grotzinger JP (2018) Shaler: in situ analysis of a fluvial sedimentary deposit on Mars. Sedimentology 65, 96-122.

Ehlmann BL and Edwards CS (2014) Mineralogy of the Martian surface. Annual Review of Earth and Planetary Sciences 42, 291-315

Ehlmann BL, Mustard JF, Fassett CI, Schon SC, Head III JW, Des Marais DJ, Grant JA and Murchie SL (2008a) Clay minerals in delta deposits and organic preservation potential on Mars. Nature Geoscience 1, 355-358.

Ehlmann BL, Mustard JF, Murchie SL, Poulet F, Bishop JL, Brown AJ, Calvin WM, Clark RN, Des Marais DJ and Milliken RE (2008b) Orbital identification of carbonate-bearing rocks on Mars. Science 322, $1828-1832$.

Ehlmann B, Edgett K, Sutter B, Achilles C, Litvak M, Lapotre M, Sullivan R, Fraeman A, Arvidson R and Blake D (2017) Chemistry, mineralogy, and grain properties at Namib and High dunes, Bagnold dune field, Gale crater, Mars: a synthesis of Curiosity rover observations. Journal of Geophysical Research: Planets 122, 2510-2543.

Eigenbrode JL, Summons RE, Steele A, Freissinet C, Millan M, Navarro-González R, Sutter B, McAdam AC, Franz HB and Glavin DP (2018) Organic matter preserved in 3-billion-year-old mudstones at Gale crater, Mars. Science 360, 1096-1101.

Eisenhofer R, Kanzawa-Kiriyama H, Shinoda K-I and Weyrich LS (2020) Investigating the demographic history of Japan using ancient oral microbiota. Philosophical Transactions of the Royal Society B 375, 20190578.

Ellery A (2016) Are self-replicating machines feasible? Journal of Spacecraft and Rockets 53, 317-327.

Ellery A (2017) Universal construction based on 3D printing electric motors: steps towards self-replicating robots to transform space exploration.2017 IEEE International Symposium on Robotics and Intelligent Sensors (IRIS). IEEE. 
Ellery A (2020) Sustainable in-situ resource utilization on the moon. Planetary and Space Science 184, 104870.

Ellery A and Muscatello A (2020) Provisioning the naked astronaut with bounty on mars using robotic self-replicators $J$ British Interplanetary Society 73, 409-424

Fairén AG, Fernández-Remolar D, Dohm JM, Baker VR and Amils R (2004) Inhibition of carbonate synthesis in acidic oceans on early Mars. Nature 431, 423-426.

Fajardo-Cavazos P, Link L, Melosh HJ and Nicholson WL (2005) Bacillus subtilis spores on artificial meteorites survive hypervelocity atmospheric entry: implications for lithopanspermia. Astrobiology $\mathbf{5}$, 726-736.

Farley K, Malespin C, Mahaffy P, Grotzinger J, Vasconcelos P, Milliken R, Malin M, Edgett K, Pavlov A and Hurowitz J (2014) In situ radiometric and exposure age dating of the Martian surface. Science 343, 1247166.

Farley KA, Williford KH, Stack KM, Bhartia R, Chen A, de la Torre M, Hand K, Goreva Y, Herd CD and Hueso R (2020) Mars 2020 mission overview. Space Science Reviews 216, 1-41.

Farquhar J, Thiemens MH and Jackson T (1998) Atmosphere-surface interactions on Mars: $\delta 17 \mathrm{O}$ measurements of carbonate from ALH 84001. Science 280, 1580-1582.

Fassett CI and Head III JW (2008a) The timing of Martian valley network activity: constraints from buffered crater counting. Icarus 195, 61-89.

Fassett CI and Head III JW (2008b) Valley network-fed, open-basin lakes on Mars: distribution and implications for Noachian surface and subsurface hydrology. Icarus 198, 37-56.

Fishbaugh KE and Head III JW (2005) Origin and characteristics of the Mars north polar basal unit and implications for polar geologic history. Icarus 174, 444-474.

Fishbaugh KE, Poulet F, Chevrier V, Langevin Y and Bibring JP (2007) On the origin of gypsum in the Mars north polar region. Journal of Geophysical Research: Planets 112. E07002, 17 pages, doi:10.1029/2006JE002862

Flynn GJ (1996) The Delivery of Organic Matter from Asteroids and Comets to the Early Surface of Mars. In Rickman H and Valtonen MJ (eds). Worlds in Interaction: Small Bodies and Planets of the Solar System. Dordrecht: Springer. https://doi.org/10.1007/978-94-009-0209-1_58.

Foing B, Stoker C and Ehrenfreund P (2011a) Astrobiology field research in Moon/Mars analogue environments. International Journal of Astrobiology 10, 137-139.

Foing B, Stoker C, Zavaleta J, Ehrenfreund P, Thiel C, Sarrazin P, Blake D, Page J, Pletser V and Hendrikse J (2011b) Field astrobiology research in Moon-Mars analogue environments: instruments and methods. International Journal of Astrobiology 10, 141.

Fonti S and Marzo G (2010) Mapping the methane on Mars. Astronomy \& Astrophysics 512, A51.

Formisano V, Atreya S, Encrenaz T, Ignatiev N and Giuranna M (2004) Detection of methane in the atmosphere of Mars. Science 306, 1758-1761.

Fox-Powell MG, Hallsworth JE, Cousins CR and Cockell CS (2016) Ionic strength is a barrier to the habitability of Mars. Astrobiology 16, 427-442.

Fraeman AA, Edgar LA, Rampe EB, Thompson LM, Frydenvang J, Fedo CM, Catalano JG, Dietrich WE, Gabriel TS and Vasavada A (2020) Evidence for a diagenetic origin of Vera Rubin Ridge, Gale crater, Mars: summary and synthesis of Curiosity's exploration campaign. Journal of Geophysical Research: Planets 125, e2020JE006527.

Fraeman AA, Arvidson RE, Catalano JG, Grotzinger JP, Morris RV, Murchie SL, Stack KM, Humm DC, McGovern JA, Seelos FP, Seelos KD and Viviano CE (2013) A hematite-bearing layer in Gale Crater, Mars: mapping and implications for past aqueous conditions. Geology 41, 1103-1106.

Frantseva K, Mueller M, ten Kate IL, van der Tak FF and Greenstreet S (2018) Delivery of organics to Mars through asteroid and comet impacts. Icarus 309, 125-133.

Freissinet C, Glavin D, Mahaffy PR, Miller K, Eigenbrode J, Summons R, Brunner A, Buch A, Szopa C and Archer Jr P (2015) Organic molecules in the sheepbed mudstone, Gale crater, Mars. Journal of Geophysical Research: Planets 120, 495-514.

Friedmann EI (1982) Endolithic microorganisms in the Antarctic cold desert. Science 215, 1045-1053.
Fries M, Christou A, Archer D, Conrad P, Cooke W, Eigenbrode J, ten Kate I, Matney M, Niles P and Sykes M (2016) A cometary origin for Martian atmospheric methane. Geochemical Perspectives Letters 2, 10-23.

Fritz J, Artemieva N and Greshake A (2005) Ejection of Martian meteorites. Meteoritics \& Planetary Science 40, 1393-1411.

Fu X, Jia L, Wang A, Cao H, Ling Z, Liu C, Shi E, Wu Z, Li B and Zhang J (2020) Thermal stability of akaganeite and its desiccation process under conditions relevant to Mars. Icarus 336, 113435.

Fujita K, Kurosawa K, Genda H, Hyodo R, Matsuyama S, Yamagishi A, Mikouchi T and Niihara T (2019) Assessment of the probability of microbial contamination for sample return from Martian moons I: departure of microbes from Martian surface. Life Sciences in Space Research 23, 73-84.

Geminale A, Formisano V and Giuranna M (2008) Methane in Martian atmosphere: average spatial, diurnal, and seasonal behaviour. Planetary and Space Science 56, 1194-1203.

Geminale A, Formisano V and Sindoni G (2011) Mapping methane in Martian atmosphere with PFS-MEX data. Planetary and Space Science 59, 137-148.

Gladman B (1997) Destination: Earth. Martian meteorite delivery. Icarus 130, 228-246.

Glotch TD and Kraft MD (2008) Thermal transformations of akaganéite and lepidocrocite to hematite: assessment of possible precursors to Martian crystalline hematite. Physics and Chemistry of Minerals 35, 569-581.

Glotch TD, Morris RV, Christensen PR and Sharp TG (2004) Effect of precursor mineralogy on the thermal infrared emission spectra of hematite: application to Martian hematite mineralization. Journal of Geophysical Research: Planets 109. E07003, 18 pages, doi:10.1029/2003JE002224

Goesmann F, Brinckerhoff WB, Raulin F, Goetz W, Danell RM, Getty SA, Siljeström S, Mißbach H, Steininger H and Arevalo Jr RD (2017) The Mars Organic Molecule Analyzer (MOMA) instrument: characterization of organic material in martian sediments. Astrobiology 17, 655-685.

Golden DC, Ming DW, Morris RV and Graff TG (2008) Hydrothermal synthesis of hematite spherules and jarosite: implications for diagenesis and hematite spherule formation in sulfate outcrops at Meridiani Planum, Mars. American Mineralogist 93, 1201-1214.

Golombek M, Grant J, Kipp D, Vasavada A, Kirk R, Fergason R, Bellutta P, Calef F, Larsen K and Katayama Y (2012) Selection of the Mars Science Laboratory landing site. Space Science Reviews 170, 641-737.

Golombek M, Williams N, Wooster P, McEwen A, Putzig N, Bramson A, Head J, Heldmann J, Marinova M and Beaty D (2021) SpaceX Starship landing sites on Mars. Lunar and Planetary Science Conference.

Golombek MP, Grant JA, Parker TJ, Kass DM, Crisp JA, Squyres SW, Haldemann AFC, Adler M, Lee WJ, Bridges NT, Arvidson R E, Carr MH, Kirk RL, Knocke PC, Roncoli RB, Weitz CM, Schofield JT, Zurek RW, Christensen P R, Fergason RL, Anderson FS and Rice JW Jr (2003) Selection of the Mars Exploration Rover landing sites. Journal of Geophysical Research: Planets, 108 NO. E12, 8072, pp. ROV13:1-48, doi:10.1029/2003JE002074.

Gooding JL, Wentworth SJ and Zolensky ME (1991) Aqueous alteration of the Nakhla meteorite. Meteoritics 26, 135-143.

Goudge TA, Mustard JF, Head JW, Fassett CI and Wiseman SM (2015) Assessing the mineralogy of the watershed and fan deposits of the Jezero crater paleolake system, Mars. Journal of Geophysical Research: Planets 120, 775-808.

Goudge TA, Milliken RE, Head JW, Mustard JF and Fassett CI (2017) Sedimentological evidence for a deltaic origin of the western fan deposit in Jezero crater, Mars and implications for future exploration. Earth and Planetary Science Letters 458, 357-365.

Grotzinger JP, Crisp J, Vasavada AR, Anderson RC, Baker CJ, Barry R, Blake DF, Conrad P, Edgett KS and Ferdowski B (2012) Mars Science Laboratory mission and science investigation. Space Science Reviews 170, 5-56.

Grotzinger J, Gupta S, Malin M, Rubin D, Schieber J, Siebach K, Sumner D, Stack K, Vasavada A and Arvidson R (2015) Deposition, exhumation, and paleoclimate of an ancient lake deposit, Gale crater, Mars. Science 350, aac7575.

Guha BK, Panda J and Chauhan P (2019) Analysing some martian atmospheric characteristics associated with a dust storm over the Lunae Planum region during October 2014. Icarus 319, 293-307.

Hallsworth JE (2019) Microbial unknowns at the saline limits for life. Nature Ecology \& Evolution 3, 1503-1504. 
Hallsworth JE (2021) Mars' surface is not universally biocidal. Environ Microbiol 23, 3345-3350.

Hallsworth JE, Koop T, Dallas TD, Zorzano MP, Burkhardt J, Golyshina O V, Martín-Torres J, Dymond MK, Ball P and Mckay CP (2021) Water activity in Venus's uninhabitable clouds and other planetary atmospheres. Nature Astronomy 5, 665-675.

Han Z, Wang J, Zhao H, Tucker ME, Zhao Y, Wu G, Zhou J, Yin J, Zhang H and Zhang X (2019) Mechanism of biomineralization induced by Bacillus subtilis $\mathrm{J} 2$ and characteristics of the biominerals. Minerals 9, 218.

Harder H and Christensen UR (1996) A one-plume model of Martian mantle convection. Nature 380, 507-509.

Harris PR (2000) Entering space-creating a spacefaring civilization. Space Policy 3, 231.

Hartmann WK and Neukum G (2001) Cratering chronology and the evolution of Mars. Space Science Reviews 96, 165-194.

Hazen RM, Papineau D, Bleeker W, Downs RT, Ferry JM, McCoy TJ, Sverjensky DA and Yang H (2008) Mineral evolution. American Mineralogist 93, 1693-1720.

Head JN, Melosh HJ and Ivanov BA (2002) Martian meteorite launch: highspeed ejecta from small craters. Science (New York, N.Y.) 298, 1752-1756.

Herd CDK, Walton EL, Agee CB, Muttik N, Ziegler K, Shearer CK, Bell AS, Santos AR, Burger PV, Simon JI, Tappa MJ, McCubbin FM, Gattacceca J, Lagroix F, Sanborn ME, Yin Q-Z, Cassata WS, Borg LE, Lindvall RE, Kruijer TS, Brennecka GA, Kleine T, Nishiizumi $K$ and Caffee MW (2017) The Northwest Africa 8159 martian meteorite: expanding the martian sample suite to the early Amazonian. Geochimica Et Cosmochimica Acta 218, 1-26.

Hesselbrock AJ and Minton DA (2017) An ongoing satellite-ring cycle of Mars and the origins of Phobos and Deimos. Nature Geoscience 10, 266-269.

Hicks LJ, Bridges JC and Gurman S (2014) Ferric saponite and serpentine in the nakhlite martian meteorites. Geochimica et Cosmochimica Acta 136, 194-210.

Horgan B, Bell III J, Noe Dobrea E, Cloutis E, Bailey D, Craig M, Roach L and Mustard J (2009) Distribution of hydrated minerals in the north polar region of Mars. Journal of Geophysical Research: Planets, 114. E01005, 27 pages, doi:10.1029/2008JE003187

Horgan BH, Anderson RB, Dromart G, Amador ES and Rice MS (2020) The mineral diversity of Jezero crater: evidence for possible lacustrine carbonates on Mars. Icarus 339, 113526.

Horneck G, Stöffler D, Ott S, Hornemann U, Cockell CS, Moeller R, Meyer C, De Vera J-P, Fritz J and Schade S (2008) Microbial rock inhabitants survive hypervelocity impacts on Mars-like host planets: first phase of lithopanspermia experimentally tested. Astrobiology 8, 17-44.

Horneck G, Klaus DM and Mancinelli RL (2010) Space microbiology. Microbiol Mol Biol Rev 74, 121-156.

Horneck G, Moeller R, Cadet J, Douki T, Mancinelli RL, Nicholson WL, Panitz C, Rabbow E, Rettberg P, Spry A, Stackebrandt E, Vaishampayan P and Venkateswaran KJ (2012) Resistance of bacterial endospores to outer space for planetary protection purposes-experiment PROTECT of the EXPOSE-E mission. Astrobiology 12(5), 445-456.

Hu R, Bloom AA, Gao P, Miller CE and Yung YL (2016) Hypotheses for near-surface exchange of methane on Mars. Astrobiology 16, 539-550.

Hu X, Oberst J and Willner K (2020) Equipotential figure of Phobos suggests its late accretion near 3.3 Mars Radii. Geophysical Research Letters 47(7), e85958.

Humayun M, Nemchin A, Zanda B, Hewins R, Grange M, Kennedy A, Lorand J-P, Göpel C, Fieni C and Pont S (2013) Origin and age of the earliest Martian crust from meteorite NWA 7533. Nature 503, 513-516.

Hurowitz JA, McLennan SM, Tosca NJ, Arvidson RE, Michalski JR, Ming DW, Schröder C and Squyres SW (2006) In situ and experimental evidence for acidic weathering of rocks and soils on Mars. Journal of Geophysical Research: Planets 111. E02S19, 16 pages, doi:10.1029/ 2005JE002515

Jakosky BM (2021) Atmospheric loss to space and the history of water on Mars. Annual Review of Earth and Planetary Sciences 49, 71-93. https:// doi.org/10.1146/annurev-earth-062420-052845

Jakosky BM, Slipski M, Benna M, Mahaffy P, Elrod M, Yelle R, Stone S and Alsaeed N (2017) Mars' atmospheric history derived from upperatmosphere measurements of 38Ar/36Ar. Science 355, 1408-1410.
Jakosky B, Brain D, Chaffin M, Curry S, Deighan J, Grebowsky J, Halekas J, Leblanc F, Lillis R and Luhmann J (2018) Loss of the Martian atmosphere to space: present-day loss rates determined from MAVEN observations and integrated loss through time. Icarus 315, 146-157.

Jheeta S (2013) Final frontiers: the hunt for life elsewhere in the Universe. Astrophysics and Space Science 348, 1-10.

Johnson J, Bell III JF, Cloutis E, Staid M, Farrand W, McCoy T, Rice M, Wang A and Yen A (2007) Mineralogic constraints on sulfur-rich soils from Pancam spectra at Gusev crater, Mars. Geophysical Research Letters, 34. L13202, 6 pages, doi:10.1029/2007GL029894

Johnson CL, Mittelholz A, Langlais B, Russell CT, Ansan V, Banfield D, Chi PJ, Fillingim MO, Forget F and Haviland HF (2020) Crustal and time-varying magnetic fields at the InSight landing site on Mars. Nature Geoscience 13, 199-204.

Josset J-L, Westall F, Hofmann BA, Spray J, Cockell C, Kempe S, Griffiths AD, De Sanctis MC, Colangeli L and Koschny D (2017) The Close-Up Imager onboard the ESA ExoMars Rover: objectives, description, operations, and science validation activities. Astrobiology 17, 595-611.

Kai M (2020) Diversity and distribution of volatile secondary metabolites throughout Bacillus subtilis isolates. Front Microbiol 11, 559.

Kallmeyer J, Pockalny R, Adhikari RR, Smith DC and D'Hondt S (2012) Global distribution of microbial abundance and biomass in subseafloor sediment. Proceedings of the National Academy of Sciences 109, 16213-16216.

Kereszturi A and Chatzitheodoridis E (2016) Searching for the source crater of nakhlite meteorites. Origins of Life and Evolution of Biospheres 46, 455-471.

Kidman G, MacLean JS and Maxwell D (2014) Evidence of large scale tectonic processes on the Tharsis Rise. Mars. The Compass: Earth Science Journal of Sigma Gamma Epsilon 86, 1.

Klingelhöfer G, Morris RV, Bernhardt B, Schröder C, Rodionov DS, De Souza PA Jr, Yen A, Gellert R, Evlanov EN, Zubkov B, Foh J, Bonnes U, Kankeleit E, Gütlich P, Ming DW, Renz F, Wdowiak T, Squyres SW and Arvidson RE (2004) Jarosite and hematite at Meridiani Planum from Opportunity's Mössbauer spectrometer. Science 306, 1740-1745.

Knapmeyer-Endrun B and Kawamura T (2020) NASA's InSight mission on Mars - first glimpses of the planet's interior from seismology. Nature Communications 11, 1-4.

Ko YS, Kim JW, Lee JA, Han T, Kim GB, Park JE and Lee SY (2020) Tools and strategies of systems metabolic engineering for the development of microbial cell factories for chemical production. Chemical Society Reviews 49(14), 4615-4636.

Koike M, Nakada R, Kajitani I, Usui T, Tamenori Y, Sugahara $H$ and Kobayashi A (2020) In-situ preservation of nitrogen-bearing organics in Noachian Martian carbonates. Nature Communications 11, 1-7.

Kong F, Zheng M, Hu B, Wang A, Ma N and Sobron P (2018) Dalangtan Saline Playa in a Hyperarid Region on Tibet Plateau: I. Evolution and environments. Astrobiology 18, 1243-1253.

Korablev OI, Dobrolensky Y, Evdokimova N, Fedorova AA, Kuzmin RO, Mantsevich SN, Cloutis EA, Carter J, Poulet F and Flahaut J (2017) Infrared spectrometer for ExoMars: a mast-mounted instrument for the rover. Astrobiology 17, 542-564.

Krasnopolsky VA (2012) Search for methane and upper limits to ethane and SO2 on Mars. Icarus 217, 144-152.

Krasnopolsky VA, Maillard JP and Owen TC (2004) Detection of methane in the martian atmosphere: evidence for life? Icarus 172, 537-547.

Kumar A, Dikshit R, Gupta N, Jain A, Dey A, Nandi A, Venugopal I, Viswanathan K, Sridhara N and Rajendra A (2020) Bacterial growth induced biocementation technology, 'Space Brick' - a proposal for experiment at microgravity and planetary environments. bioRxiv. doi: https:// doi.org/10.1101/2020.01.22.914853

Kurosawa K, Genda H, Hyodo R, Yamagishi A, Mikouchi T, Niihara T, Matsuyama S and Fujita K (2019) Assessment of the probability of microbial contamination for sample return from Martian moons II: the fate of microbes on Martian moons. Life Sciences in Space Research 23, 85-100.

Lammer H (2012) Origin and Evolution of Planetary Atmospheres: Implications for Habitability. Springer Science \& Business Media.

Langevin Y, Poulet F, Bibring J-P and Gondet B (2005) Sulfates in the north polar region of Mars detected by OMEGA/Mars Express. Science 307, $1584-1586$. 
Lapen TJ, Righter M, Andreasen R, Irving AJ, Satkoski AM, Beard BL, Nishiizumi K, Jull AJT and Caffee MW (2017) Two billion years of magmatism recorded from a single Mars meteorite ejection site. Science Advances 3. e1600922, 6 pages, DOI: 10.1126/sciadv.1600922

Laskar J, Correia A, Gastineau M, Joutel F, Levrard B and Robutel P (2004) Long term evolution and chaotic diffusion of the insolation quantities of Mars. Icarus 170, 343-364.

Lee MR and Chatzitheodoridis E (2016) Replacement of glass in the Nakhla meteorite by berthierine: implications for understanding the origins of aluminum-rich phyllosilicates on Mars. Meteoritics \& Planetary Science 51, 1643-1653.

Lele A (2014) Mission Mars: India's Quest for the Red Planet, SpringerBriefs in Applied Sciences and Technology. Springer: New Delhi, Heidelberg: New York, Dordrecht: London. DOI:10.1007/978-81-322-1521-9.

Leone G, Tackley PJ, Gerya TV, May DA and Zhu G (2014) Three-dimensional simulations of the southern polar giant impact hypothesis for the origin of the Martian dichotomy. Geophysical Research Letters 41, 8736-8743.

Léveillé RJ, Bridges J, Wiens RC, Mangold N, Cousin A, Lanza N, Forni O, Ollila A, Grotzinger J and Clegg S (2014) Chemistry of fracture-filling raised ridges in Yellowknife Bay, Gale Crater: window into past aqueous activity and habitability on Mars. Journal of Geophysical Research: Planets 119, 2398-2415.

Leverington DW (2011) A volcanic origin for the outflow channels of Mars: key evidence and major implications. Geomorphology 132, 51-75.

Lichtenberg KA, Arvidson RE, Morris RV, Murchie SL, Bishop JL, Fernandez Remolar D, Glotch TD, Noe Dobrea E, Mustard JF and Andrews-Hanna J (2010) Stratigraphy of hydrated sulfates in the sedimentary deposits of Aram Chaos. Mars. Journal of Geophysical Research: Planets 115. E00D17, 13 pages, doi:10.1029/2009JE003353

Lillis RJ, Robbins S, Manga M, Halekas JS and Frey HV (2013) Time history of the Martian dynamo from crater magnetic field analysis. Journal of Geophysical Research: Planets 118, 1488-1511.

Litvak M, Mitrofanov I, Barmakov YN, Behar A, Bitulev A, Bobrovnitsky Y, Bogolubov E, Boynton WV, Bragin S and Churin S (2008) The dynamic albedo of neutrons (DAN) experiment for NASA's 2009 Mars science laboratory. Astrobiology 8, 605-612.

Liu X, Cheng J, Zhang G, Ding W, Duan L, Yang J, Kui L, Cheng X, Ruan J and Fan W (2018) Engineering yeast for the production of breviscapine by genomic analysis and synthetic biology approaches. Nature Communications 9, 1-10.

Luo X, Reiter MA, d'Espaux L, Wong J, Denby CM, Lechner A, Zhang Y, Grzybowski AT, Harth S, Lin W, Lee H, Yu C, Shin J, Deng K, Benites VT, Wang G, Baidoo EEK, Chen Y, Dev I, Petzold CJ and Keasling JD (2019) Complete biosynthesis of cannabinoids and their unnatural analogues in yeast. Nature 567, 123-126.

Malico AA, Nichols L and Williams GJ (2020) Synthetic biology enabling access to designer polyketides. Current Opinion in Chemical Biology 58, 45-53.

Malo ME and Dadachova E (2019) Melanin as an energy transducer and a radioprotector in black fungi. In Tiquia-Arashiro MG (eds.). Fungi in Extreme Environments: Ecological Role and Biotechnological Significance, Nature Switzerland AG: Springer, pp. 175-184.

Mandon L, Parkes Bowen A, Quantin-Nataf C, Bridges JC, Carter J, Pan L, Beck P, Dehouck E, Volat M and Thomas N (2021) Morphological and spectral diversity of the clay-bearing unit at the ExoMars landing site Oxia Planum. Astrobiology 21, 464-480.

Martin W, Baross J, Kelley D and Russell MJ (2008) Hydrothermal vents and the origin of life. Nature Reviews Microbiology 6, 805-814

Martin PE, Ehlmann BL, Thomas NH, Wiens RC, Hollis JJ, Beegle LW, Bhartia R, Clegg SM and Blaney DL (2020) Studies of a lacustrine-volcanic Mars analog field site with Mars-2020-like instruments. Earth and Space Science 7, e2019EA000720.

Mathew K and Marti K (2001) Early evolution of Martian volatiles: nitrogen and noble gas components in ALH84001 and Chassigny. Journal of Geophysical Research: Planets 106, 1401-1422.

Mathew K, Sarkar S, Srinivas A, Dutta M, Rohit M, Seth H, Kumaran R, Pandya K, Kumar A and Sharma J (2015) Methane sensor for Mars. Current Science 109(6), 1087-1096.
McFadden LA and Cline TP (2005) Spectral reflectance of Martian meteorites: spectral signatures as a template for locating source region on Mars. Meteoritics \& Planetary Science 40, 151-172.

McLennan S, Anderson R, Bell J, Bridges J, Calef F, Campbell J, Clark B, Clegg S, Conrad P, Cousin A and the MSL Science Team (2014) Elemental geochemistry of sedimentary rocks at Yellowknife Bay, Gale crater, Mars. Science 343. 15 pages, DOI:10.1126/science.1244734

McLennan SM, Bell JF III, Calvin WM, Christensen PR, Clark BC, de Souza PA, Farmer J, Farrand WH, Fike DA, Gellert R, Ghosh A, Glotch TD, Grotzinger JP, Hahn B, Herkenhoff KE, Hurowitz JA, Johnson JR, Johnson SS, Jolliff B, Klingelhöfer G, Knoll AH, Learner Z, Malin MC, McSween HY Jr, Pocock J, Ruff SW, Soderblom LA, Squyres SW, Tosca NJ, Watters WA, Wyatt MB and Yen A (2005) Provenance and diagenesis of the evaporite-bearing Burns formation, Meridiani Planum, Mars. Earth and Planetary Science Letters 240, 95-121.

Mège D and Masson P (1996) A plume tectonics model for the Tharsis province, Mars. Planetary and Space Science 44, 1499-1546.

Ménez B, Pisapia C, Andreani M, Jamme F, Vanbellingen QP, Brunelle A, Richard L, Dumas P and Réfrégiers M (2018) Abiotic synthesis of amino acids in the recesses of the oceanic lithosphere. Nature 564, 59-63.

Messeri L (2016) Placing Outer Space: An Earthly Ethnography of Other Worlds. Durham, NC: Duke University Press.

Metzger PT (2016) Space development and space science together, an historic opportunity. Space Policy 37, 77-91.

Michalski JR, Dobrea EZN, Niles PB and Cuadros J (2017) Ancient hydrothermal seafloor deposits in Eridania basin on Mars. Nature Communications 8, 1-10.

Michalski JR, Onstott TC, Mojzsis SJ, Mustard J, Chan QH, Niles PB and Johnson SS (2018) The Martian subsurface as a potential window into the origin of life. Nature Geoscience 11, 21-26.

Michalski JR, Glotch TD, Rogers AD, Niles PB, Cuadros J, Ashley JW and Johnson SS (2019) The geology and astrobiology of McLaughlin crater, Mars: an ancient lacustrine basin containing turbidites, mudstones, and serpentinites. Journal of Geophysical Research: Planets 124, 910-940.

Milliken R, Grotzinger J and Thomson B (2010) Paleoclimate of Mars as captured by the stratigraphic record in Gale Crater. Geophysical Research Letters 37. L04201, 6 pages, doi:10.1029/2009GL041870

Ming DW, Archer PD Jr, Glavin DP, Eigenbrode JL, Franz HB, Sutter B, Brunner AE, Stern JC, Freissinet C, McAdam AC, Mahaffy PR, Cabane M, Coll P, Campbell JL, Atreya SK, Niles PB, Bell JF III, Bish DL, Brinckerhoff WB, Buch A, Conrad PG, Des Marais DJ, Ehlmann BL, Fairén AG, Farley K, Flesch GJ, Francois P, Gellert R, Grant JA, Grotzinger JP, Gupta S, Herkenhoff KE, Hurowitz JA, Leshin LA, Lewis KW, McLennan SM, Miller KE, Moersch J, Morris RV, Navarro-González R, Pavlov AA, Perrett GM, Pradler I, Squyres SW, Summons RE, Steele A, Stolper EM, Sumner DY, Szopa C, Teinturier S, Trainer MG, Treiman AH, Vaniman DT, Vasavada AR, Webster CR, Wray JJ, Yingst RA, MSL Science Team (2014) Volatile and organic compositions of sedimentary rocks in Yellowknife Bay, Gale Crater, Mars. Science 343. 15 pages, DOI: 10.1126/science. 1245267

Mishra MK, Chauhan P, Singh R, Moorthi S and Sarkar S (2016) Estimation of dust variability and scale height of atmospheric optical depth (AOD) in the Valles Marineris on Mars by Indian Mars Orbiter Mission (MOM) data. Icarus 265, 84-94.

Misra AK, Acosta-Maeda TE, Scott ERD and Sharma SK (2014) Possible mechanism for explaining the origin and size distribution of Martian hematite spherules. Planetary and Space Science 92, 16-23.

Mittelholz A, Johnson C, Feinberg J, Langlais B and Phillips R (2020) Timing of the martian dynamo: new constraints for a core field 4.5 and 3.7 Ga ago. Science Advances 6, eaba0513.

Morgan G, Putzig N, Perry M, Sizemore H, Bramson A, Petersen E, Bain Z, Baker D, Mastrogiuseppe M and Hoover R (2021) Availability of subsurface water-ice resources in the northern mid-latitudes of Mars. Nature Astronomy 5, 230-236.

Morris RV, Klingelhöfer G, Schröder C, Rodionov DS, Yen A, Ming DW, de Souza PA Jr., Wdowiak T, Fleischer I, Gellert R, Bernhardt B, 
Bonnes U, Cohen BA, Evlanov EN, Foh J, Gütlich P, Kankeleit E, McCoy T, Mittlefehldt DW, Renz F, Schmidt ME, Zubkov B, Squyres SW and Arvidson RE (2006) Mössbauer mineralogy of rock, soil, and dust at Meridiani Planum, Mars: Opportunity's journey across sulfate-rich outcrop, basaltic sand and dust, and hematite lag deposits. Journal of Geophysical Research: Planets 111. E12S15, 27 pages, doi:10.1029/2006JE002791

Morris RV, Klingelhöfer G, Schröder C, Rodionov DS, Yen A, Ming DW, de Souza PA, Wdowiak T, Fleischer I, Gellert R, Bernhardt B, Bonnes U, Cohen BA, Evlanov EN, Foh J, Gütlich P, Kankeleit E, McCoy T, Mittlefehldt DW, Renz F, Schmidt ME, Zubkov B, Squyres SW and Arvidson RE (2010) Identification of carbonate-rich outcrops on Mars by the Spirit Rover. Science (New York, N.Y.) 329, 421-424.

Moser DE, Chamberlain KR, Tait KT, Schmitt AK, Darling JR, Barker IR and Hyde BC (2013) Solving the Martian meteorite age conundrum using micro-baddeleyite and launch-generated zircon. Nature 499, 454.

Mouginismark PJ, McCoy TJ, Taylor GJ and Keil K (1992) Martian parent craters for the SNC meteorites. Journal of Geophysical Research-Planets 97, 10213-10225.

Mumma MJ, Villanueva GL, Novak RE, Hewagama T, Bonev BP, DiSanti MA, Mandell AM and Smith MD (2009) Strong release of methane on Mars in northern summer 2003. Science 323, 1041-1045.

Murchie SL, Mustard JF, Ehlmann BL, Milliken RE, Bishop JL, McKeown NK, Noe Dobrea EZ, Seelos FP, Buczkowski DL and Wiseman SM (2009) A synthesis of Martian aqueous mineralogy after 1 Mars year of observations from the Mars Reconnaissance Orbiter. Journal of Geophysical Research: Planets 114. E00D06, 30 pages, doi:10.1029/ 2009JE003342

Nicholson WL and Ricco AJ (2019) Nanosatellites for biology in space: In situ measurement of Bacillus subtilis spore germination and growth after 6 months in low earth orbit on the O/OREOS Mission. Life (Basel) 10(1), 1.

Nielsen J, Larsson C, Van Maris A and Pronk J (2013) Metabolic engineering of yeast for production of fuels and chemicals. Curr Opin Biotechnol 24(3), 398-404.

Niihara T (2011) Uranium-lead age of baddeleyite in shergottite Roberts Massif 04261: implications for magmatic activity on Mars. Journal of Geophysical Research 116, E12008.

Novikova ND (2004) Review of the knowledge of microbial contamination of the Russian manned spacecraft. Microbial Ecology 47, 127-132.

Nyquist LE, Bogard DD, Shih CY, Greshake A, Stoffler D and Eugster O (2001) Ages and geologic histories of Martian meteorites. Space Science Reviews 96, 105-164.

Onofri S, Selbmann L, Zucconi L and Pagano S (2004) Antarctic microfungi as models for exobiology. Planetary and Space Science 52, 229-237.

Onofri S, Barreca D, Selbmann L, Isola D, Rabbow E, Horneck G, de Vera JP, Hatton J and Zucconi L (2008) Resistance of Antarctic black fungi and cryptoendolithic communities to simulated space and Martian conditions. Studies in Mycology 61, 99-109.

Onofri S, de la Torre R, de Vera J-P, Ott S, Zucconi L, Selbmann L, Scalzi G, Venkateswaran KJ, Rabbow E and Sánchez Iñigo FJ (2012) Survival of rockcolonizing organisms after 1.5 years in outer space. Astrobiology 12, 508-516.

Osinski G, Cockell C, Pontefract A and Sapers H (2020) The role of meteorite impacts in the origin of life. Astrobiology 20, 1121-1149.

Oze C and Sharma M (2005) Have olivine, will gas: serpentinization and the abiogenic production of methane on Mars. Geophysical Research Letters 32. L10203, 4 pages, doi:10.1029/2005GL022691

Parkes RJ, Linnane CD, Webster G, Sass H, Weightman AJ, Hornibrook ER and Horsfield B (2011) Prokaryotes stimulate mineral H2 formation for the deep biosphere and subsequent thermogenic activity. Geology 39, 219-222.

Perez-Pinera P, Han N, Cleto S, Cao J, Purcell O, Shah KA, Lee K, Ram R and Lu TK (2016) Synthetic biology and microbioreactor platforms for programmable production of biologics at the point-of-care. Nature Communications 7, 1-10.

Plescia J and Golombek M (1986) Origin of planetary wrinkle ridges based on the study of terrestrial analogs. Geological Society of America Bulletin 97, 1289-1299.

Prasad V and Ellery A (2020) Analogue neural network architecture for insitu resourced computing hardware on the Moon. Proc International
Symposium on Artificial Intelligence, Robotics and Automation in Space (iSAIRAS) (V), paper no 5005

Pyne ME, Kevvai K, Grewal PS, Narcross L, Choi B, Bourgeois L, Dueber JE and Martin VJJ (2020) A yeast platform for high-level synthesis of tetrahydroisoquinoline alkaloids. Nat Commun 11, 3337.

Quantin-Nataf C, Carter J, Mandon L, Thollot P, Balme M, Volat M, Pan L, Loizeau D, Millot C and Breton S (2021) Oxia Planum: the landing site for the ExoMars 'Rosalind Franklin' rover mission: geological context and prelanding interpretation. Astrobiology 21, 345-366.

Rampe E, Ming D, Blake D, Bristow T, Chipera S, Grotzinger J, Morris R, Morrison S, Vaniman D and Yen A (2017) Mineralogy of an ancient lacustrine mudstone succession from the Murray formation, Gale crater, Mars. Earth and Planetary Science Letters 471, 172-185.

Rampe EB, Bristow TF, Morris RV, Morrison SM, Achilles CN, Ming DW, Vaniman DT, Blake DF, Tu VM, Chipera SJ, Yen AS, Peretyazhko TS, Downs RT, Hazen RM, Treiman AH, Grotzinger JP, Castle N, Craig PI, Des Marais DJ, Thorpe MT, Walroth RC, Downs GW, Fraeman AA, Siebach KL, Gellert R, Lafuente B, McAdam AC, Meslin P.-Y., Sutter B and Salvatore MR (2020) Mineralogy of Vera Rubin Ridge from the Mars Science Laboratory CheMin instrument. Journal of Geophysical Research: Planets 125, e2019JE006306.

Read P, Lewis S and Mulholland D (2015) The physics of Martian weather and climate: a review. Reports on Progress in Physics 78, 125901.

Redd NT (2020) Inner workings: early Mars may have boasted a large ocean and cool climate. Proceedings of the National Academy of Sciences 117, 31558-31560.

Reddy MS (2013) Biomineralization of calcium carbonates and their engineered applications: a review. Frontiers in Microbiology 4, 314.

Reddy CV, Venkatesh MP and Kumar P (2020) First FDA approved 3D printed drug paved new path for increased precision in patient care. Clinical Trials and Regulatory Affairs 7(2), 93-103.

Ribas I, Guinan EF, Güdel M and Audard M (2005) Evolution of the solar activity over time and effects on planetary atmospheres. I. High-energy irradiances (1-1700 ̊̊). The Astrophysical Journal 622, 680.

Rice MS, Gupta S, Treiman AH, Stack KM, Calef F, Edgar LA, Grotzinger J, Lanza N, Le Deit L and Lasue J (2017) Geologic overview of the Mars Science Laboratory rover mission at the Kimberley, Gale crater. Mars. Journal of Geophysical Research: Planets 122, 2-20.

Ro D-K, Paradise EM, Ouellet M, Fisher KJ, Newman KL, Ndungu JM, Ho KA, Eachus RA, Ham TS and Kirby J (2006) Production of the antimalarial drug precursor artemisinic acid in engineered yeast. Nature 440, 940943.

Rothschild LJ (2016) Synthetic biology meets bioprinting: enabling technologies for humans on Mars (and Earth). Biochemical Society Transactions 44, $1158-1164$.

Rull F, Maurice S, Hutchinson I, Moral A, Perez C, Diaz C, Colombo M, Belenguer T, Lopez-Reyes G and Sansano A (2017) The Raman laser spectrometer for the ExoMars rover mission to Mars. Astrobiology 17, 627-654.

Saberi AA (2020) Evidence for an ancient sea level on Mars. The Astrophysical Journal Letters 896, L25.

Santomartino R, Waajen AC, De Wit W, Nicholson N, Parmitano L, Loudon C-M, Moeller R, Rettberg P, Fuchs FM and Van Houdt R (2020) No effect of microgravity and simulated Mars gravity on final bacterial cell concentrations on the International Space Station: applications to space bioproduction. Frontiers in Microbiology 11. Article 579156, 15 pages, doi: $10.3389 / \mathrm{fmicb} .2020 .579156$

Scheller E, Ehlmann B, Hu R, Adams D and Yung Y (2021) Long-term drying of Mars by sequestration of ocean-scale volumes of water in the crust. Science 372, 56-62.

Schultz RA (1989) Strike-slip faulting of ridged plains near Valles Marineris, Mars. Nature 341, 424-426.

Schultz RA (2000) Localization of bedding plane slip and backthrust faults above blind thrust faults: keys to wrinkle ridge structure. Journal of Geophysical Research: Planets 105, 12035-12052.

Sefton-Nash E and Catling DC (2008) Hematitic concretions at Meridiani Planum, Mars: their growth timescale and possible relationship with iron sulfates. Earth and Planetary Science Letters 269, 366-376. 
Selbmann L, Zucconi L, Isola D and Onofri S (2015) Rock black fungi: excellence in the extremes, from the Antarctic to space. Current Genetics 61, 335-345.

Selbmann L, Pacelli C, Zucconi L, Dadachova E, Moeller R, de Vera J-P and Onofri S (2018) Resistance of an Antarctic cryptoendolithic black fungus to radiation gives new insights of astrobiological relevance. Fungal Biology 122, 546-554.

Sexton MR, Elwood Madden ME, Swindle AL, Hamilton VE, Bickmore BR and Elwood Madden AS (2017) Considering the formation of hematite spherules on Mars by freezing aqueous hematite nanoparticle suspensions. Icarus 286, 202-211.

Shaghaghi A and Antonakopoulos K (2012) The societal impacts of a Mars mission in the future of space exploration. Physics Procedia 38, 176-185.

Sharaf O, Amiri S, AlDhafri S, Withnell P and Brain D (2020) Sending hope to Mars. Nature Astronomy 4, 722-722.

Sherwood B, Ponce A and Waltemathe M (2019) Forward contamination of ocean worlds: a stakeholder conversation. Space Policy 48, 1-13.

Shkrob IA, Chemerisov SD and Marin TW (2010) Photocatalytic decomposition of carboxylated molecules on light-exposed martian regolith and its relation to methane production on Mars. Astrobiology 10, 425-436.

Shkrob IA, Marin TW, He H and Zapol P (2012) Photoredox reactions and the catalytic cycle for carbon dioxide fixation and methanogenesis on metal oxides. The Journal of Physical Chemistry C 116, 9450-9460.

Sholes SF, Dickeson ZI, Montgomery D and Catling D (2020) Where are Mars' hypothesized ocean shorelines? Large lateral and topographic offsets between different versions of paleoshoreline maps.

Shuster DL and Weiss BP (2005) Martian surface paleotemperatures from thermochronology of meteorites. Science (New York, N.Y.) 309, 594-600.

Singh R, Sarkar SS, Kumar M, Saxena A, Rao U, Bhardwaj A, Desai J, Sharma J, Patel A and Shinde Y (2015) Thermal infrared imaging spectrometer for Mars Orbiter Mission. Current Science 109(6), 1097-1105.

Singh R, Mishra MK and Chauhan P (2017) SWIR albedo mapping of Mars using Mars Orbiter Mission data. Current Science 113, 112.

Smith MG, Kelley M and Basner M (2020a) A brief history of spaceflight from 1961 to 2020: an analysis of missions and astronaut demographics. Acta Astronautica 175, 290-299.

Smith T, Ranjith P, He H and Zhu R (2020b) Reviewing Martian atmospheric noble gas measurements: from Martian meteorites to Mars missions. Geosciences 10, 439.

Sprockett DD, Martin M, Costello EK, Burns AR, Holmes SP, Gurven MD and Relman DA (2020) Microbiota assembly, structure, and dynamics among Tsimane horticulturalists of the Bolivian Amazon. Nature communications 11, 1-14.

Spry JA, Rummel J, Race M, Conley C, Siegel B and Kminek G (2017) Putting planetary protection parameters in place ahead of the human exploration of Mars. 47th International Conference on Environmental Systems. http://hdl.handle.net/2346/73063

Squyres SW, Arvidson RE, Bell J, Calef F, Clark B, Cohen B, Crumpler L, De Souza P, Farrand W and Gellert R (2012) Ancient impact and aqueous processes at Endeavour Crater, Mars. Science 336, 570-576.

Squyres SW, Grotzinger JP, Arvidson RE, Bell JF, Calvin W, Christensen PR, Clark BC, Crisp JA, Farrand WH, Herkenhoff KE, Johnson JR, Klingelhöfer G, Knoll AH, McLennan SM, McSween RV Jr, Morris HY, Rice JW Jr, Rieder R and Soderblom LA (2004) In situ evidence for an ancient aqueous environment at Meridiani Planum, Mars. Science (New York, N.Y.) 306, 1709-1714.

Sridhar RV, Rao M, Kalyani K, Bhaskar K, Chandran A, Mahajan M, Manja AB, Gouda GM, Tayaramman J and Amudha P (2015) Lyman Alpha Photometer: a far-ultraviolet sensor for the study of hydrogen isotope ratio in the Martian exosphere. Current Science 109(6), 1114-1120.

Stack KM, Grotzinger JP, Lamb MP, Gupta S, Rubin DM, Kah LC, Edgar LA, Fey DM, Hurowitz JA and McBride M (2019) Evidence for plunging river plume deposits in the Pahrump Hills member of the Murray formation, Gale crater, Mars. Sedimentology 66, 1768-1802.

Stähler SC, Khan A, Ceylan S, Duran AC, Garcia R, Giardini D, Huang Q, Kim D, Lognonné P and Maguire R (2021) Seismic detection of the Martian core by InSight. Copernicus Meetings.
Steele A, McCubbin FM and Fries MD (2016) The provenance, formation, and implications of reduced carbon phases in Martian meteorites. Meteoritics \& Planetary Science 51, 2203-2225.

Stern RJ (2018) The evolution of plate tectonics. Philosophical Transactions of the Royal Society A: Mathematical, Physical and Engineering Sciences 376, 20170406.

Stöffler D, Horneck G, Ott S, Hornemann U, Cockell CS, Moeller R, Meyer C, de Vera J-P, Fritz J and Artemieva NA (2007) Experimental evidence for the potential impact ejection of viable microorganisms from Mars and Mars-like planets. Icarus 186, 585-588.

Suchomel M, Lenhardt A, Kampf G and Grisold A (2019) Enterococcus hirae, Enterococcus faecium and Enterococcus faecalis show different sensitivities to typical biocidal agents used for disinfection. Journal of Hospital Infection 103, 435-440.

Sugita T and Cho $\mathbf{O}$ (2015) Significance of changes in the skin fungal microbiomes of astronauts staying on the international space station. Journal of Disaster Research 10, 1031-1034.

Sutter B, McAdam AC and Mahaffy PR (2019) Volatile detections in Gale crater sediment and sedimentary rock: results from the Mars Science Laboratory's sample analysis at Mars instrument. In Justin F and Susanne PS (eds). Volatiles in the Martian Crust. Elsevier, Chapter 12, pp. 369-392.

Swindle TD (2002) Martian noble gases. Reviews in Mineralogy and Geochemistry 47, 171-190.

Thauer RK (1998) Biochemistry of methanogenesis: a tribute to Marjory Stephenson: 1998 Marjory Stephenson prize lecture. Microbiology 144, 2377-2406

Thomson B, Bridges N, Milliken R, Baldridge A, Hook S, Crowley J, Marion G, de Souza Filho C, Brown A and Weitz C (2011) Constraints on the origin and evolution of the layered mound in Gale Crater, Mars using Mars Reconnaissance Orbiter data. Icarus 214, 413-432.

Thumm TL, Robinson JA, Buckley N, Johnson-Green P, Kamigaichi S, Karabadzhak G, Nakamura T, Sabbagh J, Sorokin I and Zell M (2012) International space station benefits for humanity.

Timmis KN (2002) Pseudomonas putida: a cosmopolitan opportunist par excellence. Environ Microbiol 4, 779-781.

Tocheva EI, Ortega DR and Jensen GJ (2016) Sporulation, bacterial cell envelopes and the origin of life. Nat Rev Microbiol 14(8), 535-542.

Tornabene LL, Moersch JE, McSween HY, McEwen AS, Piatek JL, Milam KA and Christensen PR (2006) Identification of large (2-10 km) rayed craters on Mars in THEMIS thermal infrared images: implications for possible Martian meteorite source regions. Journal of Geophysical Research-Planets 111, E10006.

Trainer MG, Wong MH, McConnochie TH, Franz HB, Atreya SK, Conrad PG, Lefèvre F, Mahaffy PR, Malespin CA and Manning HL (2019) Seasonal variations in atmospheric composition as measured in Gale Crater. Mars. Journal of Geophysical Research: Planets 124, 3000-3024.

Treiman AH (1995) S=NC multiple source areas for martian meteorites. Journal of Geophysical Research-Planets 100, 5329-5340.

Treiman AH (2005) The nakhlite meteorites: Augite-rich igneous rocks from Mars. Chemie der Erde 65, 203-270.

Treiman AH (2021) Astrobiology. 940-953. http://doi.org/10.1089/ast.2020.2306 Turner SM, Bridges JC, Grebby S and Ehlmann BL (2016) Hydrothermal activity recorded in post Noachian-aged impact craters on Mars. Journal of Geophysical Research: Planets 121, 608-625.

Usui T, Bajo K-I, Fujiya W, Furukawa Y, Koike M, Miura YN, Sugahara H, Tachibana S, Takano Y and Kuramoto K (2020) The importance of Phobos sample return for understanding the Mars-moon system. Space Science Reviews 216, 1-18.

Váci $\mathbf{Z}$ and Agee C (2020) Constraints on martian chronology from meteorites. Geosciences 10, 455 .

Vago JL, Westall F, Coates AJ, Jaumann R, Korablev O, Ciarletti V, Mitrofanov I, Josset J-L, De Sanctis MC and Bibring J-P (2017) Habitability on early Mars and the search for biosignatures with the ExoMars Rover. Astrobiology 17, 471-510.

Vakoch DA (2013) Astrobiology, History, and Society. Heidelberg, Germany: Springer. 
Vaniman DT, Martínez GM, Rampe EB, Bristow TF, Blake DF, Yen AS, Ming DW, Rapin W, Meslin P-Y and Morookian JM (2018) Gypsum, bassanite, and anhydrite at Gale crater, Mars. American Mineralogist: Journal of Earth and Planetary Materials 103, 1011-1020.

Viennet J-C, Bernard S, Guillou CL, Sautter V, Grégoire B, Jambon A, Pont S, Beyssac O, Zanda B and Hewins R (2021) Martian magmatic clay minerals forming vesicles: perfect niches for emerging life? Astrobiology 21, 605-612

Villanueva G, Mumma M, Novak R, Radeva Y, Käufl H, Smette A, Tokunaga A, Khayat A, Encrenaz T and Hartogh P (2013) A sensitive search for organics $(\mathrm{CH} 4, \mathrm{CH} 3 \mathrm{OH}, \mathrm{H} 2 \mathrm{CO}, \mathrm{C} 2 \mathrm{H} 6, \mathrm{C} 2 \mathrm{H} 2, \mathrm{C} 2 \mathrm{H} 4)$, hydroperoxyl ( $\mathrm{HO} 2)$, nitrogen compounds $(\mathrm{N} 2 \mathrm{O}, \mathrm{NH} 3, \mathrm{HCN})$ and chlorine species $(\mathrm{HCl}, \mathrm{CH} 3 \mathrm{Cl})$ on Mars using ground-based high-resolution infrared spectroscopy. Icarus 223, 11-27.

Walker JJ, Spear JR and Pace NR (2005) Geobiology of a microbial endolithic community in the Yellowstone geothermal environment. Nature 434, 10111014 .

Waltemathe M and Hemminger E (2019) Astrobiology in teacher training. Addressing research methodology and epistemology in humanities and social-science classes. EPJ Web of Conferences. EDP Sciences.

Wan W, Wang C, Li C and Wei Y (2020) China's first mission to Mars. Nature Astronomy 4, 721-721.

Wang S and Hu S (2020) Hydrogen isotopic variations in the Shergottites. Geosciences 10, 148.

Wang A and Ling Z (2011) Ferric sulfates on Mars: a combined mission data analysis of salty soils at Gusev crater and laboratory experimental investigations. Journal of Geophysical Research: Planets 116. E00F17, 22 pages, doi:10.1029/2010JE003665

Wang A, Haskin LA, Squyres SW, Jolliff BL, Crumpler L, Gellert R, Schröder C, Herkenhoff K, Hurowitz J and Tosca NJ (2006) Sulfate deposition in subsurface regolith in Gusev crater. Mars. Journal of Geophysical Research: Planets 111. E02S17, 19 pages, doi:10.1029/ 2005JE002513

Wang A, Bell J, Li R, Johnson J, Farrand W, Cloutis E, Arvidson R, Crumpler L, Squyres S and McLennan S (2008) Light-toned salty soils and coexisting Si-rich species discovered by the Mars Exploration Rover Spirit in Columbia Hills. Journal of Geophysical Research: Planets 113. E12S40, 35 pages, doi:10.1029/2008JE003126

Wang A, Jolliff BL, Liu Y and Connor K (2016) Setting constraints on the nature and origin of the two major hydrous sulfates on Mars: monohydrated and polyhydrated sulfates. Journal of Geophysical Research: Planets 121, 678-694.

Wang A, Yan Y, Dyar DM, Houghton JL, Farrell WM, Jolliff BL, McLennan SM, Shi E and Qu H (2020a) Amorphization of S. Cl-salts induced by Martian dust activities. Journal of Geophysical Research: Planets 125, e2020JE006701.

Wang A, Yan Y, Jolliff BL, McLennan SM, Wang K, Shi E and Farrell WM (2020b) Chlorine release from common chlorides by Martian dust activity. Journal of Geophysical Research: Planets 125, e2019JE006283.

Wang Y, Feng X, Zhou H, Dong Z, Liang W, Xue C and Li X (2021) Water ice detection research in Utopia Planitia based on simulation of Mars rover full-polarimetric subsurface penetrating radar. Remote Sensing 13, 2685.

Fowler AHK, Reston SD, Carter DA, Quinn DJ and Davies PA (2004) QuickFN - a less resource intensive methodology for determining the magnitude of societal risks at major accident hazard installations, Hazards XVIII Symposium Series, No. 150, pp. 627-634.

Warner N, Gupta S, Muller J-P, Kim J-R and Lin S-Y (2009) A refined chronology of catastrophic outflow events in Ares Vallis, Mars. Earth and Planetary Science Letters 288, 58-69.

Watters TR (1993) Compressional tectonism on Mars. Journal of Geophysical Research: Planets 98, 17049-17060.

Webster CR, Mahaffy PR, Atreya SK, Flesch GJ, Mischna MA, Meslin P-Y, Farley KA, Conrad PG, Christensen LE and Pavlov AA (2015) Mars methane detection and variability at Gale crater. Science 347, 415-417.

Webster CR, Mahaffy PR, Atreya SK, Moores JE, Flesch GJ, Malespin C, McKay CP, Martinez G, Smith CL and Martin-Torres J (2018)
Background levels of methane in Mars' atmosphere show strong seasonal variations. Science 360, 1093-1096.

Weidemann C (2014) Christian soteriology and extraterrestrial intelligence. JBIS 67, 418-425.

Weiss BP, Kirschvink JL, Baudenbacher FJ, Vali H, Peters NT, Macdonald FA and Wikswo JP (2000) A low temperature transfer of ALH84001 from Mars to Earth. Science 290, 791-795.

Weitz CM, Dobrea EZN, Lane MD and Knudson AT (2012) Geologic relationships between gray hematite, sulfates, and clays in Capri Chasma. Journal of Geophysical Research: Planets 117. E00J09, 29 pages, doi:10.1029/2012JE004092

Welhan JA (1988) Origins of methane in hydrothermal systems. Chemical Geology 71, 183-198.

Werner SC, Ody A and Poulet F (2014) The source crater of martian shergottite meteorites. Science 343, 1343-1346.

Westall F, Foucher F, Bost N, Bertrand M, Loizeau D, Vago JL, Kminek G, Gaboyer F, Campbell KA and Bréhéret J-G (2015) Biosignatures on Mars: what, where, and how? Implications for the search for martian life. Astrobiology 15, 998-1029.

Weyrich LS (2021) The evolutionary history of the human oral microbiota and its implications for modern health. Periodontology 2000, 90-100.

Wierzchos J, Cámara B, de Los Rios A, Davila A, Sánchez Almazo I, Artieda O, Wierzchos K, Gomez-Silva B, McKay C and Ascaso C (2011) Microbial colonization of Ca-sulfate crusts in the hyperarid core of the Atacama Desert: implications for the search for life on Mars. Geobiology 9, 44-60.

Williford KH, Farley KA, Stack KM, Allwood AC, Beaty D, Beegle LW, Bhartia R, Brown AJ, de la Torre Juarez M and Hamran S-E (2018) The NASA Mars 2020 rover mission and the search for extraterrestrial life. In Nathalie C and Edmond G (eds). From Habitability to Life on Mars. Elsevier, pp. 275-308.

Wiseman SM, Arvidson R, Morris R, Poulet F, Andrews-Hanna J, Bishop J, Murchie S, Seelos F, Des Marais D and Griffes J (2010) Spectral and stratigraphic mapping of hydrated sulfate and phyllosilicate-bearing deposits in northern Sinus Meridiani. Mars. Journal of Geophysical Research: Planets 115. E00D18, 31 pages, doi:10.1029/2009JE003354

Wordsworth RD (2016) The climate of early Mars. Annual Review of Earth and Planetary Sciences 44, 381-408.

Wordsworth R, Ehlmann B, Forget F, Haberle R, Head J and Kerber L (2018) Healthy debate on early Mars. Nature Geoscience 11, 888.

Wray JJ (2020) Contemporary liquid water on Mars? Annual Review of Earth and Planetary Sciences 49. 141-171. https://doi.org/10.1146/annurev-earth072420-071823

Wray JJ, Murchie SL, Squyres SW, Seelos FP and Tornabene LL (2009) Diverse aqueous environments on ancient Mars revealed in the southern highlands. Geology 37, 1043-1046. E01001, 41 pages, doi:10.1029/ 2010JE003694

Wray JJ, Squyres SW, Roach LH, Bishop JL, Mustard JF and Dobrea EZN (2010) Identification of the Ca-sulfate bassanite in Mawrth Vallis, Mars. Icarus 209, 416-421.

Wray J, Milliken R, Dundas CM, Swayze GA, Andrews-Hanna J, Baldridge A, Chojnacki M, Bishop J, Ehlmann B and Murchie SL (2011) Columbus crater and other possible groundwater-fed paleolakes of Terra Sirenum. Mars. Journal of Geophysical Research: Planets 116.

Wu Z, Wang A, Farrell WM, Yan Y, Wang K, Houghton J and Jackson AW (2018) Forming perchlorates on Mars through plasma chemistry during dust events. Earth and Planetary Science Letters 504, 94-105.

Yang X, Yan J, Andert T, Ye M, Pätzold M, Hahn M, Jin W, Li F and Barriot J (2019) The second-degree gravity coefficients of Phobos from two Mars Express flybys. Monthly Notices of the Royal Astronomical Society 490, 2007-2012.

Yin A (2012) Structural analysis of the Valles Marineris fault zone: possible evidence for large-scale strike-slip faulting on Mars. Lithosphere 4, 286-330.

Yoshida H, Hasegawa H, Katsuta N, Maruyama I, Sirono S, Minami M, Asahara Y, Nishimoto S, Yamaguchi Y, Ichinnorov N, Metcalfe R (2018) Fe-oxide concretions formed by interacting carbonate and acidic waters on Earth and Mars. Science Advances 4, eaau0872. 
Zahnle K, Freedman RS and Catling DC (2011) Is there methane on Mars? Icarus 212, 493-503.

Zhdanova N, Lashko T, Redchits T, Vasilevskaia A, Borisiuk L, Siniavskaia O, Gavriliuk V and Muzalev P (1991) The interaction of soil micromycetes with 'hot' particles in a model system. Mikrobiologicheskii Zhurnal 53, 9-17.
Zhou Q, Herd CDK, Yin Q-Z, Li X-H, Wu F-Y, Li Q-L, Liu Y, Tang G-Q and McCoy TJ (2013) Geochronology of the Martian meteorite Zagami revealed by $\mathrm{U}-\mathrm{Pb}$ ion probe dating of accessory minerals. Earth and Planetary Science Letters 374, 156-163.

Zubrin RM, Muscatello AC and Berggren M (2013) Integrated Mars in situ propellant production system. Journal of Aerospace Engineering 26, 43-56. 